NBER WORKING PAPER SERIES

\title{
CONSTRAINED-EFFICIENT CAPITAL REALLOCATION
}

\author{
Andrea Lanteri \\ Adriano A. Rampini \\ Working Paper 28384 \\ http://www.nber.org/papers/w28384 \\ NATIONAL BUREAU OF ECONOMIC RESEARCH \\ 1050 Massachusetts Avenue \\ Cambridge, MA 02138 \\ January 2021, Revised June 2022
}

We thank the Editor (Mikhail Golosov) and three anonymous referees for insightful suggestions. We also thank David Berger, Alberto Bisin, Eduardo Dávila, Peter Kondor, Anton Korinek, Pablo Kurlat, Jennifer La'O, Daniel Neuhann, Jaume Ventura, S. "Vish" Viswanathan, Daniel $\mathrm{Xu}$, as well as seminar participants at Duke (economics), the Econometric Society World Congress, Duke (finance), Oxford, the Virtual Australian Macro Seminar, Georgia Tech, the UVA-Richmond Fed Workshop, the PHBS Workshop in Macroeconomics and Finance, Collegio Carlo Alberto, the Search and Matching in Macro and Finance Seminar, the Barcelona GSE Summer Forum on Economic Fluctuations and Growth, University of British Columbia, Northwestern, Columbia, the Federal Reserve Board of Governors, the Finance Theory Group Meeting, CREi, Nottingham, the Theories and Methods in Macro Conference, the SFS Cavalcade, and the FIRS Conference for helpful comments. Parts of this paper were written while Lanteri was on leave at NYU and Rampini was on sabbatical leave at Princeton University and NYU; their hospitality is gratefully acknowledged. First draft: August 2020. Lanteri is a CEPR Research Affiliate. Rampini is an NBER Research Associate and a CEPR Research Fellow. Alessandro Villa and Jui-Lin Chen provided excellent research assistance. The views expressed herein are those of the authors and do not necessarily reflect the views of the National Bureau of Economic Research.

NBER working papers are circulated for discussion and comment purposes. They have not been peer-reviewed or been subject to the review by the NBER Board of Directors that accompanies official NBER publications.

(C) 2021 by Andrea Lanteri and Adriano A. Rampini. All rights reserved. Short sections of text, not to exceed two paragraphs, may be quoted without explicit permission provided that full credit, including $(\subset$ notice, is given to the source. 
Constrained-Efficient Capital Reallocation

Andrea Lanteri and Adriano A. Rampini

NBER Working Paper No. 28384

January 2021, Revised June 2022

JEL No. D51,E22,E44,G31,H21

\title{
ABSTRACT
}

We characterize efficiency in an equilibrium model of investment and capital reallocation with heterogeneous firms facing collateral constraints. The model features two types of pecuniary externalities: collateral externalities, because the resale price of capital affects collateral constraints, and distributive externalities, because buyers of old capital are more financially constrained than sellers, consistent with empirical evidence. We prove that the stationaryequilibrium price of old capital is inefficiently high, because the distributive pecuniary externality exceeds the collateral externality, by a factor of two in our calibrated model. New investment reduces the future price of old capital, providing a rationale for new-investment subsidies.

\author{
Andrea Lanteri \\ Duke University \\ Department of Economics \\ 233 Social Sciences Building \\ Durham, NC 27708 \\ andrea.lanteri@duke.edu \\ Adriano A. Rampini \\ Duke University \\ Fuqua School of Business \\ 100 Fuqua Drive \\ Durham, NC 27708 \\ Durham, NC 27708 \\ and NBER \\ rampini@duke.edu
}




\section{Introduction}

Collateral constraints distort the level of aggregate investment and the allocation of capital across firms. What is the nature of the inefficiency induced by these constraints? Is the equilibrium resale price of capital - that is, the value of collateral -inefficiently low or inefficiently high? What is the allocation of capital that maximizes welfare taking collateral constraints as given? To address these questions, we develop an equilibrium model of investment and capital reallocation with collateral constraints. We then characterize the constrained-efficient allocation, that is, the allocation that would arise if a benevolent planner made investment decisions on behalf of firms, using the same markets and subject to the same financing constraints firms face in the competitive equilibrium. We use this benchmark to show that in stationary competitive equilibrium the resale price of capital is inefficiently high and a lower price would facilitate capital reallocation toward the most financially constrained firms.

In our framework, heterogeneous firms face collateral constraints on borrowing as well as costs of issuing equity. They produce output by investing in new capital or by acquiring old capital from other firms. Old capital is reallocated in a competitive secondary market. Importantly, the model is consistent with the key facts about capital reallocation: On average, older assets flow to more financially constrained and more productive firms. These firms have a high marginal value of current net worth. Thus, they take advantage of the fact that old capital is cheaper and has hence a lower financing need than new capital, because it has a lower future residual value. On the other hand, larger, less financially constrained firms tend to acquire newer investment goods, as they effectively discount the future resale value of capital at a lower rate. These firms account for most of the formation of new capital in the economy, and typically resell their capital on the secondary market as it ages.

Because of financial frictions, the competitive-equilibrium price of old capital does not coincide with its social value: Financial frictions manifest themselves as pecuniary externalities. Specifically, our economy encompasses both collateral externalities, because the resale value of capital affects firms' ability to borrow, and distributive externalities, because buyers and sellers of old capital have different valuations of internal funds. We show that the price of old capital, which serves as collateral, affects the aggregate value of these externalities with opposite sign. On the one hand, a higher resale price of capital relaxes collateral constraints. On the other hand, because buyers of old capital tend to be more financially constrained than sellers, a lower price of old capital redistributes resources toward firms with a higher marginal product of capital.

Our main result is that this distributive externality is larger than the collateral exter- 
nality in stationary equilibrium. As a consequence, the equilibrium price of old capital is higher than the constrained-efficient price. An additional unit of new investment today increases the supply of old capital in the future, thereby reducing its price and creating a positive externality on future constrained firms, who are net buyers of old capital. In the decentralized equilibrium, investing firms do not take this effect into account. A subsidy on new investment may thus lead to a more efficient allocation.

Importantly, a low price of old capital is optimal, despite its negative effect on the value of collateral. The economic intuition is that the buyers of old capital are the most constrained firms, whereas the firms that purchase new capital and borrow against its collateral value are less constrained or unconstrained. Thus, the marginal value of net worth of firms that benefit from the distributive externality of a lower price of old capital is higher than the marginal value of net worth of the firms that are negatively affected by the collateral externality of a lower price of old capital.

To formalize this result, we consider a planner who faces the same constraints and has access to the same markets as private firms, but, crucially, internalizes all pecuniary externalities. The planner needs to respect all individual budget constraints and cannot redistribute net worth across firms, that is, cannot "remove" financial frictions. We solve for the constrained-efficient allocation and compare it with the stationary competitive equilibrium. We show, both analytically and quantitatively, that the price of old capital is inefficiently high in competitive equilibrium. The constrained-efficient allocation induces a lower price of old capital, allowing financially constrained firms to produce at larger scale.

Our analysis is organized in three parts. First, we consider a stylized infinite-horizon model of capital reallocation and pecuniary externalities with over-lapping generations of firms and capital that lasts for two periods. In this model, we characterize the stationary equilibrium analytically and obtain a formal result on the sign of the inefficiency in equilibrium: The distributive externality is larger than the collateral externality. Importantly, this result holds independently of specific assumptions about the distribution of net worth. We then provide a closed-form solution for the constrained-efficient allocation, as well as a Ramsey implementation of this allocation with proportional subsidies on investment in new capital and taxes on investment in old capital, rebated in a lump-sum fashion to each firm. We also consider several alternative restrictions on the set of policy instruments available to the planner. All of these policy experiments confirm that the planner aims to reduce the price of old capital.

Second, we consider three relevant generalizations of the assumptions of the stylized model, namely entrepreneurial risk aversion, heterogeneity in firm productivity, and when both firms and capital goods are long-lived. We show that our main analytical results 
obtain in these more general models, as well as under a different timing assumption for the collateral constraint. We highlight the essential role of heterogeneity and equilibrium reallocation for these results and show how to apply these insights to an environment with productive assets in fixed supply. We also provide explicit guidance on the role of different assumptions for the comparison of collateral and distributive externality, connecting to other results in the literature on pecuniary externalities. In particular, we discuss how modifying our assumptions on collateralizability of new and old capital, on discount rates vs. the interest rate, or on the type of market incompleteness may lead to different implications for the relative size of the two types of externalities.

Third, we consider a richer quantitative model with persistent idiosyncratic productivity shocks and long-lived firms and capital, which nests our stylized model. We calibrate the model to match empirical moments related to US firm dynamics and financing costs, and use it to perform a quantitative efficiency analysis, with a main focus on the stationary equilibrium. We find that the distributive externality is over twice as large as the collateral externality in competitive equilibrium. Moreover, output and consumption are respectively $10 \%$ and $7 \%$ lower than in the first-best allocation. The constrained-efficient allocation recovers approximately $70 \%$ of these losses ( 7 percentage points of output and 5 percentage points of consumption), by substantially decreasing the price of old capital. This outcome can be implemented in competitive equilibrium, with a mix of subsidies on new investment and taxes on purchases of old capital. We also perform several additional policy experiments with restricted sets of policy instruments, which buttress our main conclusion on the desirability of policy interventions to stimulate new investment and reduce the resale price of capital.

The paper proceeds as follows. Section 2 discusses the related literature. Section 3 presents our main theoretical results in a stylized model of capital reallocation. Section 4 provides analytical results in more general models and discusses the role of different assumptions. Section 5 introduces the quantitative model with idiosyncratic productivity shocks and characterizes the constrained-efficient allocation. Section 6 presents our quantitative results. Section 7 discusses additional analyses. Section 8 concludes.

\section{Related Literature}

This paper contributes to several strands of the literature, specifically on capital reallocation and the role of secondary markets, on pecuniary externalities with collateral constraints, on constrained efficiency in dynamic heterogeneous-agent economies, and on the effect of 
financial frictions on capital misallocation. ${ }^{1}$

Capital reallocation and secondary markets. Several papers study the reallocation of durable assets across heterogeneous producers, starting with Eisfeldt and Rampini (2006). A robust empirical finding of this literature is that financially constrained agents tend to buy assets in the secondary market. In particular, Eisfeldt and Rampini (2007) analyze investment in new and used capital in the presence of financial frictions, and present empirical evidence that more financially constrained firms tend to acquire older investment goods, using both the Annual Capital Expenditure Survey and micro data on commercial trucks. More recently, Ma, Murfin, and Pratt (forthcoming) leverage a large dataset on equipment transactions to document a negative correlation between firm age and capital age. We relate our quantitative results to their estimates. Gavazza, Lizzeri, and Roketskiy (2014) provide a quantitative analysis of the welfare gains due to secondary markets for durable goods in the presence of consumer heterogeneity. Gavazza and Lanteri (2021) emphasize the role of secondary markets in reallocating used consumer durable goods from wealthier to poorer households and argue that this mechanism contributes to the transmission of credit shocks. Lanteri (2018) analyzes the market for used investment goods in a quantitative business-cycle model with heterogeneous firms subject to idiosyncratic productivity shocks. Rampini (2019) analyzes the effects of asset durability on the financing of investment with collateral constraints. ${ }^{2}$ We build on his model and develop a quantitative framework with idiosyncratic productivity shocks and a general depreciation schedule for capital. Different from the existing literature on capital reallocation, our focus is on efficiency. ${ }^{3}$

Pecuniary externalities and constrained efficiency. Several papers study pecuniary externalities related to asset prices in economies with collateral constraints - as introduced by Kiyotaki and Moore (1997) — or other financial frictions. In a seminal contribution, Lorenzoni (2008) develops a finite-horizon model with production heterogeneity between borrowers and lenders and aggregate shocks, and emphasizes how financial frictions may induce an inefficient level of borrowing and investment. Dávila and Korinek (2018) show

\footnotetext{
${ }^{1}$ To focus on the effects of collateral constraints on the efficiency of investment and capital reallocation, we abstract from adverse selection (as in the seminal paper of Akerlof, 1970, and more recently Kurlat, 2013, for example), illiquidity due to search frictions (as in, for example, Gavazza, 2011, 2016, Ottonello, 2021, and Wright, Xiao, and Zhu, 2020), and heterogeneity not due to differences in net worth or productivity (as in, for example, Bond, 1983).

${ }^{2}$ Rampini and Viswanathan $(2010,2013)$ study a dynamic model of firm financing with tangible assets serving as collateral, deriving the collateral constraints from limited enforcement without exclusion.

${ }^{3}$ Cooper and Schott (2020) analyze capital reallocation and aggregate fluctuations by formulating a planning problem, but abstract from financial frictions and the related inefficiency. Cui (forthcoming) studies the effects of financing constraints and partial irreversibility on the cyclicality of capital liquidation. $\mathrm{Ai}, \mathrm{Li}$, and Yang (2020) study the link between financial intermediation and capital reallocation. See Eisfeldt and Shi (2018) for a survey of the literature on capital reallocation.
} 
that, in general, financial frictions may give rise to both distributive externalities, that is, externalities between sellers and buyers of assets, and collateral externalities, that is, externalities deriving from the dependence of financial constraints on asset prices, and that prices could be too high or too low. ${ }^{4}$ In quantitative analyses of models with pecuniary externalities stemming from asset prices, the literature typically focuses on collateral externalities, abstracting from distributive externalities by assuming a representative producer: Bianchi and Mendoza (2018) and Jeanne and Korinek (2019) analyze infinite-horizon small open economy models with a representative firm and an asset in fixed supply. In these models, the price of collateral is too low in states of the world in which collateral constraints bind, and optimal policy can improve efficiency by increasing collateral values. ${ }^{5}$ We contribute to this literature by analyzing an infinite-horizon model of investment with heterogeneous firms, consistent with the key facts about capital reallocation. We build on the analysis of externalities of Dávila and Korinek (2018) and show that, in the stationary equilibrium of our economy, the distributive externality is larger than the collateral externality. The price of collateral is too high from the perspective of a planner, because the most financially constrained firms are net buyers of old capital, that is, collateral. A related literature analyzes constrained efficiency in dynamic general-equilibrium models with incomplete markets, with a focus on distributive externalities through wages and interest rates: Dávila, Hong, Krusell, and Ríos-Rull (2012) analyze constrained efficiency in the Aiyagari (1994) model; Park (2018) extends their framework to characterize the efficient allocation of human capital; Itskhoki and Moll (2019) analyze optimal development policies that redistribute between workers and entrepreneurs in an economy with financial constraints. ${ }^{6}$ Relative to this literature, the focus of our paper is on efficiency in investment and capital reallocation. To our knowledge, we provide the first analysis of optimal

\footnotetext{
${ }^{4}$ See Diamond (1967), Stiglitz (1982), and Geanakoplos and Polemarchakis (1986) for early contributions on efficiency in the presence of market incompleteness. He and Kondor (2016) study the role of pecuniary externalities in liquidity management for the efficiency of investment over the cycle. Kurlat (2021) considers the role of asymmetric information about capital quality for pecuniary externalities and the efficiency of investment.

${ }^{5}$ Michelacci and Pozzi (2022) characterize the efficient price of land in a small-open-economy model with collateral constraints and measure the collateral externality using Italian real-estate price data. Villalvazo (2022) explores the role of household heterogeneity for sudden stops in a small open economy with collateral constraints. A related literature in international macroeconomics analyzes endowment economies in which the relative price of non-tradable goods affects the value of collateral, which is assumed to be income, instead of capital. See, for instance, Bianchi (2011), Benigno, Chen, Otrok, Rebucci, and Young (2013), and Ottonello, Perez, and Varraso (2021). Bianchi and Mendoza (2020) survey both strands of this literature, with capital or income as collateral, and connect them in a model with endogenous investment, in which the price of capital is tied to the price of non-tradable goods.

${ }^{6}$ Nuño and Moll (2018) develop tools to study constrained efficiency in economies with heterogeneous agents in continuous time.
} 
investment subsidies in the presence of financial frictions. ${ }^{7}$

Financial frictions and capital misallocation. A large literature studies the role of financial frictions for the allocation of capital across heterogeneous firms. See, for instance, Buera, Kaboski, and Shin (2011), Midrigan and Xu (2014), and Moll (2014). ${ }^{8}$ These papers provide theoretical and quantitative insights on the efficiency gains that could be achieved by removing financial frictions. We focus on what gains could be achieved if a benevolent planner were to face the same set of financial constraints as private agents. ${ }^{9}$ In so doing, we build a bridge between the quantitative literature on capital misallocation and the theoretical literature on efficiency in presence of pecuniary externalities. Thus, our results provide guidance for the design of second-best policies, such as investment subsidies. ${ }^{10}$

\section{Capital Reallocation and Pecuniary Externalities}

In this section, we describe a stylized model of capital reallocation with new and old capital building on Rampini (2019). We analytically characterize the constrained efficiency of the allocation of capital in the presence of financial frictions that induce distributive and collateral externalities. We show that the distributive externality dominates the collateral externality; the price of old capital in stationary competitive equilibrium is too high from the perspective of efficiency. The economic intuition is as follows. The most financially constrained firms buy old capital due to its lower financing need; firms that buy new capital are less constrained or unconstrained, and while some of these firms benefit from a higher price of old capital, since they borrow against the resale value of their investment in terms of old capital, the severely constrained firms benefit from a lower price of old capital

\footnotetext{
${ }^{7}$ While we focus on a Ramsey implementation of the constrained-efficient allocation, Kilenthong and Townsend (2021) propose a market-based approach to implementing efficient allocations in the presence of pecuniary externalities. Related to our analysis of investment taxes and subsidies, Dávila and Hébert (2021) study the optimal design of corporate taxation in the presence of financial frictions. Parodi (2020) provides a quantitative analysis of optimal subsidies on consumer durable goods in presence of partial irreversibility. Samaniego and Sun (forthcoming) analyze the long-run effects of vintage-specific investment subsidies in a vintage capital model.

${ }^{8}$ Restuccia and Rogerson (2008) and Hsieh and Klenow (2009) provide early contributions on the aggregate effects of capital misallocation across heterogeneous producers. David and Venkateswaran (2019) quantify the roles of different types of frictions, including financial ones, for capital misallocation. Asriyan, Laeven, Van der Ghote, and Vanasco (2022) analyze the effects of interest rates on misallocation in a model with an endogenous price of capital, emphasizing a crowding out effect on investment that is related to the distributive effect that we emphasize.

${ }^{9} \mathrm{Ai}$, Bhandari, Chen, and Ying (2021) develop an optimal contracting model subject to agency frictions. The optimal allocation features dispersion in marginal products of capital across firms and can be implemented with state-contingent securities and collateral constraints.

${ }^{10}$ Relatedly, Gourio and Miao (2010) and Jo and Senga (2019) use quantitative models with heterogeneous firms to study the effects of dividend taxes and credit subsidies respectively.
} 
considerably more.

\subsection{Environment}

Time is discrete and the horizon infinite, that is, $t=0,1,2, \ldots$ There is an infinitely-lived, risk-neutral representative household with preferences

$$
\sum_{t=0}^{\infty} \beta^{t} C_{t}
$$

where $\beta \in(0,1)$ is the discount factor and $C_{t}$ is consumption.

There are over-lapping generations of firms and the representative household owns all firms. At each date, a continuum of firms with measure one is born. Firms live at two dates, make an investment decision when young and produce when old. Each firm has access to a production function $f$ with $f(0)=0, f_{k}>0$, and $f_{k k}<0$; investing capital $k_{t}>0$ at date $t$ yields output $f\left(k_{t}\right)$ at date $t+1$. Output can be used to make new capital goods and it takes one unit of output to make a unit of new capital goods. Capital goods are productive for two periods and then fully depreciate. We refer to capital goods with two periods of useful life as "new" capital (denoted $k_{t}^{N}$ ) and to capital goods with a single residual period of productive life as "old" (denoted $k_{t}^{O}$ ). New and old capital goods are perfect substitutes in production and we define the total capital of a firm as $k_{t} \equiv k_{t}^{N}+k_{t}^{O}$.

\subsection{Frictionless Economy and First Best}

We start by considering a frictionless economy in which the representative household can choose investment in each firm without facing any financial frictions. We index firms of each generation by $w \in \mathcal{W}=\left[w_{\min }, w_{\max }\right]$ with distribution $\pi(w) .{ }^{11}$ The aggregate resource constraint for the frictionless economy is

$$
\int f\left(k_{t-1}^{N}(w)+k_{t-1}^{O}(w)\right) d \pi(w)=C_{t}+\int k_{t}^{N}(w) d \pi(w)
$$

aggregate output equals consumption of the representative household plus aggregate investment in new capital goods. Aggregate investment in new capital at date $t-1$ determines the aggregate stock of old capital at date $t$

$$
\int k_{t-1}^{N}(w) d \pi(w)=\int k_{t}^{O}(w) d \pi(w)
$$

\footnotetext{
${ }^{11}$ We will later interpret $w$ as the initial net worth of each firm.
} 
The first best (FB) allocation maximizes the utility of the representative household (1) by choosing aggregate consumption $C_{t}$ and an allocation of new and old capital $k_{t}^{N}(w)$ and $k_{t}^{O}(w), \forall w \in \mathcal{W}$, subject to the resource constraints (2) and (3), and taking as given $k_{-1}^{N}(w)$ and $k_{-1}^{O}(w), \forall w \in \mathcal{W}$. The first-order conditions with respect to new and old capital satisfy

$$
\begin{aligned}
1 & =\beta\left[f_{k}\left(k_{t}^{F B}\right)+q_{t+1}^{F B}\right] \\
q_{t}^{F B} & =\beta f_{k}\left(k_{t}^{F B}\right),
\end{aligned}
$$

where we use $q_{t}^{F B}$ to denote the shadow value of old capital $k_{t}^{O}$ in terms of date $t$ consumption. Thus, $q_{t}^{F B}$ can be interpreted as the first-best valuation (or price) of old capital. The economy is in steady state from date 1 onwards. Notice that the allocation of total capital is the same for all firms. By combining equations (4) and (5), we get that in a steady state $q^{F B}=\frac{1}{1+\beta}$, and the optimal scale of production for all firms is $k^{F B}=f_{k}^{-1}\left(\frac{1}{\beta(1+\beta)}\right)$. In the spirit of Jorgenson (1963), we can define the frictionless user cost of new and old capital as $u_{N}^{F B} \equiv 1-\beta q^{F B}$ and $u_{O}^{F B} \equiv q^{F B}$, and note that $u_{N}^{F B}=u_{O}^{F B} \equiv u^{F B}$. The user cost would be the rental rate in a frictionless rental market and we define it as of the beginning of the period. The allocation of new and old capital across firms is indeterminate, but must satisfy $\int k_{t+1}^{O}(w) d \pi(w)=\int k_{t}^{N}(w) d \pi(w)=\frac{k^{F B}}{2}$.

\subsection{Financial Frictions and Competitive Equilibrium}

We now consider a competitive equilibrium with financial frictions. Firms are born with exogenous net worth $w$ distributed over the interval $\left[w_{\min }, w_{\max }\right]$ according to an exogenous non-degenerate distribution $\pi(w)$, with $0<w_{\min }<q^{F B} k^{F B}$ and $k^{F B}<w_{\max }$, with positive mass in a neighborhood of $w_{\min }$ and $w_{\max }$. We index firms by their net worth, but suppress the dependence on net worth wherever appropriate.

Firms can borrow from the representative household at rate $R \equiv \beta^{-1}$, but borrowing is subject to a collateral constraint. The collateral constraint requires that debt repayments do not exceed a fraction $\theta \in[0,1)$ of the future resale value of new capital purchases. That is, the collateral value of new capital goods is the future price at which these can be sold as old capital next period. Old capital purchases have no future resale value, as old capital fully depreciates at the end of the period. ${ }^{12}$ Rampini and Viswanathan (2010, 2013) show how to derive such collateral constraints in an economy with limited enforcement without exclusion, in which firms can default on their promises and retain their output, a fraction $1-\theta$ of their capital, and access to the markets for capital goods and financing.

\footnotetext{
${ }^{12}$ In Section 4.3 we consider a model with standard geometric depreciation, in which both new and old capital serve as collateral.
} 
Firms can also raise additional internal funds from the representative household, that is, issue equity by paying negative dividends $d<0$, at a cost $\phi(-d)$ incurred by the household, such that $\phi(-d)=0$ if $d \geq 0, \phi(-d)>0$ if $d<0$. We denote the marginal cost of equity issuance by $\phi_{d}(-d) \equiv \frac{\partial \phi(-d)}{\partial(-d)}$ and assume it is positive, increasing, and convex. Specifically, $\phi_{d} \geq 0, \phi_{d}(0)=0$ and $\phi_{d d} \equiv \frac{\partial^{2} \phi(-d)}{\partial(-d)^{2}} \geq 0$ (see, for example, Gomes, 2001). This assumption is made for tractability, but the main economic insight obtains with a simple non-negativity constraint on dividends as well.

Given their initial net worth $w$ and the price of old capital $q_{t}$, firms maximize the present discounted value of their dividends net of equity issuance costs, that is, their value to the household, by choosing dividends $d_{0 t}$ and $d_{1, t+1}$, new and old capital $k_{t}^{N}$ and $k_{t}^{O}$, and borrowing $b_{t}$, to solve

$$
\max _{\left\{d_{0 t}, d_{1, t+1}, b_{t}, k_{t}^{N}, k_{t}^{O}\right\} \in \mathbb{R}^{3} \times \mathbb{R}_{+}^{2}} d_{0 t}-\phi\left(-d_{0 t}\right)+\beta d_{1, t+1}
$$

subject to the budget constraints for the current and the next period,

$$
\begin{aligned}
w_{0 t}+b_{t} & =d_{0 t}+k_{t}^{N}+q_{t} k_{t}^{O} \\
f\left(k_{t}^{N}+k_{t}^{O}\right)+q_{t+1} k_{t}^{N} & =d_{1, t+1}+\beta^{-1} b_{t}
\end{aligned}
$$

and the collateral constraint

$$
\theta q_{t+1} k_{t}^{N} \geq \beta^{-1} b_{t}
$$

Denote the multipliers on the budget constraints by $\mu_{0 t}$ and $\beta \mu_{1, t+1}$, on the collateral constraint by $\beta \lambda_{t}$, and on non-negativity constraint for new and old capital by $\underline{\nu}_{t}^{N}$ and $\underline{\nu}_{t}^{O}$, respectively. The optimal demand for new capital, old capital, and borrowing, as functions of initial net worth $w$, satisfy the following first-order conditions

$$
\begin{aligned}
1+\phi_{d, t} & =\beta\left[f_{k}\left(k_{t}\right)+q_{t+1}\right]+\beta \theta \lambda_{t} q_{t+1}+\underline{\nu}_{t}^{N} \\
q_{t}\left(1+\phi_{d, t}\right) & =\beta f_{k}\left(k_{t}\right)+\underline{\nu}_{t}^{O} \\
1+\phi_{d, t} & =1+\lambda_{t},
\end{aligned}
$$

where $k_{t}=k_{t}^{N}+k_{t}^{O}$. Moreover, the firm's marginal value of net worth at date $t$ is $\mu_{0, t}=$ $1+\phi_{d, t} \geq 1$, that is, equals one plus the marginal cost of raising additional equity. In contrast, the firm's marginal value of net worth at date $t+1$ is $\mu_{1, t+1}=1$, as the firm pays out all its remaining net worth as dividends to the representative household when it exits. Finally, the premium on internal funds $\phi_{d, t}=\lambda_{t}$, that is, equals the multiplier on the collateral constraint. 
A stationary competitive equilibrium is a set of policy functions mapping initial net worth to an allocation $\left\{d_{0}(w), d_{1}(w), k^{N}(w), k^{O}(w), b(w)\right\}$, that is, dividends, investment, and debt choices, and a price of old capital $q$, such that firms maximize the present discounted value of dividends net of equity issuance cost, $\forall w \in \mathcal{W}$, and the market for old capital clears, that is, $\int k^{N}(w) d \pi(w)=\int k^{O}(w) d \pi(w)$.

In a stationary equilibrium, the first-order conditions for new and old capital (10) and (11) can be expressed as investment Euler equations, after subtracting the quantity $\beta \theta q\left(1+\phi_{d}\right)$ from both sides of equation (10) and using $\lambda=\phi_{d}$ from (12):

$$
\begin{aligned}
& 1 \geq \beta \frac{1}{1+\phi_{d}} \frac{f_{k}(k)+(1-\theta) q}{\wp_{N}} \\
& 1 \geq \beta \frac{1}{1+\phi_{d}} \frac{f_{k}(k)}{q}
\end{aligned}
$$

with equality if $k_{N}>0$ and $k_{O}>0$, respectively, where $k=k_{N}+k_{O}$, and we define the down payment per unit on new capital $\wp_{N} \equiv 1-\beta \theta q$, that is, the price per unit of new capital minus the maximal amount the firm can borrow against the residual value next period, which is determined by the collateral constraint. Analogously, we can define the down payment on old capital as $\wp_{O} \equiv q$, as the firm cannot borrow against old capital. In the spirit of Jorgenson (1963) we can rewrite (13) and (14) as

$$
\begin{aligned}
u_{N}(w) \equiv u_{N}+\phi_{d} \wp_{N} & =1-\beta q+\phi_{d}(1-\beta \theta q) \geq \beta f_{k}(k) \\
u_{O}(w) & \equiv u_{O}+\phi_{d} \wp_{O}=q+\phi_{d} q \geq \beta f_{k}(k),
\end{aligned}
$$

where $u_{N}(w)\left(u_{O}(w)\right)$ is the user cost of new (old) capital to a firm with net worth $w$. The choice between investment in new and old capital is determined by the trade-off between their user costs if the firm were unconstrained and their down payments.

Combining (13) and (14) we moreover have

$$
1=\beta \frac{1}{\left(1+\phi_{d}\right)} \frac{(1-\theta) q}{\wp_{N}-\wp_{O}}+\frac{\left(\underline{\nu}^{N}-\underline{\nu}^{O}\right) /\left(1+\phi_{d}\right)}{\wp_{N}-\wp_{O}} .
$$

If $\wp_{N} \leq \wp_{O}$, then (17) implies $\underline{\nu}^{O}>0$, so no firm would buy old capital, which cannot be true in equilibrium. Therefore, in a stationary equilibrium, $\wp_{N}>\wp_{O}$, which means the down payment for new capital exceeds the down payment for old capital; equivalently, $\frac{1}{1+\beta \theta}>q$.

But then (15) and (16) imply that $u_{N} \leq u_{O}$, as otherwise there would be no investment in new capital, which is not an equilibrium; equivalently, $q \geq q^{F B}$, that is, the price of old capital in competitive equilibrium weakly exceeds the price in a frictionless economy. 
To interpret (17), define $R_{O} \equiv \frac{(1-\theta) q}{\wp_{N}-\wp_{O}}$; this can be interpreted as the shadow interest rate on the additional amount the firm can implicitly borrow by buying old capital instead of new capital. Since $q \geq q^{F B}, R_{O} \geq \beta^{-1}$, that is, borrowing more by buying old capital is costly in equilibrium, and strictly so if $q>q^{F B}$.

Note that in the problem in (6) to (9) the objective is (weakly) concave and the constraint set (with constraints stated as inequality constraints) convex. Hence, the induced value function is weakly concave and, using the envelope condition, the marginal value $1+\phi_{d}$ weakly decreasing in $w$. Since $u_{O}(w)-u_{N}(w)=u_{O}-u_{N}-\phi_{d}\left(\wp_{N}-\wp_{O}\right)$, the difference in user costs between old and new capital is increasing in $w$. Old capital is relatively less costly for more financially constrained firms. This implies that in equilibrium, firms that are sufficiently constrained invest in only old capital, and firms shift to investing in new capital as their net worth increases. We stress that this equilibrium property of our model is consistent with the empirical evidence on capital reallocation (for example, Eisfeldt and Rampini, 2007, and Ma, Murfin, and Pratt, forthcoming).

In particular, dividend-paying firms have $\phi_{d}=0$, so $u_{N}(w) \leq u_{O}(w)$, that is, prefer new capital at least weakly. Such firms invest $\bar{k}$ which solves $1=\beta\left(f_{k}(k)+q\right)$, where $\bar{k} \geq k^{F B}$ with equality iff $q=q^{F B}$. Firms pay dividends if $w \geq \bar{w}=\wp_{N} \bar{k}$. Firms that are indifferent between new and old capital must have $\beta \frac{1}{1+\phi_{d}}=R_{O}^{-1}$ (from (17)) and invest $\underline{k}$, which solves $1=R_{O}^{-1} \frac{f_{k}(k)+(1-\theta) q}{\wp_{N}}$, where $\underline{k} \leq k^{F B}$ with equality iff $q=q^{F B}$. Firms are indifferent between new and old capital at the margin if $w \in\left(\underline{w}_{N}, \bar{w}_{O}\right)$, where $\underline{w}_{N}=\underline{d}_{0}+q \underline{k}$ and $\bar{w}_{O}=\underline{d}_{0}+\wp_{N} \underline{k}, \underline{d}_{0}=0$ if $q=q^{F B}$, and $\underline{d}_{0}$ solves $1+\phi_{d}=\beta R_{O}$ if $q>q^{F B}$.

We summarize these results in the following proposition:

Proposition 1 (Stationary Competitive Equilibrium Characterization) A stationary competitive equilibrium is characterized as follows:

(i) New capital has a higher down payment than old capital $\left(\wp_{N}>\wp_{O}\right)$, but a (weakly) lower user cost from the perspective of an unconstrained firm $\left(u_{N} \leq u_{O}\right)$.

(ii) The price of old capital (weakly) exceeds the price in a frictionless economy $\left(q \geq q^{F B}\right)$.

(iii) If $q>q^{F B}$, there exist thresholds $\underline{w}_{N}<\bar{w}_{O}<\bar{w}$ such that: firms with $w \leq \underline{w}_{N}$ invest only in old capital; firms with $w \in\left(\underline{w}_{N}, \bar{w}_{O}\right)$ invest $\underline{k}$ and invest in both new and old capital; firms with $w \geq \bar{w}_{O}$ invest only in new capital; and firms with net worth $w \geq \bar{w}$ pay dividends and invest $\bar{k}>k^{F B}>\underline{k}$. If $q=q^{F B}$, there exists thresholds $\underline{w}_{N}<\bar{w}_{O}=\bar{w}$ such that: firms with $w \leq \underline{w}_{N}$ invest only in old capital; firms with $w \geq \bar{w}_{O}$ invest $k^{F B}$ and are indifferent between new and old capital at the margin; firms with $w \in\left(\underline{w}_{N}, \bar{w}_{O}\right)$ invest a strictly positive minimum amount in old capital.

We now compute a numerical example and use it to illustrate the main properties of the stationary competitive equilibrium. We assume the production function is $f(k)=k^{\alpha}$ 

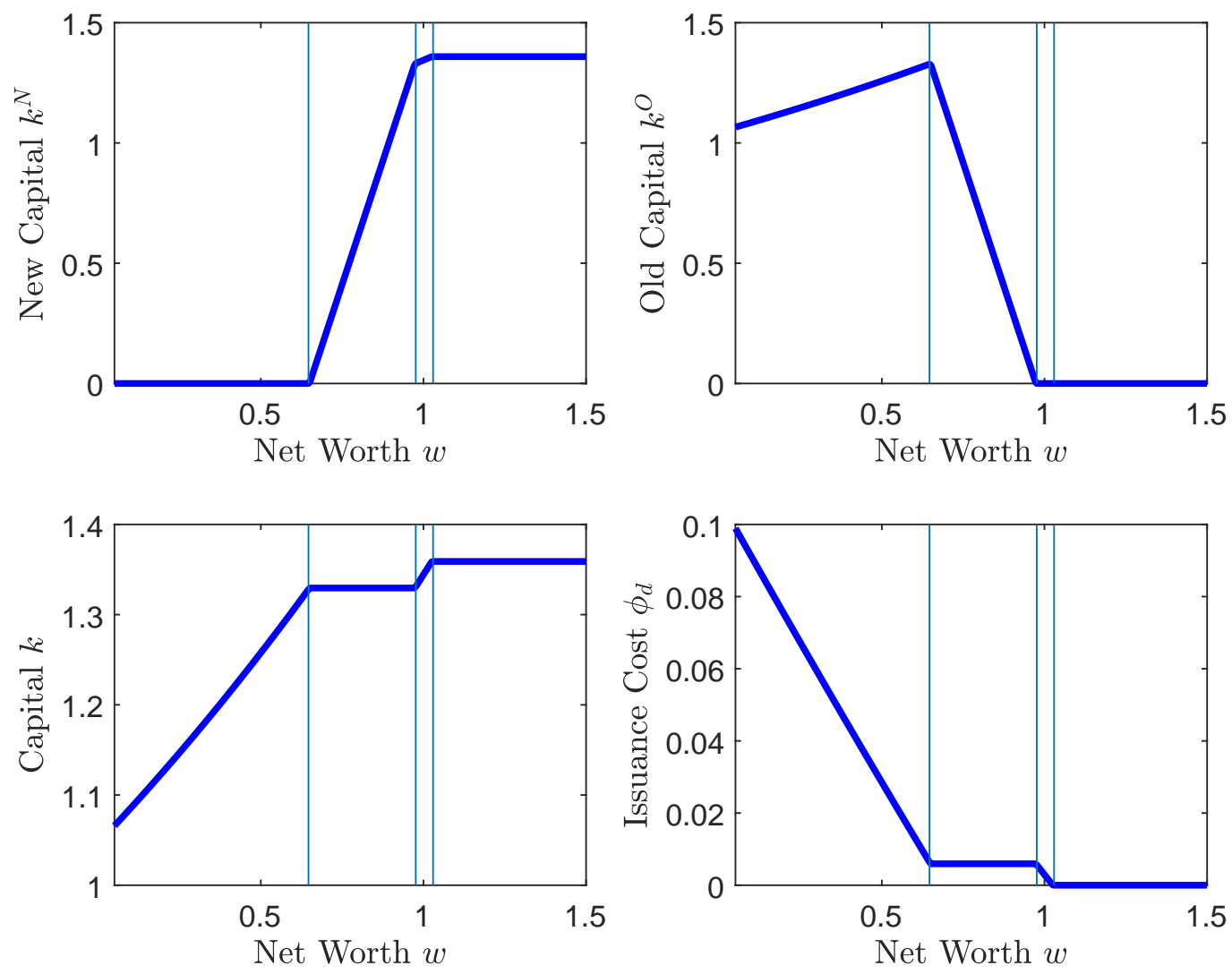

Figure 1: Stationary competitive equilibrium - example. Top left: new capital $k^{N}$; top right: old capital $k^{O}$; bottom left: total capital $k$; bottom right: marginal cost of equity issuance $\phi_{d}$. The $x$-axes report net worth $w$. The parameter values are: discount rate $\beta=0.96$; support of net worth distribution $w_{\min }=0.05$ and $w_{\max }=1.5$; curvature of production function $\alpha=0.6$; collateralizability $\theta=0.5$; and cost of raising equity parameters $\phi_{0}=0.1$ and $\phi_{1}=2$.

with $\alpha \in(0,1)$. Net worth is uniformly distributed on $\left[w_{\min }, w_{\max }\right]$. The cost of equity issuance is a power function, $\phi(-d)=\phi_{0}(-d)^{\phi_{1}}$ for $d<0$ and $\phi(-d)=0$ otherwise. The caption of Figure 1 reports all parameter values used in the example.

The stationary-equilibrium price of old capital associated with this parametrization is $q=0.511>q^{F B}=0.51$. Figure 1 displays the policy functions for new capital (top left), old capital (top right), total capital, that is, the sum of new and old capital (bottom left), and the marginal cost of equity issuance (bottom right), in stationary equilibrium. Consistent with the characterization in Proposition 1, there are three thresholds $\underline{w}_{N}<\bar{w}^{O}<\bar{w}$, which we highlight with vertical lines in the figure. Firms with $w \leq \underline{w}_{N}$ invest only in old capital. Their total investment increases in net worth, and their marginal cost of equity issuance decreases in net worth. Firms with $\underline{w}_{N}<w<\bar{w}^{O}$ invest in both new and old capital, keeping the total investment $\underline{k}$ constant, and issue a common level of equity, resulting in 
a constant marginal cost of equity issuance. Firms with $\bar{w}^{O} \leq w<\bar{w}$ invest only in new capital, while still issuing equity. Firms with $w \geq \bar{w}$ invest only in new capital and are unconstrained in their investment $\bar{k}$; these firms pay dividends.

\subsection{Constrained (In-)Efficiency}

We now characterize the constrained-efficient allocation in this economy, that is, the allocation that arises if a benevolent planner with full commitment makes investment decisions on behalf of firms, subject to the same constraints that are present in the competitive equilibrium. This characterization serves primarily as a tool to analyze the nature of constrained inefficiency in competitive equilibrium. We then present an implementation of this allocation with proportional taxes on new and old capital, rebated in a lump-sum fashion to each firm, in Section 3.5.

Given initial conditions $k_{-1}^{N}(w), k_{-1}^{O}(w), b_{-1}(w)$, the planner chooses sequences of allocations $\left\{d_{0 t}(w), d_{1, t+1}(w), k_{t}^{N}(w), k_{t}^{O}(w), b_{t}(w)\right\}_{t=0}^{\infty}$ and a sequence of prices $\left\{q_{t}\right\}_{t=0}^{\infty}$, to maximize the present discounted value of aggregate dividends net of costs of equity issuance or, equivalently, aggregate consumption

$$
\int\left[d_{10}(w)+\sum_{t=0}^{\infty} \beta^{t}\left(d_{0 t}(w)-\phi\left(-d_{0 t}(w)\right)+\beta d_{1, t+1}(w)\right)\right] d \pi(w)
$$

subject to the budget constraints (7) and (8) with multipliers $\beta^{t} \mu_{0, t}$ and $\beta^{t+1} \mu_{1, t+1}$, the collateral constraint (9) with multiplier $\beta^{t+1} \lambda_{t}$, the non-negativity constraints on new and old capital with multipliers $\beta^{t} \underline{\nu}_{t}^{N}$ and $\beta^{t} \underline{\nu}_{t}^{O}$, and the market clearing condition for old capital (3) with multiplier $\beta^{t} \eta_{t}{ }^{13}$

Two aspects of the planner's problem are worth emphasizing. First, the planner is subject to the same collateral constraints that firms are in competitive equilibrium. The decentralized economy subject to such collateral constraints is equivalent to an economy with long-term contracting subject to limited enforcement without exclusion as shown by Rampini and Viswanathan (2010, 2013), and we assume that the planner can only choose allocations that satisfy these same constraints. Second, in addition to an allocation, the planner is choosing a sequence of prices because they appear in firms' budget and collateral constraints, but these prices must be consistent with market clearing. ${ }^{14}$ Furthermore, in our

\footnotetext{
${ }^{13}$ We explicitly formulate the Lagrangian of this problem in the Appendix.

${ }^{14}$ In some models analyzed in the literature on constrained efficiency, such as the neoclassical growth model with idiosyncratic income shocks of Dávila, Hong, Krusell, and Ríos-Rull (2012), it is possible to formulate equilibrium prices as functions of allocations in closed form and use these expressions to substitute out prices in the planning problem. In the case of our model, this is not possible, including when we consider additional restrictions on the planner, and we thus add the price as a choice variable for
} 
implementation with proportional taxes on investment in new and old capital in Section 3.5, the policy instruments pin down both allocations and prices. ${ }^{15}$

The planner's first-order conditions with respect to new and old capital are

$$
\begin{aligned}
1+\phi_{d, t} & =\beta\left[f_{k}\left(k_{t}\right)+q_{t+1}\right]+\beta \theta \lambda_{t} q_{t+1}+\underline{\nu}_{t}^{N}+\beta \eta_{t+1} \\
q_{t}\left(1+\phi_{d, t}\right)+\eta_{t} & =\beta f_{k}\left(k_{t}\right)+\underline{\nu}_{t}^{O}
\end{aligned}
$$

and with respect to debt (12). The first-order condition with respect to the price of old capital $q_{t}$ for $t=1,2, \ldots$ is

$$
\int k_{t}^{O}(w)\left(1+\phi_{d, t}(w)\right) d \pi(w)=\int k_{t-1}^{N}(w)\left(1+\theta \lambda_{t-1}(w)\right) d \pi(w)
$$

The left-hand side of equation (21) reports the marginal effect of an increase in $q_{t}$ on dividends of young firms at $t$, net of equity issuance costs. The right-hand side reports its marginal effect on the dividends of old firms at $t$, as well as its effect on collateral constraints at $t-1$. Equivalently, we can write

$$
\int k_{t}^{O}(w)\left(1+\phi_{d, t}(w)\right) d \pi(w)-\int k_{t-1}^{N}(w) d \pi(w)=\theta \int k_{t-1}^{N}(w) \lambda_{t-1}(w) d \pi(w),
$$

where the left-hand side reports the net distributive effect of the price of old capital on buyers and sellers, whereas the right-hand side reports its aggregate collateral effect. In the absence of financial frictions, we would have $\phi_{d, t}(w)=\lambda_{t-1}(w)=0$; thus, equation (22) would coincide with the market-clearing condition for old capital (3), and the aggregate welfare effect of a marginal change in $q_{t}$ would be zero. Moreover, using the market clearing condition (3), we can simplify equation (21) to isolate the pecuniary externalities induced by the presence of financial frictions:

$$
\int k_{t}^{O}(w) \phi_{d, t}(w) d \pi(w)=\theta \int k_{t-1}^{N}(w) \lambda_{t-1}(w) d \pi(w)
$$

The left-hand side of equation (23) represents the aggregate distributive externality induced by a marginal increase in the price of old capital $q_{t}$ : Firms that purchase old the planner and the market-clearing condition as a constraint.

${ }^{15}$ To be consistent with this implementation, we assume $0<\underline{q} \leq q_{t} \leq \bar{q}<\infty$. We interpret the lower bound $\underline{q}$, which ensures a strictly positive price, as the scrap value of old capital and assume it is strictly lower than the first-best price. To focus on an interior solution, for our analytical results we let $\frac{q}{S}<\frac{w_{\min }}{k^{F B}}$; we then analyze the effects of a binding constraint on the price in the quantitative model of Section 5. We further set $\bar{q}=\beta^{-1}$; if the price were higher than this upper bound, there would be an arbitrage opportunity because it would be profitable to produce new capital and resell it as old without investing it in production. 
capital at $t$ value the additional expenditure they need to incur as the product of the quantity purchased $k_{t}^{O}$ and their marginal cost of equity issuance $\phi_{d, t}$.

The right-hand side of equation (23) represents the aggregate collateral externality induced by the same marginal increase in $q_{t}$ : Firms that purchase new capital at $t-1$ and face a binding collateral constraint are able to borrow against a fraction $\theta$ of the additional collateral value, and thus increase their investment; they value this benefit as the product of the additional collateral $\theta k_{t-1}^{N}$ and the Lagrange multiplier on their collateral constraint $\lambda_{t-1} \cdot{ }^{16}$

Thus, a marginal increase in $q_{t}$ induces a negative externality on the value of firms that issue equity to purchase old capital at $t$, and a positive externality on firms that purchase new capital at $t-1$ and are constrained in their borrowing. Equation (23) highlights that these two opposite externalities must offset each other in the constrained-efficient allocation.

Before proceeding to characterize the planning solution, we show that in the stationary competitive equilibrium, the aggregate distributive externality is larger than the aggregate collateral externality, resulting in an equilibrium price of old capital that is higher than the constrained-efficient one. Specifically, we prove that in stationary competitive equilibrium, we have

$$
\int k^{O}(w) \phi_{d}(w) d \pi(w)>\theta \int k^{N}(w) \lambda(w) d \pi(w)
$$

Let us start by considering the case $q>q^{F B}$. Using the characterization in Proposition 1 , we know that $k_{N}=0$ for $w \leq \underline{w}_{N}, k_{O}=0$ for $w \geq \bar{w}_{O}$, and $\phi_{d}=0$ for $w \geq \bar{w}$, with $\underline{w}_{N}<\bar{w}_{O}<\bar{w}$. Firms that are indifferent between new and old capital, that is, firms with $w \in\left(\underline{w}_{N}, \bar{w}_{O}\right)$, have the same (positive) marginal cost of equity, which we denote by $\bar{\phi}_{d}$.

As $\phi_{d}$ is weakly decreasing in $w$, no firm purchasing old capital has a marginal value of net worth less than $1+\bar{\phi}_{d}$, and no firm purchasing new capital has a marginal value of net worth larger than $1+\bar{\phi}_{d}$. Formally, we have $\phi_{d} \geq \bar{\phi}_{d}$ for $w \leq \bar{w}_{O}$, and $\phi_{d} \leq \bar{\phi}_{d}$ for $w \geq \underline{w}_{N}$.

Furthermore, using the optimality condition for debt (12), $\lambda(w)=\phi_{d}(w)$ and we can rewrite the right-hand-side of (24) as $\theta \int k^{N} \phi_{d} d \pi$. We can then bound the two integrals in (24) as follows:

$$
\int k^{O}(w) \phi_{d}(w) d \pi(w)=\int^{\bar{w}_{O}} k^{O}(w) \phi_{d}(w) d \pi(w) \geq \bar{\phi}_{d} \int^{\bar{w}_{O}} k^{O}(w) d \pi(w),
$$

\footnotetext{
${ }^{16}$ The effect of the current price of old capital on past collateral constraints implies that the constrainedefficient plan is time inconsistent. A planner without commitment, such as the one considered by Bianchi and Mendoza (2018), would disregard this effect. However, as we show below, even under our assumption of full commitment, the collateral externality is dominated by the distributive externality.
} 
and

$$
\int k^{N}(w) \phi_{d}(w) d \pi(w)=\int_{\underline{w}_{N}}^{\bar{w}} k^{N}(w) \phi_{d}(w) d \pi(w) \leq \bar{\phi}_{d} \int_{\underline{w}_{N}}^{\bar{w}} k^{N}(w) d \pi(w) .
$$

Furthermore, the market-clearing condition for old capital (3), together with the characterization in Proposition 1, implies

$$
\int_{\underline{w}_{N}}^{\bar{w}} k^{N}(w) d \pi(w)<\int^{\bar{w}_{O}} k^{O}(w) d \pi(w),
$$

because the left-hand side of (27) is less than the aggregate supply of old capital in stationary equilibrium, whereas the right-hand side represents aggregate demand for old capital. ${ }^{17}$ Combining (25), (26), and (27), we have

$$
\int k^{O}(w) \phi_{d}(w) d \pi(w)>\int k^{N}(w) \phi_{d}(w) d \pi(w),
$$

which implies $(24)$ since $\theta<1^{18}$

Let us now consider the case $q=q^{F B}$. All firms investing in new capital, that is, with $w>\underline{w}_{N}$, are unconstrained. Thus their marginal cost of equity issuance is zero and we have $\int k^{O}(w) \phi_{d}(w) d \pi(w)>0=\int k^{N}(w) \phi_{d}(w) d \pi(w)$.

Hence, in stationary equilibrium, the aggregate distributive externality is larger than the aggregate collateral externality. By comparing this result with the constrained-efficiency condition for the price of old capital (23), we find that a marginal reduction in the price of old capital has a positive effect on aggregate welfare, implying that the competitiveequilibrium price is too high from the perspective of constrained efficiency.

We summarize this result in the following proposition:

Proposition 2 (Sign of Constrained Inefficiency) In stationary competitive equilibrium, the aggregate distributive externality is larger than the aggregate collateral externality, that is, $\int k^{O}(w) \phi_{d}(w) d \pi(w)>\theta \int k^{N}(w) \lambda(w) d \pi(w)$. A marginal decrease in the price of

\footnotetext{
${ }^{17}$ Inequality (27) is strict since we assume a positive mass of firms with $w>\bar{w}$.

${ }^{18}$ Notice that even if we were to assume a degenerate distribution of initial net worth, so that all young firms would be equally financially constrained, we would still conclude that the distributive externality between young and old firms dominates the collateral externality; in this case, inequality (28) would be an equality, and (24) would still be a strict inequality because $\theta<1$. Importantly, this alternative model would still be a model with heterogeneity in the marginal value of net worth, specifically between young and old firms. However, this model would not generate the equilibrium sorting of firms into new and old investment observed in the empirical evidence on capital reallocation, because all firms would have the same composition of investment. As we discuss in Section 4.5 in more detail, in the case of common net worth for young firms in a model with assets in fixed supply, the distributive externality dominates the collateral externality, too. In contrast, a model with an infinitely-lived representative firm would feature no reallocation and hence no distributive externality in stationary equilibrium.
} 

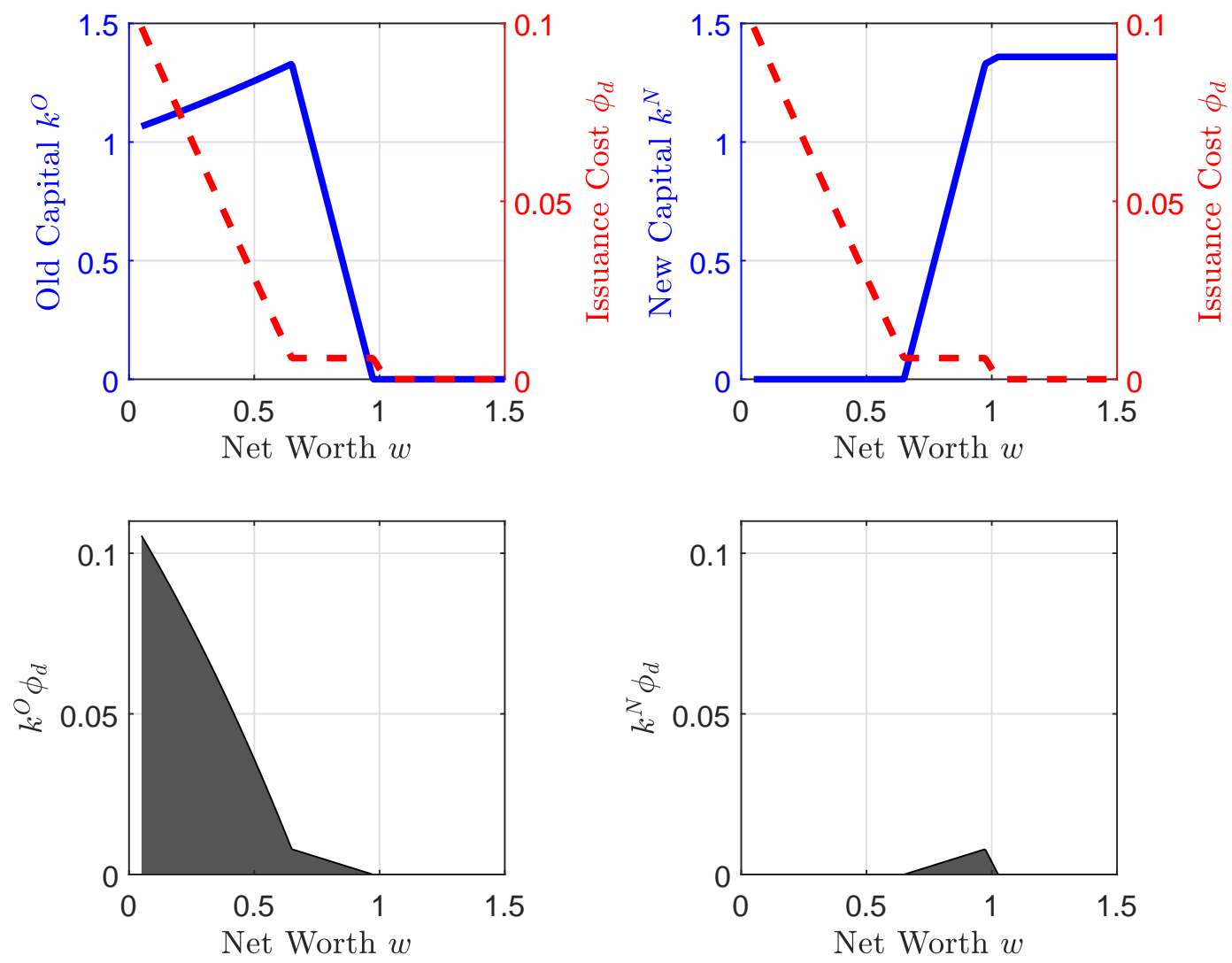

Figure 2: Illustration of left-hand side and right-hand side of inequality (28). Top left: old capital $k^{O}$ (solid line, left axis) and marginal cost of equity issuance $\phi_{d}$ (dashed line, right axis); top right: new capital $k^{N}$ (solid line, left axis) and marginal cost of equity issuance $\phi_{d}$ (dashed line, right axis); bottom left: area under $k^{O} \phi^{d}$, the integrand of the left-hand side of (28); bottom right: area under $k^{N} \phi^{d}$, the integrand of the right-hand side of (28). The $x$-axes report net worth $w$. See the caption of Figure 1 for the parameter values.

old capital induces a positive welfare gain.

The economic intuition is as follows: In stationary equilibrium, the buyers of old capital are the more constrained firms whereas the sellers of old capital are old firms which are unconstrained and thus the distributive externality is sizable; the sellers also benefit from the collateral externality to the extent that they were constrained in the previous period, but since these firms invested in new capital last period, they must have been less constrained, and thus the collateral externality is more moderate. Stationarity is used in two ways here: First, aggregate investment in new capital equals aggregate investment in old capital and, second, the distribution of the marginal value of net worth is the same across periods.

We use again our numerical example to illustrate and decompose each side of inequality (28) in Figure 2. The left panels of the figure refer to the left-hand side of inequality (28). 
In particular, the top-left panel displays old capital $k^{O}(w)$ and the marginal cost of equity issuance $\phi_{d}(w)$, highlighting that investment in old capital is high when the marginal value of net worth is also high, that is, for firms with low net worth. The bottom-left panel displays the area under the product of these two functions, $k^{O}(w) \phi_{d}(w)$. Because we assume in the numerical example that the distribution of net worth $\pi(w)$ is uniform, the size of this area is (proportional to) the integral on the left-hand side of inequality (28). The area is largest in the range of low net worth where firms invest only in old capital.

The right panels of the figure refer to the right-hand side of inequality (28). The topright panel displays new capital $k^{N}(w)$ and the marginal cost of equity issuance $\phi_{d}(w)$, highlighting the negative correlation between investment in new capital and the marginal value of net worth. The bottom-left panel displays the area under the product of these two functions, $k^{N}(w) \phi_{d}(w)$. The size of this area is (proportional to) the integral on the right-hand side of inequality (28). Clearly, this area is zero in the range of net worth $w$ for which either new investment is zero or firms are unconstrained.

\subsection{Constrained-Efficient Allocation and Implementation}

We now analyze the stationary constrained-efficient allocation and describe an implementation with taxes. To obtain a stark characterization, we assume that there is a sufficiently large mass of firms with net worth larger than $k^{F B}$; if $\pi$ is uniform, as in our numerical example, it is sufficient that $w_{\max }>k^{F B}$ as we have already assumed. Under this assumption, we show that the planner achieves the first-best level of welfare in the stylized model. In stationary equilibrium, the optimality condition for the price of old capital (23) reads

$$
\int k^{O}(w) \phi_{d}(w) d \pi(w)=\theta \int k^{N}(w) \lambda(w) d \pi(w)
$$

Clearly, an allocation such that all firms pay non-negative dividends, that is, $\phi_{d}=\lambda=0$ for all $w$, satisfies this condition. We now show that the planner induces an allocation that satisfies all budget and financial constraints, allowing all firms to be unconstrained and produce at the efficient scale $k^{F B}$. Imposing $\phi_{d}=0$ for all $w$, we can rewrite the optimality conditions (19) and (20) in stationary-equilibrium as follows:

$$
\begin{aligned}
1 & =\beta\left(f_{k}\left(k^{F B}\right)+q^{*}\right)+\beta \eta \\
q^{*}+\eta & =\beta f_{k}\left(k^{F B}\right),
\end{aligned}
$$

where $q^{*}$ is the stationary-equilibrium price of old capital in the constrained-efficient plan, and we have restricted attention to an allocation such that $\underline{\nu}^{N}=\underline{\nu}^{O}=0$ for all $w$. 
Let $q^{*}=\frac{w_{\min }}{k^{F B}}$. At this price, firms with the lowest level of initial net worth produce at the efficient scale, by investing entirely in old capital, without issuing equity: $k^{O}\left(w_{\min }\right)=$ $k^{F B}$. As an example of allocation of new and old capital that satisfies this condition, consider the following one, in which firms substitute linearly away from old capital until they become unconstrained:

$$
k^{N}(w)= \begin{cases}\frac{w-q^{*} k^{F B}}{1-q^{*}(1+\beta \theta)} & \text { if } w \leq k^{F B}\left(1-\beta \theta q^{*}\right) \\ k^{N} & \text { if } w>k^{F B}\left(1-\beta \theta q^{*}\right)\end{cases}
$$

and $k^{O}(w)=k^{F B}-k^{N}(w)$. The value of $\bar{k}^{N}$ is then determined by the market-clearing condition (3) and our assumption that there is a sufficiently large mass of firms with net worth larger than $k^{F B}$ ensures that $\bar{k}^{N}$ is in the interval $\left[0, k^{F B}\right]$.

We now present a Ramsey implementation of the constrained efficient allocation. The planner's allocation can be decentralized as a competitive equilibrium with proportional taxes at rates $\tau^{N}$ and $\tau^{O}$ on new and old capital, respectively. These taxes are offset by lump-sum transfers to each firm, in order not to redistribute resources across firms. Tax rates and transfers can be firm specific, that is, are functions of net worth $w$. With this implementation, the budget constraint of a newborn firm with initial net worth $w$ becomes

$$
w+b_{t}+T_{t}=d_{0 t}+k_{t}^{N}\left(1+\tau_{t}^{N}\right)+q_{t} k_{t}^{O}\left(1+\tau_{t}^{O}\right)
$$

with a lump-sum transfer $T_{t}=\tau_{t}^{N} k_{t}^{N}+\tau_{t}^{O} q_{t} k_{t}^{O}$.

By inspection of equations (29) and (30), we see that the tax rates that implement the first-best stationary equilibrium are

$$
\tau^{N}=-\beta \eta=-\beta\left(q^{F B}-q^{*}\right)
$$

and

$$
\tau^{O}=\frac{\eta}{q^{*}}=\frac{q^{F B}}{q^{*}}-1 .
$$

As $\eta=\beta f^{\prime}\left(k^{F B}\right)-q^{*}>0$, that is, old capital is scarce from the perspective of the planner, we have $\tau^{N}<0$ and $\tau^{O}>0$. The planner internalizes the distributive externalities in the market for old capital and induces a price of old capital sufficiently low that all firms can afford the optimal production scale without incurring equity issuance costs. The optimal policy that supports this allocation is a subsidy on new capital, which increases the future supply of old capital, combined with a tax on old capital, which ensures the first-best production scale is optimal given the low price of old capital required to undo the effects 
of financial frictions. It might seem counterintuitive that the planner taxes old capital, given the objective to make it cheaper. However, recall that these taxes are rebated in a lump-sum fashion to each agent. Thus, a tax on old capital has only a positive effect on buyers of old capital, that is, constrained firms, because it allows the planner to reduce the price they face. Indeed, the larger the reduction in price required relative to the first-best price $q^{F B}$, the larger is the optimal tax $\tau^{O}$. Notice that both tax rates $\tau^{N}$ and $\tau^{O}$ are constant and independent of firms' net worth, whereas they are offset by lump-sum taxes or transfers that vary with firms' net worth, because of heterogeneity in the composition of investment between new and old capital.

We consider again our numerical example and obtain the constrained-efficient allocation and its implementation. The first-best outcome requires the planner to reduce the equilibrium price to $q^{*}=0.037$. The tax rates that decentralize this outcome are $\tau^{N}=-0.454$ and $\tau^{O}=12.819$. We provide a graphical illustration of this allocation in Online Appendix A.1.

\subsection{Restrictions on Policy Instruments}

We have shown that a combination of subsidies on new investment and taxes on purchases of old capital, rebated in a lump-sum fashion to each firm, can increase welfare in stationary equilibrium by reducing the price of old capital. We now analyze the problem of a planner that faces restrictions on the set of policy instruments. We use our numerical example to show that the main insights that we have derived from the constrained-efficient plan survive also when the planner faces these restrictions. We report the main findings here and provide a more detailed analysis in Online Appendix A.2.

No Taxes on Old Capital. We consider the case in which the planner cannot tax old capital. To perform this analysis and the following one without subsidies on new capital, it is convenient to assume that new and old capital are imperfect substitutes to focus on interior solutions for investment. Specifically, capital in production is a constant elasticity of substitution (CES) aggregate of new and old capital. We assume a high elasticity of substitution (equal to 50) to approximate the baseline case of perfect substitution. ${ }^{19}$ The planner makes investment decisions on behalf of firms, taking each firm's Euler equation for old capital as a constraint. In this case, the planner cannot implement the first-best allocation. We find that the planner chooses to subsidize new capital to reduce the price

\footnotetext{
${ }^{19}$ Imperfect substitutability is a realistic assumption that we also make in the quantitative model of Section 5. We introduce it in this analysis with restricted instruments because a single tax (on new or on old capital), combined with perfect substitutability between new and old capital, may lead to failure of the monotonicity of the preference for new vs. old capital as a function of net worth, which complicates the analysis without adding significant insights. All other functional forms and parameter values are as in the baseline numerical example (see caption of Figure 1).
} 
of old capital, although at a lower rate than in the baseline case (the subsidy is on average slightly less than 1\%), because the absence of taxes on old capital implies that only a smaller reduction in the price of old capital can be achieved. Moreover, we find that the size of the subsidy on new capital depends on firm net worth because the planner uses the available policy instrument to partly substitute for the missing instrument. In particular, the planner subsidizes investment at higher rate for financially constrained firms. In so doing, it induces a higher marginal value of net worth for these firms, thus making them perceive purchases of old capital as more "expensive," partly substituting for the lack of a tax on old capital. This effect is absent for unconstrained firms, because their marginal value of net worth is constant and equal to one, and thus cannot be distorted.

No Subsidies on New Capital. We also consider the complementary case in which the planner faces the constraint that new investment cannot be distorted. We confirm that the planner chooses to tax old capital, again to reduce its price, although by less than in the baseline case in which all instruments are available (again, the average tax approximately equals 1\%). We also find that the planner taxes purchases of old capital at a lower rate for financially constrained firms.

No Lump-Sum Transfers. The implementation we discuss in the previous section involves lump-sum transfers to each firm. The reason for this requirement is that we assume, similar to Dávila, Hong, Krusell, and Ríos-Rull (2012), that the planner cannot redistribute resources across firms, except by inducing changes in the price of old capital. Hence, any tax payments - positive or negative - must be rebated to each firm lump sum. Nevertheless, this assumption leads to the question of whether the desired sign of policy interventions would be different in the absence of lump-sum taxes or transfers.

To address this question, we perform the following experiment. We assume that the government subsidies new investment with an exogenously fixed proportional tax $\tau^{N}=$ -0.03 (other values of the tax rate yield similar results) and raises taxes on purchases of old capital to balance the budget. Specifically, we compute the tax rate on old capital that satisfies the balanced-budget condition:

$$
\tau^{N} \int k^{N}(w) d \pi(w)+\tau^{O} q \int k^{O}(w) d \pi(w)=0
$$

where $q$ is the stationary-equilibrium price of old capital consistent with the tax policy plan $\left(\tau^{N}, \tau^{O}\right)$. Using the market-clearing condition (3), we can also express the tax rate on old capital as follows: $\tau^{O}=-\frac{\tau^{N}}{q}$. In our numerical example, we obtain $\tau^{O}=0.062$.

Notice that the absence of lump-sum transfers and taxes implies that a subsidy on new capital combined with a tax on old capital now effectively redistributes resources from 
financially constrained firms, which invest more heavily in old capital, to unconstrained firms, which invest more heavily in new capital. Hence, this is a seemingly counterproductive policy in the presence of financial frictions. Nevertheless, consistent with the main insight of our efficiency analysis, this policy plan increases the stationary-equilibrium value of all firms because of its general-equilibrium effects. In particular, the policy reduces the price of old capital enough that the after-tax price of capital $q\left(1+\tau^{O}\right)$ is lower than the competitive equilibrium price, making firms with low net worth better off, despite the fact that they are paying a tax. At the same time, the after-tax user cost of new capital $u_{N}=1+\tau^{N}-\beta q$ is also lower than in the absence of the policy, because the subsidy on new investment more than compensates for the lower future resale price, making firms with high net worth also better off.

\section{Extensions and Limitations of Efficiency Result}

In this section, we first show that the our main insight on the sign of inefficiency obtains in several models that generalize the assumptions of our stylized model of Section 3. We then discuss the crucial role of heterogeneity and equilibrium reallocation for these results and show how several assumptions may be modified to obtain different conclusions on the nature of inefficiency.

\subsection{Risk-Averse Entrepreneurs}

In our stylized model, firms maximize the present discounted value of dividends net of equity issuance cost, and the planner maximizes consumption of an infinitely-lived representative household who consumes aggregate dividends. We now consider the case in which firms are owned by over-lapping generations of risk-averse entrepreneurs, whose individual consumption coincides with dividends from their own firm.

Specifically, entrepreneurs maximize $u\left(c_{0 t}\right)+\beta u\left(c_{1, t+1}\right)$, where $u$ is a utility function, with $u_{c}>0, u_{c c}<0, \lim _{c \rightarrow 0} u_{c}(c)=+\infty$, and entrepreneurial consumption coincides with dividends, which satisfy the budget constraints (7) and (8).

A utilitarian planner maximizes the present discounted value of utility of all (present

and future) entrepreneurs. We assume that the planner's discount factor is equal to $\beta$ and that the interest rate equals $\beta^{-1}$. We analyze this version of the model in detail in Online Appendix B.1. We also discuss the role of alternative assumptions on discounting and the interest rate in Section 4.6 and Online Appendix B.6.

The (stationary) constrained-efficient price of old capital satisfies the following optimal- 
ity condition:

$$
\int k^{O}(w) u_{c}\left(c_{0}(w)\right) d \pi(w)=\int k^{N}(w)\left[u_{c}\left(c_{1}(w)\right)+\theta \lambda(w)\right] d \pi(w)
$$

where the left-hand side and the first term in the sum on the right-hand side represent the distributive externalities on buyers and sellers of old capital, respectively, whereas the second term on the right-hand side represents the collateral externality.

In this model, the marginal value of entrepreneurial net worth equals the marginal utility of consumption, which is strictly decreasing in net worth, in contrast to the marginal equity issuance cost in the baseline model, which is equal to a positive constant in the indifference region between new and old capital, and equal to zero for unconstrained firms. Despite this difference, the fact that the marginal utility of consumption is decreasing implies that the planner still wants to induce a lower price of old capital than in competitive equilibrium, in order to redistribute resources toward more financially constrained entrepreneurs, who are net buyers of old capital in equilibrium. Hence, our result on the sign of constrained inefficiency obtains also with risk-averse entrepreneurs. We now state this result formally and prove it in Online Appendix B.1. ${ }^{20}$

\section{Proposition 3 (Sign of Constrained Inefficiency - Risk-Averse Entrepreneurs)} Assume that in stationary equilibrium $q>q^{F B}$. Then, the aggregate distributive externality exceeds the aggregate collateral externality, that is

$$
\int k^{O}(w) u_{c}\left(c_{0}(w)\right) d \pi(w)>\int k^{N}(w)\left[u_{c}\left(c_{1}(w)\right)+\theta \lambda(w)\right] d \pi(w)
$$

A marginal decrease in the price of old capital induces a positive welfare gain.

\subsection{Heterogeneity in Productivity}

In our baseline model, firms are heterogeneous only in their initial net worth. We now extend this framework to allow for heterogeneity in productivity and show that our main efficiency result obtains in this richer model. At their initial date, firms draw initial net worth $w$ and a level of productivity $s \in \mathcal{S} \equiv\left\{s_{1}, \ldots, s_{N}\right\}$ from a joint distribution $\pi(w, s)$. At the production date, firms produce output with production function $y_{t}=s f\left(k_{t}\right)$. We discuss this model in detail in Online Appendix B.2.

Allocations in stationary equilibrium are functions of $(w, s)$, and the preference for new vs. old capital is thus tied to both net worth and productivity. Crucially, we show the

\footnotetext{
${ }^{20}$ While the proposition focuses on the case $q>q^{F B}$, Online Appendix B.1 provides a weak condition under which the same result obtains when $q=q^{F B}$.
} 
marginal equity issuance cost is (weakly) increasing in productivity: $\frac{\partial \phi_{d}(w, s)}{\partial s} \geq 0$. Thus, firms with lower net worth and higher productivity tend to prefer old capital, whereas less financially constrained firms, that is, firms with higher net worth and lower productivity tend to purchase new capital. The market for old capital reallocates capital from less productive and less constrained to more productive and more constrained firms.

The (stationary) constrained-efficient price of old capital satisfies the following optimality condition:

$$
\int k^{O}(w, s) \phi_{d}(w, s) d \pi(w, s)=\theta \int k^{N}(w, s) \lambda(w, s) d \pi(w, s),
$$

where the left-hand side represents the aggregate distributive externality from a marginal change in the price of old capital, and the right-hand side represents the aggregate collateral externality.

In competitive equilibrium, we show that all firms that are indifferent between new and old capital have the same marginal value of net worth, independent of their productivity. This feature allows us to generalize our main efficiency result also to the case with heterogeneous productivity. We now state this result formally and prove it in Online Appendix B.2.

\section{Proposition 4 (Sign of Constrained Inefficiency - Heterogeneity in Productivity)} In the stationary competitive equilibrium, the aggregate distributive externality exceeds the aggregate collateral externality, that is,

$$
\int k^{O}(w, s) \phi_{d}(w, s) d \pi(w, s)>\theta \int k^{N}(w, s) \lambda(w, s) d \pi(w, s) .
$$

A marginal decrease in the price of old capital induces a positive welfare gain.

\subsection{Firm Life Cycle and Long-Lived Capital}

In our stylized model, firms live for two dates and capital is productive for two periods. The assumption that firms live for only one period rules out endogenous net worth dynamics. The assumption that capital is unproductive after two dates rules out the possibility of using old capital as collateral. We now show that our main result on the sign of the inefficiency in competitive equilibrium obtains in a more general version of the model in which firms have a stochastic life cycle and capital is long lived.

To this end, we generalize the model in two ways. First, firms follow a stochastic life cycle. Specifically, at each date, with exogenous probability $\rho \in(0,1]$, firms learn that they will die after producing and paying their remaining net worth as a dividend. With probability $1-\rho$, firms continue their activity. Thus, as long as $\rho<1$, firm net worth 
evolves endogenously. At each date, a measure $\rho$ of new firms is born with initial net worth drawn from an exogenous distribution $\pi_{0}\left(w_{0}\right)$. The stationary distribution of net worth $\pi(w)$, however, is an equilibrium object.

Second, capital goods depreciate as follows. For each unit of new capital, a fraction $\delta^{N} \in(0,1]$ becomes old after production. Old capital depreciates at geometric rate $\delta^{O} \in$ $(0,1]$ each period. With these assumptions, firms can pledge a fraction $\theta$ of the resale value of capital next period $\left(1-\delta^{N}\left(1-q_{t+1}\right)\right) k_{t}^{N}+q_{t+1}\left(1-\delta^{O}\right) k_{t}^{O}$ as collateral. Hence, both new and old capital serve as collateral. This environment nests the baseline model, which can be recovered by setting $\rho=\delta^{N}=\delta^{O}=1$. $^{21}$

We analyze this model in Online Appendix B.3. In stationary equilibrium, the effective depreciation rate of new capital $\delta^{N}(1-q)$ is lower than that of old capital, which equals $\delta^{O}$, inducing a preference for old capital from financially constrained firms. We now state our main result on constrained inefficiency, after introducing the following notation. We denote firm age by $a=0,1, \ldots$ and the mass of age $a$ firms that survive into the next period by $\gamma_{a} \equiv \rho(1-\rho)^{a}$. The (stationary) constrained-efficient price of old capital satisfies the following optimality condition:

$$
\begin{aligned}
& \int \sum_{a=0}^{\infty} \gamma_{a}\left[k_{a}^{O} \phi_{d, a}-\left(\delta^{N} k_{a}^{N}+\left(1-\delta^{O}\right) k_{a}^{O}\right)\right.\left.(1-\rho) \phi_{d, a+1}\right] d \pi_{0}\left(w_{0}\right)= \\
& \theta \int \sum_{a=0}^{\infty} \gamma_{a} \lambda_{a}\left(\delta^{N} k_{a}^{N}+\left(1-\delta^{O}\right) k_{a}^{O}\right) d \pi_{0}\left(w_{0}\right)
\end{aligned}
$$

where the left-hand side represents the aggregate distributive externality from a marginal change in the price of old capital and the right-hand side the aggregate collateral externality.

Different from the stylized model without firm life cycle, the marginal value of net worth is no longer necessarily constant in the indifference region between new and old capital. Moreover, old capital also serves as collateral, thus inducing a richer set of externalities from the price of old capital. Despite these differences with our baseline case, we can show that our result on the sign of the constrained inefficiency generalizes also to this environment. The economic intuition is that the more constrained firms are net buyers of old capital; although reducing the price of old capital decreases its collateral value, this effect is dominated by the distributive effect of making old capital cheaper for these firms. We now state this result, which we prove in Online Appendix B.3, formally.

\section{Proposition 5 (Sign of Constrained Inefficiency - Long-Lived Firms and Capital)} In the stationary competitive equilibrium, the aggregate distributive externality exceeds the

\footnotetext{
${ }^{21}$ The environment also nests a model in which all new investment is transformed into a homogenous type of capital after one period; this model can be recovered by setting $\delta^{N}=1$ and $\delta^{O} \equiv \delta \in(0,1)$.
} 
aggregate collateral externality, that is, the left-hand side of (33) is strictly larger than the right-hand side. A marginal decrease in the price of old capital induces a positive welfare gain.

\subsection{Timing of Resale Price in Collateral Constraint}

Our analysis assumes that the future price of old capital $q_{t+1}$ appears in the collateral constraint (9) at date $t$, following a standard microfoundation, according to which the borrower can default on its debt when the repayment is due - that is, at date $t+1-$ absconding with all output and a fraction $1-\theta$ of its assets (see Rampini and Viswanathan, 2010, 2013). However, the literature on pecuniary externalities has also analyzed models in which the current price of capital constrains current debt issuance (see, for example, Bianchi and Mendoza, 2018). To analyze the effects of these different assumptions on the comparison between collateral and distributive externalities, in Online Appendix B.4, we consider a version of our stylized model in which firms can default on their debt within the period, and thus the collateral constraint features the current price of old capital:

$$
\theta\left(k_{t}^{N}+q_{t} k_{t}^{O}\right) \geq b_{t}
$$

We show that also in this case the distributive externality dominates the collateral externality. The intuition for this result is that in this model the planner could benefit buyers of old capital in two alternative ways. On the one hand, a lower current price would directly relax their budget constraint. On the other hand, a higher current price would relax their collateral constraint. However, because only a fraction $\theta$ of the asset can be pledged as collateral, the first effect is larger and thus overall the price is inefficiently high in the stationary competitive equilibrium.

\subsection{Essential Role of Heterogeneity and Reallocation}

Our results show that the distributive externality exceeds the collateral externality in stationary competitive equilibrium under quite general conditions. We now discuss the essential role of heterogeneity and equilibrium reallocation for this result, and compare our insights with the related literature on collateral constraints that depend on asset prices.

As Dávila and Korinek (2018) show in a two-period model, distributive externalities

arise because of two features: (i) heterogeneity in the marginal valuation of resources, due to market incompleteness; and (ii) non-zero net asset trading, that is, in our context, a positive volume of capital reallocation in stationary equilibrium. Our assumption that there are over-lapping generations of firms subject to financial constraints induces both 
(i) heterogeneity in the marginal value of net worth - among firms of different age, as well as among firms of the same age, but with different levels of net worth or productivity - and (ii) positive capital reallocation, that is, trade in old capital, in stationary equilibrium, because younger and more productive firms purchase old capital from older firms. In the quantitative model of Section 5, we also obtain heterogeneity in the marginal value of net worth and reallocation of old capital due to idiosyncratic productivity shocks.

When there are both collateral and distributive externalities, it is in general not possible to sign the net effects of asset prices on welfare (see Dávila and Korinek, 2018). Nevertheless, in the class of infinite-horizon models we consider, we obtain an unambiguous result. Given our formulation of the collateral constraint that depends linearly on the resale value of capital (as in Kiyotaki and Moore, 1997, and Rampini and Viswanathan, 2010, 2013), the firm optimality condition with respect to debt imposes a tight link between the collateral externality and the distributive externality in stationary equilibrium. For instance, in the model of Section 3.4 we can express the collateral externality for a firm with net worth $w$ as $\theta \lambda(w) k^{N}(w)=\theta \phi_{d}(w) k^{N}(w)$ using equation (12) and exploiting stationarity. Thus, the comparison of aggregate distributive and collateral externalities reduces to a comparison of the covariance between the marginal value of net worth and purchases of old capital and the covariance between the marginal value of net worth and purchases of new capital. Furthermore, in stationary equilibrium, aggregate purchases of new capital coincide with aggregate sales of old capital, by market clearing. Because of equilibrium sorting of more constrained firms into old capital, the former covariance is larger than the latter, delivering our result on the sign of the inefficiency.

This insight generalizes to the case in which the marginal value of net worth is the marginal utility of consumption, the case in which the marginal value of net worth depends on productivity, as well as the case in which both new and old capital serve as collateral, and the distribution of net worth is endogenous.

To further highlight the essential role of heterogeneity and reallocation, we can compare our model with models that feature an infinitely-lived representative entrepreneur and exante heterogeneity between the impatient representative entrepreneur and a patient lender as in Kiyotaki and Moore (1997) or a representative entrepreneur in a small open economy. In these models, there are no distributive externalities in stationary equilibrium, because the representative entrepreneur must keep a constant amount of capital (or land), by definition of stationary equilibrium, implying that there is no equilibrium reallocation. ${ }^{22}$ There is misallocation but no reallocation in these models, and thus they feature only collateral externalities in stationary equilibrium.

\footnotetext{
${ }^{22}$ Even if lender and entrepreneur have different marginal values of net worth, they do not trade capital in stationary equilibrium.
} 
To show this formally, we analyze the connection between our results and the large literature on models with a representative entrepreneur and assets in fixed supply further in Online Appendix B.5. Specifically, we first consider a model with a representative entrepreneur and land and show that lack of reallocation in stationary equilibrium implies that there is only a collateral externality, which is closely related to the effects of assetprice changes analyzed by Kiyotaki and Moore (1997). Next, we consider a version of the same model, but with over-lapping generations of entrepreneurs; this modification implies heterogeneity among entrepreneurs and positive reallocation in stationary equilibrium and thus distributive externalities. We show that the distributive externality dominates the collateral externality in this model, when the discount factor equals the inverse of the equilibrium interest rate. We also analyze the role of entrepreneurial impatience for pecuniary externalities.

\subsection{Obtaining Opposite Sign of Inefficiency}

Having established the crucial roles of heterogeneity and reallocation for our main result, in this section we discuss three modifications of our assumptions that may lead to the opposite sign of constrained efficiency in stationary equilibrium. This analysis serves two main purposes. First, by showing how changing certain assumptions may alter the sign of the inefficiency, we clarify the role of those assumptions for our results. Second, some of these modified assumptions have been explored in the literature on pecuniary externalities. Thus, this analysis allows us to better connect to previous results.

Specifically, we consider three versions of the model. We highlight the main insights in this section and provide detailed analyses in Online Appendix B.6. In the first version of the model, the point of departure is the model with long-lived new and old capital, but we modify the assumptions on collateralizability of new and old capital. In the second and third version of the model, the point of departure is the model with risk-averse entrepreneurs, but in one case we modify the assumptions on discount rates and the interest rate and in the other case we introduce saving constraints.

Role of Collateralizability. We consider the model of Section 4.3 with long-lived new and old capital. However, we generalize the model, by allowing for a different collateralizability of new and old capital. Specifically, let $\theta^{N}$ be the collateralizability parameter for new capital and $\theta^{O}$ for old capital. We show that if the degree of collateralizability of new capital is sufficiently higher than that of old capital $\left(\theta^{N}>>\theta^{O}\right)$, then financially constrained firms prefer to invest in new capital in stationary equilibrium, because new capital has a lower down payment. As a consequence, the collateral externality may dominate the distributive externality and a higher price of old capital may be desirable. 
Role of Discounting. We consider the model of Section 4.1 with risk-averse entrepreneurs. However, we generalize the model to allow for different discount rates for planner and entrepreneurs, as well as a generic value for the interest rate, not necessarily tied to entrepreneurs' discount factor. We show that if entrepreneurs are sufficiently impatient relative to the interest rate or the planner is sufficiently impatient relative to entrepreneurs, then the collateral externality may dominate the distributive externality and a higher price of old capital may be desirable. The intuition for this result is that the price of old capital $q_{t}$ affects the tightness of the collateral constraint at date $t-1$, whereas it affects budget constraints at date $t$ through the distributive externality. As a consequence, sufficient impatience boosts the value of the collateral externality relative to the distributive externality. This analysis of the role of discounting is useful to connect our results to the literature on pecuniary externalities in small open economies, which typically assumes that the interest rate is smaller than the inverse of the discount factor.

Role of Saving Constraints. We consider again the model with risk-averse entrepreneurs of Section 4.1. We assume that all entrepreneurs are born with a common initial endowment. Nevertheless, the economy features heterogeneity between young and old entrepreneurs. Moreover, we assume that entrepreneurs cannot borrow or save using bonds. For a sufficiently large initial endowment, entrepreneurs would desire to save using bonds, if they were allowed, and thus the saving constraint is binding. As a result, the marginal utility of consumption of old entrepreneurs is higher than that of young entrepreneurs, implying that the distributive externality has the opposite sign with respect to our baseline case and a higher price of old capital may be desirable. This analysis is useful in relating our results to the literature that builds on Lorenzoni (2008). In that model, the distributive externality has the opposite sign relative to our baseline results because, in some states of the world, financially constrained entrepreneurs are net sellers of assets. To obtain this result, Lorenzoni (2008) assumes lack of commitment of both households and entrepreneurs, effectively preventing entrepreneurs from saving funds into those states.

\section{Quantitative Model}

We now consider a quantitative model of investment and capital reallocation with a stochastic firm life cycle, long-lived capital, and persistent idiosyncratic productivity shocks. In this model, both financial frictions and stochastic productivity are drivers of capital reallocation. We calibrate this model to analyze efficiency quantitatively in Section 6 . 


\section{$5.1 \quad$ Environment}

Time is discrete and the horizon is infinite. As in the model of Section 3, a representative household with linear utility and discount factor $\beta$ owns all firms in the economy. In every period, a continuum of measure $\rho$ of firms are born and receive a common initial endowment of output $w_{0}$ from the household. ${ }^{23}$ Firm $i$ at time $t$ produces output $y_{i t}$ combining new and old capital goods $k_{i, t-1}^{N}$ and $k_{i, t-1}^{O}$, subject to idiosyncratic productivity shocks $s_{i t}$ with the following technology

$$
y_{i t}=s_{i t} f\left(k_{i, t-1}\right)
$$

with $f_{k}>0, f_{k k}<0, k_{i, t-1} \equiv g\left(k_{i, t-1}^{N}, k_{i, t-1}^{O}\right)$, where $g$ is a constant returns to scale bundle of new and old capital, with $g_{N}, g_{O}>0, g_{N N}, g_{O O} \leq 0$, and subscripts denote first and second partial derivatives with respect to new $(\mathrm{N})$ and old $(\mathrm{O})$ capital, respectively. We assume that new and old capital are imperfect substitutes in the quantitative model, because this is empirically plausible and facilitates the computation by avoiding corner solutions.

As in the model of Section 4.3, firms die with probability $\rho$ at the end of each period. Dying firms produce output and then distribute their new worth as a dividend. We denote age by $a$ and let $s^{a}$ be a history of realizations of idiosyncratic shocks up to firm age $a$, with associated exogenous probability $p\left(s^{a}\right)$. The measure of firms of age $a$ that survive and invest to produce in the following period is $\gamma_{a}=\rho(1-\rho)^{a}$.

Output can be consumed by the household or transformed into new capital with constant unit marginal cost. Investment requires one period of time to build. A fraction $\delta^{N}$ of each unit of new capital becomes old in the following period. A fraction $\delta^{O}$ of each unit of old capital becomes useless in the following period. Firms can also scrap old capital and recover $\underline{q} \geq 0$ units of output. This assumption is empirically plausible and imposes a lower bound on the price of old capital that the planner can induce. We assume $q$ is sufficiently low that no capital is scrapped either in the first-best allocation or in equilibrium.

\subsection{Frictionless Economy and First Best}

The aggregate resource constraint of the frictionless economy is

$$
\sum_{a=0}^{\infty} \gamma_{a} \sum_{s^{a+1}} p\left(s^{a+1}\right)\left[s_{a+1} f\left(g\left(k_{t-1}^{N}\left(s^{a}\right), k_{t-1}^{O}\left(s^{a}\right)\right)\right)+\left(1-\delta^{N}\right) k_{t-1}^{N}\left(s^{a}\right)\right]=C_{t}+\sum_{a=0}^{\infty} \gamma_{a} \sum_{s^{a}} p\left(s^{a}\right) k_{t}^{N}\left(s^{a}\right),
$$

where the left-hand side is aggregate output and undepreciated new capital, and the righthand side is consumption of the representative household and aggregate new capital. The

\footnotetext{
${ }^{23}$ Heterogeneity in net worth arises endogenously because of productivity shocks and net worth accumulation. Thus, for simplicity, we abstract from initial heterogeneity.
} 
evolution of the stock of old capital satisfies

$$
\sum_{a=0}^{\infty} \gamma_{a} \sum_{s^{a}} p\left(s^{a}\right)\left[\delta^{N} k_{t-1}^{N}\left(s^{a}\right)+\left(1-\delta^{O}\right) k_{t-1}^{O}\left(s^{a}\right)\right]=\sum_{a=0}^{\infty} \gamma_{a} \sum_{s^{a}} p\left(s^{a}\right) k_{t}^{O}\left(s^{a}\right),
$$

where the left-hand side is the sum of depreciated new capital and undepreciated old capital from the previous period, that is, the aggregate supply of old capital, and the right-hand side is the aggregate demand for old capital.

The first-best allocation maximizes the utility of the representative household (1) subject to the resource constraints (36) and (37). The optimality conditions for new and old capital are

$$
\begin{aligned}
1 & =\beta \mathbb{E}_{t}\left[s_{a+1} f_{k}\left(k_{t}^{F B}\left(s^{a}\right)\right) g_{N, t}\left(s^{a}\right)+\left(1-\delta^{N}\left(1-q_{t+1}^{F B}\right)\right)\right] \\
q_{t}^{F B} & =\beta \mathbb{E}_{t}\left[s_{a+1} f_{k}\left(k_{t}^{F B}\left(s^{a}\right)\right) g_{O, t}\left(s^{a}\right)+\left(1-\delta^{O}\right) q_{t+1}^{F B}\right],
\end{aligned}
$$

where $\mathbb{E}_{t}$ denotes the expectation conditional on information at date $t, q_{t}^{F B}$ denotes the firstbest valuation of old capital, and we use shorthand notation $g_{N, t}\left(s^{a}\right)$ and $g_{O, t}\left(s^{a}\right)$ to denote the marginal effect of investment in new and old capital on total capital in production, that is, $g_{N}\left(k_{t}^{N}\left(s^{a}\right), k_{t}^{O}\left(s^{a}\right)\right)$ and $g_{O}\left(k_{t}^{N}\left(s^{a}\right), k_{t}^{O}\left(s^{a}\right)\right)$, respectively.

Different from the stylized model, when new and old capital are imperfect substitutes, equations (38) and (39) determine a unique allocation of new and old capital for all firms.

\subsection{Financial Frictions and Competitive Equilibrium}

We now consider the competitive equilibrium in the presence of financial frictions. As in the stylized model, firms can raise external funds in two ways. First, they can issue equity, subject to a twice differentiable, convex equity issuance cost $\phi$. This cost is zero if firms pay a non-negative dividend. Second, they can issue non-contingent debt at interest rate $\beta^{-1}$, subject to a collateral constraint, which specifies that the promised repayment cannot exceed a fraction $\theta$ of the total resale value of new and old capital in the following period.

The expected present discounted value of dividends, net of equity issuance costs, of a firm born at time $t$ is

$$
\sum_{a=0}^{\infty} \beta^{a} \gamma_{a} \sum_{s^{a}} p\left(s^{a}\right)\left[d_{t+a}\left(s^{a}\right)-\phi\left(-d_{t+a}\left(s^{a}\right)\right)\right]+\sum_{a=1}^{\infty} \beta^{a} \gamma_{a-1} \rho \sum_{s^{a}} p\left(s^{a}\right) w_{t+a}\left(s^{a}\right)
$$

where $d_{t}\left(s^{a}\right)$ are dividends of continuing firms and $w_{t}\left(s^{a}\right)$ is net worth, which is paid out 
as a liquidating dividend by dying firms. The dividend of a continuing firm satisfies the following budget constraint:

$$
d_{t}\left(s^{a}\right)=w_{t}\left(s^{a}\right)+b_{t}\left(s^{a}\right)-k_{t}^{N}\left(s^{a}\right)-q_{t} k_{t}^{O}\left(s^{a}\right),
$$

where $q_{t}$ is the price of old capital and $b_{t}\left(s^{a}\right)$ is non-contingent debt. Firm net worth evolves as follows. All firms are born with $w_{t}\left(s^{0}\right)=w_{0}$. For $a=1,2, \ldots$, we have

$w_{t}\left(s^{a}\right)=s_{a} f\left(k_{t-1}\left(s^{a-1}\right)\right)+\left(1-\delta^{N}\left(1-q_{t}\right)\right) k_{t-1}^{N}\left(s^{a-1}\right)+q_{t}\left(1-\delta^{O}\right) k_{t-1}^{O}\left(s^{a-1}\right)-\beta^{-1} b_{t-1}\left(s^{a-1}\right)$

and total capital in production is given by a bundle of new and old capital,

$$
k_{t-1}\left(s^{a-1}\right)=g\left(k_{t-1}^{N}\left(s^{a-1}\right), k_{t-1}^{O}\left(s^{a-1}\right)\right) .
$$

Firms face a collateral constraint, which states that debt cannot exceed a fraction $\theta$ of the resale value of new and old capital:

$$
\theta\left[\left(1-\delta^{N}\left(1-q_{t+1}\right)\right) k_{t}^{N}\left(s^{a}\right)+q_{t+1}\left(1-\delta^{O}\right) k_{t}^{O}\left(s^{a}\right)\right] \geq \beta^{-1} b_{t}\left(s^{a}\right) .
$$

The square bracket on the left-hand side of equation (44) reports the value of collateral, which consists of undepreciated new capital, depreciated new capital that is transformed into old capital, and undepreciated old capital.

We denote by $\beta^{t+1} \gamma_{a} p\left(s^{a}\right) \lambda_{t}\left(s^{a}\right)$ the multiplier on the collateral constraint and $\phi_{d, t}\left(s^{a}\right)$ the marginal equity issuance cost. The firm optimality conditions for new capital, old capital, and debt, are

$$
\begin{aligned}
1+\phi_{d, t}\left(s^{a}\right)= & \beta \mathbb{E}_{t}\left[\left(s_{a+1} f_{k}\left(k_{t}\left(s^{a}\right)\right) g_{N, t}\left(s^{a}\right)+\left(1-\delta^{N}\left(1-q_{t+1}\right)\right)\right)\right. \\
& \left.\times\left(1+(1-\rho) \phi_{d, t+1}\left(s^{a+1}\right)\right)\right]+\beta \theta \lambda_{t}\left(s^{a}\right)\left(1-\delta^{N}\left(1-q_{t+1}\right)\right) \\
q_{t}\left(1+\phi_{d, t}\left(s^{a}\right)\right)= & \beta \mathbb{E}_{t}\left[\left[s_{a+1} f_{k}\left(k_{t}\left(s^{a}\right)\right) g_{O, t}\left(s^{a}\right)+\left(1-\delta^{O}\right) q_{t+1}\right]\right. \\
& \left.\times\left(1+(1-\rho) \phi_{d, t+1}\left(s^{a+1}\right)\right)\right]+\beta \theta \lambda_{t}\left(s^{a}\right)\left(1-\delta^{O}\right) q_{t+1} \\
\phi_{d, t}\left(s^{a}\right)= & (1-\rho) \mathbb{E}_{t} \phi_{d, t+1}\left(s^{a+1}\right)+\lambda_{t}\left(s^{a}\right) .
\end{aligned}
$$

We highlight some important differences between these optimality conditions and their counterparts in the stylized model, that is, equations (10), (11), (12). First, productivity is stochastic, implying that both future marginal products and future marginal equity issuance costs are also stochastic. Moreover, we assume that markets are incomplete and firms issue noncontingent debt. Thus, all three optimality conditions (45), (46), and (47) 
involve the conditional-expectation operator $\mathbb{E}_{t}$. Second, both new and old capital are long lived, and both serve as collateral. Thus, equation (46) equates the marginal cost of investing in old capital, on the left-hand side, with the marginal benefit, which depends on the future marginal product, as well as the future resale value, and the effect of old capital on the collateral constraint. In equilibrium, the price of old capital $q_{t}$ satisfies the market-clearing condition (37).

\subsection{Constrained Efficiency}

We now consider the problem of a planner who chooses investment in new and old capital, as well as debt, on behalf of individual firms, under the same set of constraints and frictions, but internalizing the effects of these choices on the price of old capital. This allocation can be implemented with firm-specific proportional taxes on new and old capital, rebated in a lump-sum fashion to each firm.

The planner maximizes the present discounted value of aggregate dividends

$$
\sum_{t=0}^{\infty} \beta^{t}\left[\sum_{a=0}^{\infty} \sum_{s^{a}} p\left(s^{a}\right) \gamma_{a}\left[d_{t}\left(s^{a}\right)-\phi\left(-d_{t}\left(s^{a}\right)\right)\right]+\sum_{a=1}^{\infty} \sum_{s^{a}} p\left(s^{a}\right) \gamma_{a-1} \rho w_{t}\left(s^{a}\right)\right]
$$

subject to firms' budget constraints, collateral constraints, with multiplier $\beta^{t+1} \lambda_{t}\left(s^{a}\right)$, and the market-clearing condition (37), with multiplier $\beta^{t} \eta_{t}$. Furthermore, the planner must induce a price of old capital that is weakly larger than the scrap value. We denote the multiplier on this constraint by $\beta^{t} \zeta_{t}{ }^{24}$

The optimality conditions for new capital, old capital, and debt, are

$$
\begin{aligned}
1+\phi_{d, t}\left(s^{a}\right)= & \beta \mathbb{E}_{t}\left[\left(s_{a+1} f_{k}\left(k_{t}\left(s^{a}\right)\right) g_{N, t}\left(s^{a}\right)+\left(1-\delta^{N}\left(1-q_{t+1}\right)\right)\right)\right. \\
& \left.\times\left(1+(1-\rho) \phi_{d, t+1}\left(s^{a+1}\right)\right)\right]+\beta \theta \lambda_{t}\left(s^{a}\right)\left(1-\delta^{N}\left(1-q_{t+1}\right)\right)+\beta \delta^{N} \eta_{t+1} \\
q_{t}\left(1+\phi_{d, t}\left(s^{a}\right)\right)= & \beta \mathbb{E}_{t}\left[\left(s_{a+1} f_{k}\left(k_{t}\left(s^{a}\right)\right) g_{O, t}\left(s^{a}\right)+\left(1-\delta^{O}\right) q_{t+1}\right)\right. \\
& \left.\times\left(1+(1-\rho) \phi_{d, t+1}\left(s^{a+1}\right)\right)\right]+\beta \theta\left(1-\delta^{O}\right) \lambda_{t}\left(s^{a}\right) q_{t+1}-\eta_{t}+\beta\left(1-\delta^{O}\right) \eta_{t+1},
\end{aligned}
$$

and (47). When choosing new and old capital, the planner takes into account the effect of these investment decisions on the resource constraint for old capital, and thus on its price. In particular, an additional unit of new capital leads to $\delta^{N}$ additional units of supply of old capital in the following period. In a similar fashion, demand for old capital draws from the current stock, and adds $\left(1-\delta^{O}\right)$ units to the future stock. The terms involving the

\footnotetext{
${ }^{24}$ Following the same no-arbitrage argument as in Footnote 15, we also impose an upper bound $\bar{q}=$ $\frac{1-\beta\left(1-\delta^{N}\right)}{\beta}$.
} 
multipliers $\eta_{t}$ and $\eta_{t+1}$ in equations (49) and (50) internalize these effects.

The optimality condition for the price of old capital is

$$
\begin{aligned}
& \sum_{a=0}^{\infty} \gamma_{a} \sum_{s^{a}} p\left(s^{a}\right) k_{t}^{O}\left(s^{a}\right)\left(1+\phi_{d, t}\left(s^{a}\right)\right)= \\
& \sum_{a=0}^{\infty} \gamma_{a} \sum_{s^{a+1}} p\left(s^{a+1}\right)\left[\delta^{N} k_{t-1}^{N}\left(s^{a}\right)+\left(1-\delta^{O}\right) k_{t-1}^{O}\left(s^{a}\right)\right]\left(1+(1-\rho) \phi_{d, t}\left(s^{a+1}\right)+\theta \lambda_{t-1}\left(s^{a}\right)\right)+\zeta_{t} .
\end{aligned}
$$

The sum on the left-hand side of equation (51) represents the marginal cost of increasing the price $q_{t}$ for firms that purchase old capital. The sum on the right-hand side represents the marginal benefit of increasing net worth for firms that own old capital, as well as the marginal effect of $q_{t}$ on the borrowing capacity of constrained firms at $t-1$.

In Online Appendix C.1, we describe our solution method for the stationary constrainedefficient allocation.

\section{Calibration and Quantitative Analysis}

In this section, we calibrate the quantitative model with idiosyncratic productivity shocks from Section 5. We then provide a quantitative analysis of inefficiency in competitive equilibrium and compare the stationary equilibrium with the constrained-efficient allocation.

\subsection{Calibration}

We now describe our choices of parameter values, which we report in Table 1. A period in the model coincides with a year, and we thus set $\beta=0.96$. We make the following assumptions about functional forms. The production function is $f(k)=k^{\alpha}$ with $\alpha \in$ $(0,1)$. We set $\alpha=0.6$ to reflect a typical value for the capital share in the literature on firm dynamics, adjusted to account for the choice of labor input, which we abstract from modelling. ${ }^{25}$

Firms combine new and old capital in a CES bundle $g\left(k^{N}, k^{O}\right)=\left[\left(\sigma^{N}\right)^{\frac{1}{\epsilon}}\left(k^{N}\right)^{\frac{\epsilon-1}{\epsilon}}+(1-\right.$ $\left.\left.\sigma^{N}\right)^{\frac{1}{\epsilon}}\left(k^{O}\right)^{\frac{\epsilon-1}{\epsilon}}\right]^{\frac{\epsilon}{\epsilon-1}}$. In our stylized model, we assumed perfect substitutability between new and old capital. We use the quantitative model to show that the key insights are robust to a plausible degree of imperfect substitutability. We thus set $\epsilon=5$ following Lanteri (2018)

\footnotetext{
${ }^{25}$ With a production function $y=k^{\alpha_{k}} n^{\alpha_{n}}$, where $n$ is labor, assuming time to build in capital and flexible labor choice, the effective elasticity of output with respect to capital that is relevant for investment is $\alpha \equiv \frac{\alpha_{k}}{1-\alpha_{n}}$. Common values in the investment literature are $\alpha_{k} \approx 0.25$ and $\alpha_{n} \approx 0.6$, which support our choice of parameter value.
} 
and $\sigma^{N}=0.5$, thereby treating new and old capital symmetrically in production. ${ }^{26}$ We further set the depreciation parameters $\delta^{N}=\delta^{O}=0.2$, which implies that the effective depreciation rate for new investment, accounting for the transition probability from new to old capital, and the equilibrium price of old capital, is approximately $9 \%$. With these parameter values, the average age of new (old) capital is equal to 4 (9) years.

The cost of equity issuance is a power function, $\phi(-d)=\phi_{0}(-d)^{\phi_{1}}$ for $d<0$ and $\phi(-d)=0$ otherwise. We set $\phi_{0}=0.1$ and $\phi_{1}=5$. This parameterization implies marginal costs of equity in the range of the relevant empirical estimates - for example, Hennessy and Whited (2007) and Catherine, Chaney, Huang, Sraer, and Thesmar (forthcoming). On average, the premium on internal funds is approximately 5\% (12\% conditional on firms that pay negative dividends in equilibrium). We set $\theta=0.5$, which implies that firms can borrow up to half of the resale value of their capital. This value is close to the estimates by Li, Whited, and Wu (2016).

The idiosyncratic productivity shock follows an $\mathrm{AR}(1)$ process in logs with persistence parameter $\chi_{s}$ and standard deviation of innovations $\sigma_{s}$. We set $\chi_{s}=0.7$ and $\sigma_{s}=0.12$, similar to models in the literature on investment and reallocation with firm-level productivity shocks (see Khan and Thomas, 2013, and Lanteri, 2018). We then discretize this process with a two-state Markov chain using the method of Rouwenhorst (1995). Given this process for the shocks, the standard deviation of firm-level investment rates in competitive equilibrium is equal to 0.32, close to empirical estimates (see Cooper and Haltiwanger, 2006). We set $\rho=0.1$, which approximately matches the average entry (and exit) rate for U.S. firms (see Decker, Haltiwanger, Jarmin, and Miranda, 2014).

Newborn firms receive an initial net worth $w_{0}=5$, which corresponds to approximately $9 \%$ of the unconstrained-optimal capital level for high-productivity firms. Under this calibration, our model is broadly consistent with the evidence on the empirical relationship between firm age and capital age reported by Ma, Murfin, and Pratt (forthcoming). They focus on equipment and find that age- 0 firms buy machines that are on average 5.5 years old, whereas age-10 firms tend to buy capital that is on average 4 years old. In our model, which encompasses a broader notion of capital (including structures), the corresponding figures are 7.5 and 6.4 years. $^{27}$ Also consistent with their empirical findings, the slope of

\footnotetext{
${ }^{26}$ Edgerton (2011) estimates the elasticity of substitution between new and old capital for several industries and finds values in the range between 1 and 10.

${ }^{27}$ Our quantitative model features a clear distinction between new and old capital, but does not necessarily distinguish between capital goods of different ages, given the partial depreciation structure with rates $\delta^{N}$ and $\delta^{O}$. Thus, to compute firm-level capital age in the model, we first compute the average age of new capital and the average age of old capital, which are $\frac{1-\delta^{N}}{\delta^{N}}$ and $\frac{1-\delta^{N}}{\delta^{N}}+\frac{1}{\delta^{O}}$, respectively. Specifically, the average age of new capital is 4 years and the average age of old capital is 9 years in our calibration. Next, we use the optimal portfolio weights on new and old capital for each firm to compute the average capital age for each firm, thereby assuming that the distribution of capital age within new capital and within old
} 
Table 1: Parameter Values - Calibration

\begin{tabular}{llll}
\hline \hline & & Parameter & Value \\
\hline Preferences & Discount rate & $\beta$ & 0.96 \\
Life cycle & Initial net worth & $w_{0}$ & 5 \\
& Death probability & $\rho$ & 0.1 \\
& Curvature of production function & $\alpha$ & 0.6 \\
& CES elasticity of substitution & $\epsilon$ & 5 \\
& CES new capital share & $\sigma^{N}$ & 0.5 \\
& Depreciation of new capital & $\delta^{N}$ & 0.2 \\
& Depreciation of old capital & $\delta^{O}$ & 0.2 \\
& Scrap value & $\underline{q}$ & 0.1 \\
& Productivity persistence & $\chi_{s}$ & 0.7 \\
& Productivity st. dev. of innovations & $\sigma_{s}$ & 0.12 \\
& Collateralizability & $\theta$ & 0.5 \\
& Cost of raising equity parameters & $\phi_{0}$ & 0.1 \\
& & $\phi_{1}$ & 5 \\
\hline
\end{tabular}

capital age with respect to firm age is steeper for younger firms, which are more financially constrained and thus purchase a larger share of old capital goods in our model.

\subsection{Quantitative Results}

Given our calibration, the stationary competitive-equilibrium price of old capital equals 0.553, whereas the first-best price of old capital equals 0.547. Equilibrium down payments and user costs (from the perspective of unconstrained firms) are

$$
\wp_{N} \equiv 1-\beta \theta\left(1-\delta^{N}(1-q)\right)=0.563>\wp_{O} \equiv q\left[1-\beta \theta\left(1-\delta^{O}\right)\right]=0.341
$$

and

$$
u_{N} \equiv 1-\beta\left(1-\delta^{N}(1-q)\right)=0.126<u_{O} \equiv q\left[1-\beta\left(1-\delta^{O}\right)\right]=0.128,
$$

respectively.

Figure 3 illustrates the key firm decision rules in the stationary competitive equilibrium (solid) and under the constrained efficient allocation (dashed). We start by discussing the policy functions in competitive equilibrium. Old capital accounts for a larger fraction of the capital operated by firms with lower net worth. As firms grow, they increase the share of capital is homogeneous across firms. 

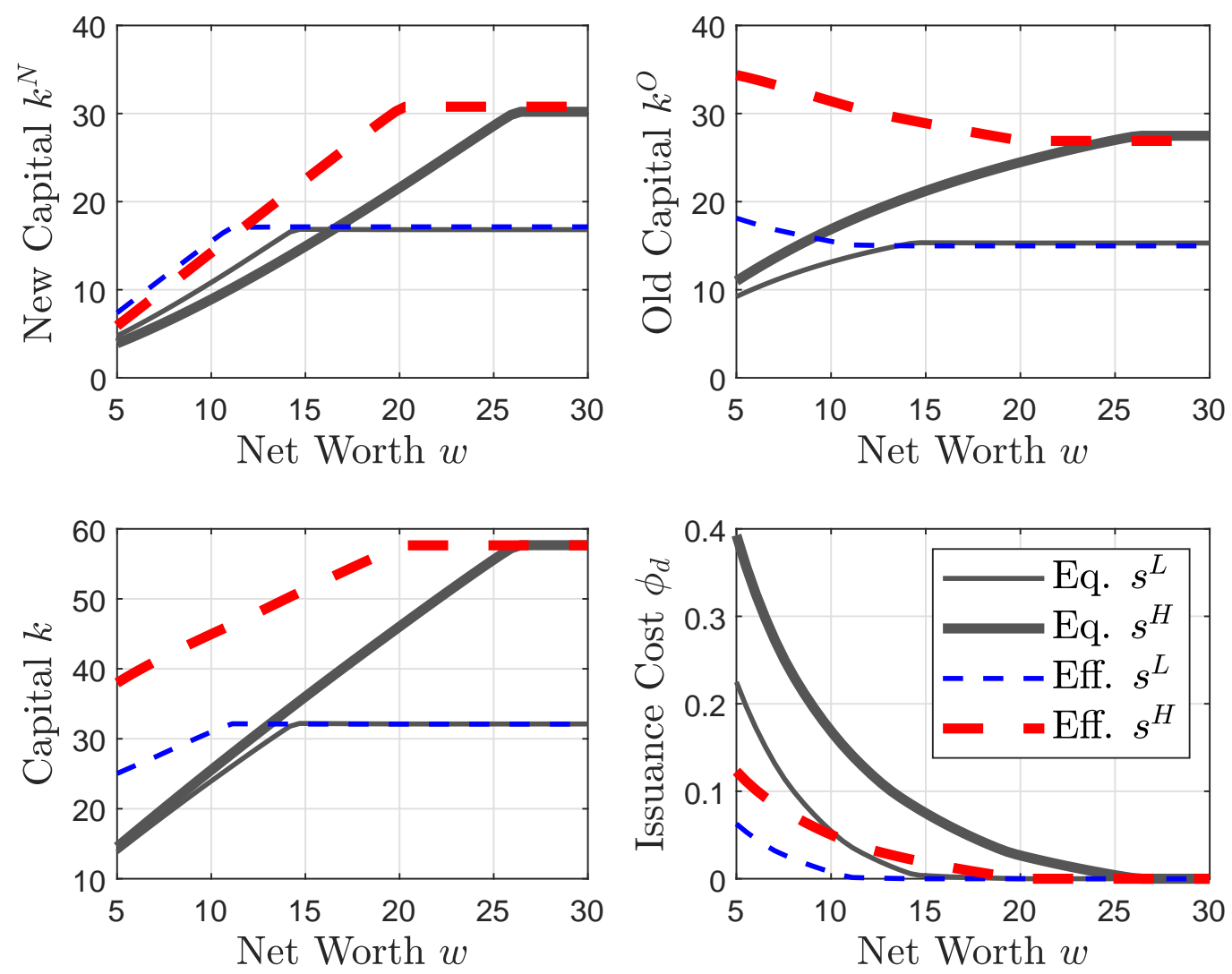

Figure 3: Stationary equilibrium and constrained efficient allocation. Top left: new capital $k^{N}$; top right: old capital $k^{O}$; bottom left: capital bundle $k$; bottom right: marginal cost of equity issuance $\phi_{d}$. The $x$-axes report net worth $w$. Solid lines denote the competitive-equilibrium allocation, dashed lines the constrained-efficient allocation. Thick lines denote the high productivity state, thin lines the low state. See Table 1 for the parameter values.

new investment goods in their capital bundle. Furthermore, for a given level of net worth, firms with higher productivity (thick lines) are more financially constrained, as indicated by a higher marginal equity issuance cost, and thus choose a higher fraction of old capital goods. Thus, on average, the market for old capital reallocates assets from firms with high net worth and lower productivity to firms with low net worth and high productivity.

We now discuss the constrained-efficient allocation. We find that the planner optimally drives the price of old capital down to the scrappage value, thereby fostering capital reallocation toward financially constrained firms, which increase their purchases of old capital and thus their overall productive capacity substantially. The marginal value of net worth of the most constrained firms induced by this allocation is significantly lower than in the competitive equilibrium. However, because all firms invest in new capital in the first-best allocation due to imperfect substitutability and moreover the lower bound for the equilib- 
rium price of old capital is binding, the constrained-efficient allocation does not achieve first-best welfare.

We also compute the tax rates on new and old capital that implement the constrainedefficient allocation as a competitive equilibrium with taxes, rebated to each firm in a lumpsum fashion. ${ }^{28}$ On average, the subsidy on new capital equals $8.6 \%$ and the tax on old capital equals $103.7 \%$. Consistent with the intuition developed in our analytical results in Section 3.5, a large tax on old capital reflects the fact that the planner achieves a significant reduction of the price of old capital from its competitive-equilibrium value, which exceeds the first-best value, to the lower bound, the scrappage value $\underline{q} \cdot{ }^{29}$ The combination of subsidies on new capital and taxes on old capital raises net fiscal revenue, implying that lump-sum transfers to firms are positive in the aggregate.

We now use our quantitative model to measure the pecuniary externalities in the stationary competitive equilibrium. Consistent with our analytical results, we find that the distributive externality dominates the collateral externality. In the aggregate, the distributive externality is approximately 2.3 times as large as the collateral externality.

In Figure 4, we explore the heterogeneous effects of the pecuniary externalities through the price of old capital, by displaying the cross section of distributive externalities (left panel) and collateral externalities (right panel) as functions of firms' state variables. The distributive externality is defined as the marginal effect on firm value of decreasing the price of old capital due to a change in the value of old capital traded. This externality is largest for firms with low net worth and high productivity, because they are net buyers of old capital. As firms' net worth increases, they eventually become net sellers of old capital, and the distributive externality accordingly becomes negative. The collateral externality is defined as the marginal effect on firm value of increasing the (future) price of collateral. This externality is also highest for the most financially constrained firms and goes to zero as firms become unconstrained. However, the figure confirms that overall the distributive externality is significantly larger and thus a reduction in the price of old capital is desirable.

In Table 2, we compare the main long-run aggregate outcomes under three alternative allocations: first best; competitive equilibrium; and constrained-efficient allocation. Competitive-equilibrium and constrained-efficient allocations and prices are expressed as fractions of the corresponding first-best value, which we report in parenthesis in the first column. We find that financial frictions induce an aggregate output loss of approximately 10\%, and an aggregate consumption loss of approximately $7 \%$, relative to first best. ${ }^{30}$ Notice

\footnotetext{
${ }^{28}$ We illustrate these tax rates in Online Appendix C.2.

${ }^{29}$ Accordingly, in Section 7.2 we analyze the sensitivity with respect to the scrappage value $q$ and find that optimal taxes on old capital are sensitive to this parameter. Specifically, a larger price reduction requires higher taxes on old capital to offset the effect of a low price on firms' optimal production scale.

${ }^{30}$ For comparison, Catherine, Chaney, Huang, Sraer, and Thesmar (forthcoming) estimate the aggregate
} 

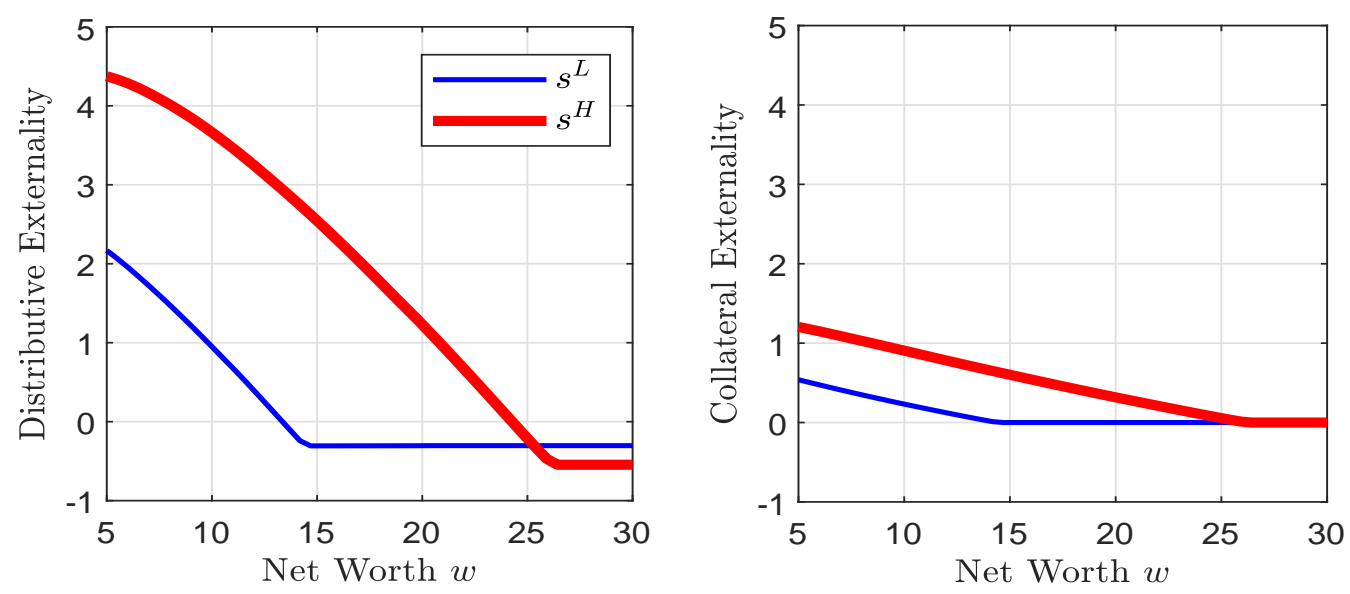

Figure 4: Pecuniary externalities in stationary equilibrium. Left panel: distributive externality; right panel: collateral externality. The $x$-axes report net worth $w$. Thick red lines denote the high productivity state, thin blue lines the low state. Using equation (51) and recursive notation, we define the distributive externality as $k^{O}(w, s)\left(1+\phi_{d}(w, s)\right)-\left[\delta^{N} k^{N}(w, s)+\left(1-\delta^{O}\right) k^{O}(w, s)\right](1+$ $\left.(1-\rho) \mathbb{E}\left[\phi_{d}\left(w^{\prime}, s^{\prime}\right) \mid w, s\right]\right)$. This is the marginal gain from a decrease in the price of old capital due to investment in old capital from firms with state variables $(w, s)$, net of the marginal loss due to sales of old capital from firms that had the same state variables at the previous date. The collateral externality equals $\theta \lambda(w, s)\left[\delta^{N} k^{N}(w, s)+\left(1-\delta^{O}\right) k^{O}(w, s)\right]$. This is the marginal gain from an increase in the value of collateral for firms with state variables $(w, s)$. See Table 1 for the parameter values.

that aggregate consumption is the relevant measure of welfare, under our assumption of linear utility.

These welfare losses due to financial frictions could be eliminated if a planner could directly redistribute resources from financially unconstrained firms to constrained firms. We explicitly exclude this possibility for the planner in the constrained-efficient allocation, imposing that all individual budget constraints must be respected. Nevertheless, the constrained-efficient allocation increases output by $8 \%$ and consumption by $5 \%$ relative to the competitive equilibrium.

\section{Restricted Policy Instruments and Sensitivity}

This section provides additional analyses of our quantitative model and discusses the sensitivity of our quantitative results with respect to several parameters.

output cost of collateral constraints (and costly equity issuance) for US firms to be approximately $7 \%$. 


\section{Table 2: Quantitative Results}

Output, investment, consumption, and the price of used capital for the competitive equilibrium and the constrained-efficient allocation are expressed as fractions of the corresponding first-best value, reported in parenthesis in the first column. See Table 1 for the parameter values.

\begin{tabular}{lccc}
\hline \hline Variable & First Best & Comp. Eq. & Constr. Eff. \\
\hline Output & $(9.910)$ & 0.899 & 0.973 \\
Investment & $(4.497)$ & 0.857 & 0.962 \\
Consumption & $(5.413)$ & 0.933 & 0.983 \\
Price $q$ & $(0.547)$ & 1.010 & 0.183 \\
Average tax $\tau^{N}$ & 0 & 0 & $-8.6 \%$ \\
Average tax $\tau^{O}$ & 0 & 0 & $103.7 \%$ \\
\hline
\end{tabular}

\subsection{Policy Experiments with Restricted Instruments}

The implementation of the constrained-efficient allocation in the previous section involves firm-specific tax rates on new and old capital, as well as lump-sum rebates. We now perform several policy experiments with restrictions on the set of instruments. We report the results of this analysis in more detail in Online Appendix C.2.

Uniform Taxes. To assess the importance of firm-level variation in tax rates on new and old capital, we recompute the stationary equilibrium when all firms face the same subsidy on new capital and the same tax on old capital; we set each instrument equal to its average value in the implementation of the constrained-efficient allocation. As in our baseline case, we rebate the tax revenue to each firm with a lump-sum transfer. We find that the allocation is broadly similar whether tax rates are firm specific or not. A noticeable difference is that uniform tax rates limit the degree to which the planner manages to increase investment in old capital by high-productivity firms with low levels of net worth. Despite this difference, aggregate outcomes as well as welfare are overall similar across the two economies considered.

Taxes on a Single Type of Capital. We analyze the case in which only new-capital taxesrebated with lump-sum transfers to each firm - are available. Despite the absence of taxes on old capital, new-investment subsidies reduce the stationary-equilibrium price of old capital. For example, a $1 \%$ subsidy on new-capital uniform across firms reduces the price of old capital by approximately $4 \%$ relative to the undistorted competitive equilibrium and increases consumption by approximately $2 \%$. We also investigate the relative effectiveness of distortions only on new capital or only on old capital in decreasing the price of old capital. We find that for a given size of the policy distortion, subsidies on new capital achieve a 
reduction in the price of old capital that is about $80 \%$ larger than the one induced by taxes on old capital.

No Lump-Sum Transfers. We also evaluate a balanced-budget policy without lump-sum taxes or rebates in our quantitative model, as we do in Section 3.6 for the stylized model. In particular, we consider again a tax rate on new capital $\tau^{N}=-0.03$ and compute the tax rate on old capital that satisfies the balanced-budget condition:

$$
\tau^{N} \int k^{N}(w, s) d \pi(w, s)+\tau^{O} q \int k^{O}(w, s) d \pi(w, s)=0
$$

where $q$ is the stationary-equilibrium price of old capital consistent with the policy plan $\left(\tau^{N}, \tau^{O}\right)$. We obtain $\tau^{O}=0.073$ and $q=0.412$ (compared to $q=0.553$ in the stationary equilibrium without policy intervention). Because the policy is highly effective at reducing the price of old capital, the overall effects are a positive aggregate welfare gain and a reduction in the tightness of financing constraints for all firms. Higher investment in new capital from unconstrained firms facilitates larger purchases of old capital from constrained firms.

These results in the quantitative model confirm that the optimal direction of policy interventions in our model, due to the importance of distributive pecuniary externalities, is robust to restricting the set of policy instruments and deviating from the baseline notion of constrained efficiency.

Transition Dynamics. We also perform an analysis of the transition dynamics associated with the implementation of subsidies on new investment. To make this analysis tractable, we consider the undistorted stationary equilibrium as the initial condition and assume that, unexpectedly, all firms face a common, time-invariant tax rate $\tau^{N}=-0.3 \%$. At this value, the subsidy on new investment maximizes household utility starting from the undistorted stationary equilibrium.

\subsection{Sensitivity}

We now discuss the sensitivity of our quantitative results with respect to changes in several parameters. We report more detailed results in Table $\mathrm{C} 1$ in the Online Appendix.

Collateralizability. We solve the model for $\theta=0$ (no borrowing) and $\theta=0.75$. With $\theta=0$, financial frictions induce substantially larger losses than in our baseline calibration. For instance, competitive-equilibrium output is approximately $20 \%$ lower than in the firstbest allocation. Moreover, the only pecuniary externality is the distributive externality, contributing to larger gains from the optimal policy of subsidizing investment and reduc- 
ing the price of old capital. With $\theta=0.75$, the effects of financial frictions are smaller (competitive-equilibrium output is approximately $5 \%$ smaller than under first best), and, accordingly, so are the gains from optimal policy. The distributive externality is $45 \%$ larger than the collateral externality in competitive equilibrium. We find, however, that optimal tax rates on new and old capital are quite similar across all values of $\theta$ we consider.

Substitutability of New and Old Capital. Next, we consider different values for the elasticity of substitution $\epsilon$, namely $\epsilon=1$ and $\epsilon=10$. A comparison of the competitive equilibrium outcomes across these values allows us to assess the efficiency gains due to reallocation of old capital to more constrained firms, which are higher, the higher the substitutability. Our results on constrained efficiency are quite robust with respect to these changes in $\epsilon$. The higher the elasticity of substitution, however, the more effective the planner is in allowing constrained firms to produce at a larger scale by using a larger share of old capital, consistent with our theoretical result that first-best welfare can be achieved with perfect substitutability (see Section 3.5).

Scrap Value. Furthermore, we consider a lower and a higher scrap value $(\underline{q}=0.05$ and $\underline{q}=0.2)$ relative to our baseline value $(\underline{q}=0.1)$, to investigate whether this lower bound for the price of old capital, which is a binding constraint for the planner, is important for our results. We find that optimal allocations are similar, irrespective of this change, and, intuitively, welfare gains are larger, the lower the scrap value. We also find that the optimal tax on old capital that supports the constrained-efficient allocation is highly sensitive to this parameter, ranging from approximately $40 \%$ when $\underline{q}=0.2$ to approximately $230 \%$ when $\underline{q}=0.05$.

Idiosyncratic Shocks and Volume of Reallocation. Finally, we analyze the role of the volume of reallocation for our results on the size of the distributive externality. To preserve tractability of the planning problem in our quantitative model, we have assumed that there are no trading frictions in the market for old capital, such as trading costs or irreversibility due to capital specificity. As a result, whereas our model matches the volume of firm exit and entry with the exogenous death process, it implies that capital reallocation among continuing firms is highly responsive to idiosyncratic shocks - more so than models with frictions that are explicitly calibrated to match the volume of trade in the secondary market (for example, Lanteri, 2018). To gauge the importance of the volume of reallocation in response to productivity shocks for our measurement of the pecuniary externalities, we switch off the productivity shocks and solve the model assuming that all firms have constant productivity $s=1$, while maintaining all other parameter at their baseline values. Despite this change, we confirm that the distributive externality is more than twice as large as the collateral externality. 


\section{Conclusion}

We analyze the constrained-efficient allocation in an equilibrium model of investment and capital reallocation both theoretically and quantitatively. Financial frictions induce pecuniary externalities in the secondary market for capital. Because financially constrained firms tend to be net buyers of old capital, and unconstrained firms tend to sell old capital and replace it with new capital, the competitive-equilibrium price of old capital is inefficiently high. This distributive externality dominates the collateral externality, which would call for increasing the resale price of capital instead, and which is the focus of much of the existing quantitative literature using models with a representative firm. A planner can induce a more efficient allocation by subsidizing new capital, thereby increasing the future supply of old capital and thus alleviating the effects of financial constraints for constrained firms in the future.

Subsidies on new investment are a widely-used policy tool. ${ }^{31}$ Despite their popularity, to the best of our knowledge there is scarce theoretical foundation for these policies. Our analysis highlights that new investment induces a positive externality by fostering capital reallocation, thus providing a rationale for investment subsidies. We also show the efficiency gains associated with investment subsidies are tightly linked to equilibrium prices and policy interventions in secondary markets, thus providing a new perspective and guidance on the optimal design of investment incentives.

Our focus is on the nature of pecuniary externalities in a stationary economy, that is, in steady state. In an economy with aggregate fluctuations, the relative importance of distributive and collateral externalities, and the sign of distributive externalities, may differ between expansion and downturns, that is, vary with macroeconomic conditions. We leave an efficiency analysis of capital reallocation and pecuniary externalities in response to macroeconomic shocks for future work.

\footnotetext{
${ }^{31}$ For instance, in the US, bonus depreciation is a federal budget provision that historically subsidized investment in new equipment. Since 2018, this provision has been extended to include purchases of used capital goods at least until 2023.
} 


\section{References}

Ai, H., A. Bhandari, Y. Chen, and C. Ying (2021): "Capital Misallocation and Risk Sharing," Working paper.

Ai, H., K. Li, And F. YAng (2020): "Financial Intermediation and Capital Reallocation," Journal of Financial Economics, 138(3), 663-686.

Aiyagari, S. R. (1994): "Uninsured Idiosyncratic Risk and Aggregate Saving," Quarterly Journal of Economics, 109(3), 659-684.

Akerlof, G. A. (1970): "The Market for 'Lemons': Quality Uncertainty and the Market Mechanism," Quarterly Journal of Economics, 84(3), 488-500.

Asriyan, V., L. Laeven, A. Van der Ghote, and V. Vanasco (2022): "Falling Interest Rates and Credit Misallocation: Lessons from General Equilibrium," CEPR Discussion Paper No. 16720.

Benigno, G., H. Chen, C. Otrok, A. Rebucci, and E. R. Young (2013): "Financial Crises and Macro-Prudential Policies," Journal of International Economics, 89(2), 453470.

BiAnchi, J. (2011): "Overborrowing and Systemic Externalities in the Business Cycle," American Economic Review, 101(7), 3400-3426.

Bianchi, J., and E. G. Mendoza (2018): "Optimal Time-Consistent Macroprudential Policy," Journal of Political Economy, 126(2), 588-634.

(2020): "A Fisherian Approach to Financial Crises: Lessons from the Sudden Stops Literature," Review of Economic Dynamics, 37(S1), S254-S283.

Bond, E. W. (1983): "Trade in Used Equipment with Heterogeneous Firms," Journal of Political Economy, 91(4), 688-705.

Buera, F. J., J. P. Kaboski, and Y. Shin (2011): "Finance and Development: A Tale of Two Sectors," American Economic Review, 101(5), 1964-2002.

Catherine, S., T. Chaney, Z. Huang, D. Sraer, and D. Thesmar (forthcoming): "Quantifying Reduced-Form Evidence on Collateral Constraints," Journal of Finance.

Cooper, R. W., and J. C. Haltiwanger (2006): "On the Nature of Capital Adjustment Costs," The Review of Economic Studies, 73(3), 611-633.

Cooper, R. W., And I. Schott (2020): "Capital Reallocation and Aggregate Productivity," Working paper.

CuI, W. (forthcoming): "Macroeconomic Effects of Delayed Capital Liquidation," Journal of the European Economic Association.

David, J. M., And V. Venkateswaran (2019): "The Sources of Capital Misallocation," American Economic Review, 109(7), 2531-2567. 
DÁvila, E., And B. HÉBert (2021): "Optimal Corporate Taxation Under Financial Frictions," Working paper.

Dávila, E., And A. Korinek (2018): "Pecuniary Externalities in Economies with Financial Frictions," Review of Economic Studies, 85(1), 352-395.

Dávila, J., J. H. Hong, P. Krusell, and J. V. Ríos-Rull (2012): "Constrained Efficiency in the Neoclassical Growth Model with Uninsurable Idiosyncratic Shocks," Econometrica, 80(6), 2431-2467.

Decker, R., J. Haltiwanger, R. Jarmin, and J. Miranda (2014): "The Role of Entrepreneurship in US Job Creation and Economic Dynamism," Journal of Economic Perspectives, 28(3), 3-24.

Diamond, P. A. (1967): "The Role of a Stock Market in a General Equilibrium Model with Technological Uncertainty," American Economic Review, 57(4), 759-776.

Edgerton, J. (2011): "The Effects of Taxation on Business Investment: New Evidence from Used Equipment," Working paper.

Eisfeldt, A., AND A. A. RAmpini (2006): "Capital Reallocation and Liquidity," Journal of Monetary Economics, 53(3), 369-399.

- (2007): "New or Used? Investment with Credit Constraints," Journal of Monetary Economics, 54(8), 2656-2681.

Eisfeldt, A., And Y. Shi (2018): "Capital Reallocation," Annual Review of Financial Economics, 10, 361-386.

Gavazza, A. (2011): "The Role of Trading Frictions in Real Asset Markets," American Economic Review, 101(4), 1106-1143.

(2016): "An Empirical Equilibrium Model of a Decentralized Asset Market," Econometrica, 84(5), 1755-1798.

Gavazza, A., And A. Lanteri (2021): "Credit Shocks and Equilibrium Dynamics in Consumer Durable Goods Markets," Review of Economic Studies, 88(6), 2935-2969.

Gavazza, A., A. Lizzeri, and N. Roketskiy (2014): "A Quantitative Analysis of the Used-Car Market," American Economic Review, 104(11), 3668-3700.

Geanakoplos, J. D., and H. M. Polemarchakis (1986): "Existence, regularity, and constrained suboptimality of competitive allocations when the asset market is incomplete," in Uncertainty, Information, and Communication: Essays in Honor of Kenneth J. Arrow, Volume III, ed. by W. P. Heller, R. M. Starr, and D. A. Starrett, pp. 65-95. Cambridge University Press.

Gomes, J. F. (2001): "Financing Investment," American Economic Review, 91(5), 12631285.

Gourio, F., And J. Miao (2010): "Firm Heterogeneity and the Long-Run Effects of 
Dividend Tax Reform," American Economic Journal: Macroeconomics, 2(1), 131-168.

He, Z., And P. Kondor (2016): "Inefficient Investment Waves," Econometrica, 84(2), $735-180$.

Hennessy, C. A., And T. M. Whited (2007): "How Costly is External Financing? Evidence from a Structural Estimation," Journal of Finance, 62(4), 1705-1745.

Hsieh, C.-T., And P. J. Klenow (2009): "Misallocation and Manufacturing TFP in China and India," Quarterly Journal of Economics, 124(4), 1403-1448.

Itskhoki, O., And B. Moll (2019): "Optimal Development Policies with Financial Frictions," Econometrica, 87(1), 139-173.

Jeanne, O., And A. KorineK (2019): "Managing Credit Booms and Busts: A Pigouvian Taxation Approach," Journal of Monetary Economics, 107, 2-17.

Jo, I. H., And T. Senga (2019): "Aggregate Consequences of Credit Subsidy Policies: Firm Dynamics and Misallocation," Review of Economic Dynamics, 32, 68-93.

Jorgenson, D. W. (1963): "Capital Theory and Investment Behavior," American Economic Review (Papers and Proceedings), 53, 247-259.

Khan, A., and J. K. Thomas (2013): "Credit Shocks and Aggregate Fluctuations in an Economy with Production Heterogeneity," Journal of Political Economy, 121(6), 10551107.

Kilenthong, W. T., And R. M. Townsend (2021): "A Market-Based Solution for Fire Sales and Other Pecuniary Externalities," Journal of Political Economy, 129(4), 981-1010.

Kiyotaki, N., And J. Moore (1997): "Credit Cycles," Journal of Political Economy, $105(2), 211-248$.

Kurlat, P. (2013): "Lemons Markets and the Transmission of Aggregate Shocks," American Economic Review, 103(4), 1463-1489.

(2021): "Investment Externalities in Models of Fire Sales," Journal of Monetary Economics, 122, 102-118.

LAnteri, A. (2018): "The Market for Used Capital: Endogenous Irreversibility and Reallocation over the Business Cycle," American Economic Review, 108(9), 2383-2419.

Li, S., T. M. Whited, And Y. Wu (2016): "Collateral, Taxes, and Leverage," Review of Financial Studies, 29(6), 1453-1500.

Lorenzoni, G. (2008): "Inefficient Credit Booms," Review of Economic Studies, 75(3), 809-833.

Ma, S., J. Murfin, and R. Pratt (forthcoming): "Young Firms, Old Capital," Journal of Financial Ecnomics.

Michelacci, C., And A. Pozzi (2022): “Are Housing Prices too Low?," Working paper. 
Midrigan, V., And D. Y. Xu (2014): "Finance and Misallocation: Evidence from PlantLevel Data," American Economic Review, 104(2), 422-458.

Mold, B. (2014): "Productivity Losses from Financial Frictions: Can Self-Financing Undo Capital Misallocation?," American Economic Review, 104(10), 3186-3221.

Nuño, G., And B. Moll (2018): "Social Optima in Economies with Heterogeneous Agents," Review of Economic Dynamics, 28, 150-180.

Ottonello, P. (2021): "Capital Unemployment," Working paper.

Ottonello, P., D. J. Perez, and P. Varraso (2021): "Are Collateral-Constraint Models Ready for Macroprudential Policy Design?," NBER Working Paper No. 29204.

PArk, Y. (2018): "Constrained Efficiency in a Human Capital Model," American Economic Journal: Macroeconomics, 10(3), 179-214.

PArodi, F. (2020): "Taxation of Consumption and Labor Income: A Quantitative Approach," Working paper.

Rampini, A. A. (2019): "Financing Durable Assets," American Economic Review, 109(2), $664-701$.

Rampini, A. A., And S. Viswanathan (2010): "Collateral, Risk Management, and the Distribution of Debt Capacity," Journal of Finance, 65(6), 2293-2322.

- (2013): "Collateral and Capital Structure," Journal of Financial Economics, $109(2), 466-492$.

Restuccia, D., and R. Rogerson (2008): "Policy distortions and aggregate productivity with heterogeneous establishments," Review of Economic Dynamics, 11(4), 707-720.

Rouwenhorst, K. G. (1995): "Asset Pricing Implication of Equilibrium Business Cycle Models," in Frontiers of Business Cycle Research, ed. by T. J. Cooley, chap. 10, pp. 294-330. Princeton University Press.

Samaniego, R. M., And J. Y. Sun (forthcoming): "The Embodiment Controversy: On the Policy Implications of Vintage Capital Models," Journal of Money, Credit and Banking.

Schmidt, K. (2003): "On the Covariance of Monotone Functions of a Random Variable," Dresdner Schriften zur Versicherungsmathematik.

Stiglitz, J. E. (1982): "The Inefficiency of the Stock Market Equilibrium," Review of Economic Studies, 49(2), 241-261.

Villalvazo, S. (2022): "Inequality and Asset Prices during Sudden Stops," Working Paper.

Wright, R., S. X. XiaO, and Y. Zhu (2020): "Frictional Capital Reallocation with Ex Post Heterogeneity," Review of Economic Dynamics, 37, S227-S253. 


\section{APPENDIX}

\section{Lagrangian for Planner's Problem in Stylized Model}

In this appendix, we explicitly formulate the Lagrangian of the problem in Section 3.4 used to characterize the constrained-efficient allocation. The planner chooses sequences of functions $\left\{d_{0 t}(w), d_{1, t+1}(w), k_{t}^{N}(w), k_{t}^{O}(w), b_{t}(w)\right\}_{t=0}^{\infty}$ and a sequence of prices $\left\{q_{t}\right\}_{t=0}^{\infty}$, given initial conditions $k_{-1}^{N}(w), k_{-1}^{O}(w), b_{-1}(w)$, to maximize the present discounted value of aggregate dividends net of equity issuance costs subject to the sequence of firms' budget constraints when young and old (with multipliers $\beta^{t} \mu_{0 t}(w)$ and $\beta^{t+1} \mu_{1 t+1}(w)$, respectively), collateral constraints (with multiplier $\beta^{t+1} \lambda_{t}(w)$ ), non-negativity constraints on new and old capital (with multipliers $\beta^{t} \underline{\nu}_{t}^{N}(w)$ and $\beta^{t} \underline{\nu}_{t}^{O}(w)$, respectively), and market-clearing conditions for old capital (with multiplier $\beta^{t} \eta_{t}$ ). We now state the Lagrangian of this problem, dropping the dependence of allocation and distribution on net worth $w$ to simplify notation:

$$
\begin{aligned}
\mathcal{L} \equiv & \sum_{t=0}^{\infty} \beta^{t}\left\{\int\left(d_{0 t}-\phi\left(-d_{0 t}\right)+d_{1 t}\right) d \pi+\int \mu_{0 t}\left(w+b_{t}-d_{0 t}-k_{t}^{N}-q_{t} k_{t}^{O}\right) d \pi\right. \\
& +\int \mu_{1 t}\left(f\left(k_{t-1}^{N}+k_{t-1}^{O}\right)+q_{t} k_{t-1}^{N}-d_{1 t}-\beta^{-1} b_{t-1}\right) d \pi+\int \lambda_{t}\left(\beta \theta q_{t+1} k_{t}^{N}-b_{t}\right) d \pi \\
& \left.+\int \underline{\nu}_{t}^{N} k_{t}^{N} d \pi+\int \underline{\nu}_{t}^{O} k_{t}^{O} d \pi+\eta_{t}\left(\int k_{t-1}^{N} d \pi-\int k_{t}^{O} d \pi\right)\right\} .
\end{aligned}
$$

Notice that maximizing the present discounted value of aggregate dividends is equivalent to maximizing the present discounted value of aggregate consumption, after taking into account the exogenous initial net worth of firms. 


\section{ONLINE APPENDIX}

\section{A Stylized Model}

This appendix provides additional details and results on the analysis of the stylized model of Section 3.

\section{A.1 Graphical Representation of Implementation of First Best}

In Figure A1, we illustrate the stationary competitive equilibrium (solid lines) in our numerical example for the stylized model of Section 3, and contrast it with the constrained-efficient allocation rule that supports the first-best outcome described in equation (31) (dashed lines). While total capital (bottom left) is weakly increasing in net worth in competitive equilibrium, inducing inefficient dispersion in marginal products, the constrained-efficient allocation equalizes the scale of production across all firms, increasing aggregate investment and reallocating old capital towards the most constrained firms, without incurring any equity issuance costs (bottom right).

\section{A.2 Restrictions on Policy Instruments in the Stylized Model}

In this section, we provide additional results on the policy experiments with restricted instruments in the stylized model from Section 3.6.

\section{A.2.1 No Taxes on Old Capital}

We first consider the case in which the planner cannot tax old capital. In this case, and in the following one without subsidies on new capital, we assume that new and old capital are imperfect substitutes: $y=f(k)$ and $k=g\left(k^{N}, k^{O}\right)$, where $g$ is a constant elasticity of substitution (CES) aggregator of new and old capital, as we assume in the quantitative model:

$$
g\left(k^{N}, k^{O}\right)=\left[\left(\sigma^{N}\right)^{\frac{1}{\epsilon}}\left(k^{N}\right)^{\frac{\epsilon-1}{\epsilon}}+\left(1-\sigma^{N}\right)^{\frac{1}{\epsilon}}\left(k^{O}\right)^{\frac{\epsilon-1}{\epsilon}}\right]^{\frac{\epsilon}{\epsilon-1}} .
$$

Specifically, for our numerical example we set the elasticity of substitution $\epsilon=50$, thus assuming high substitutability, similar to the baseline case for the stylized model, but retaining an interior solution for all firms. We further set $\sigma^{N}=0.5$, thus treating new and old capital symmetrically. All other functional forms and parameter values are as in the baseline numerical example (see caption of Figure 1). 

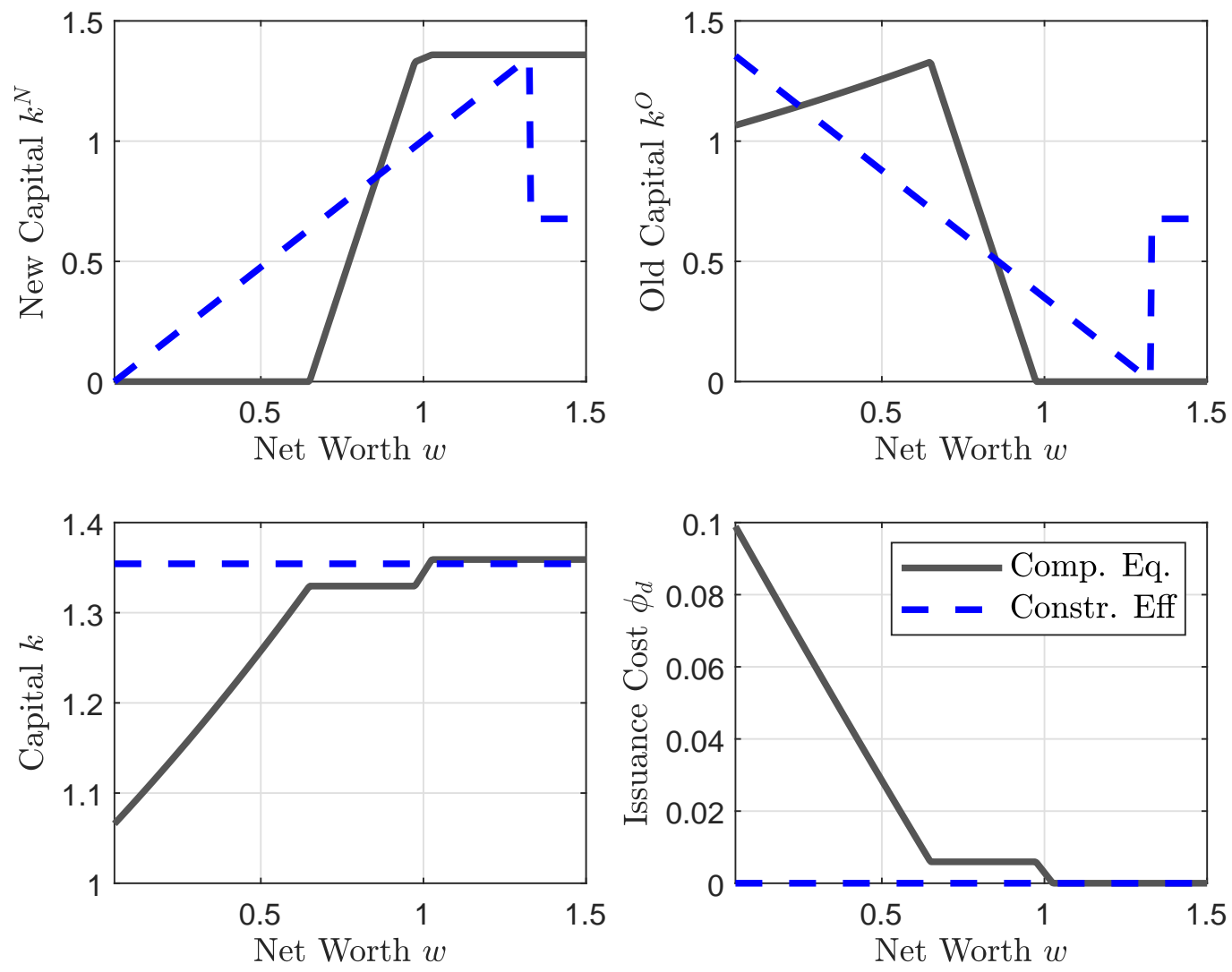

Figure A1: Stationary competitive equilibrium and constrained-efficient allocation - example. Top left: new capital $k^{N}$; top right: old capital $k^{O}$; bottom left: total capital $k$; bottom right: marginal cost of equity issuance $\phi_{d}$. The $x$-axes report net worth $w$. Solid lines denote the competitive-equilibrium allocation, dashed lines the constrained-efficient allocation. See the caption of Figure 1 for the parameter values.

The competitive-equilibrium optimality conditions for new and old capital are

$$
\begin{aligned}
1+\phi_{d, t} & =\beta\left(f_{k}\left(k_{t}\right) g_{N}\left(k_{t}^{N}, k_{t}^{O}\right)+q_{t+1}\left(1+\theta \lambda_{t}\right)\right) \\
q_{t}\left(1+\phi_{d, t}\right) & =\beta f_{k}\left(k_{t}\right) g_{O}\left(k_{t}^{N}, k_{t}^{O}\right),
\end{aligned}
$$

where we denote by $g_{N}$ and $g_{O}$ the partial derivatives of the bundle with respect to new and old capital, respectively.

To reflect the assumption that the planner cannot tax old capital, the planner faces the Euler equation for old capital (A2) as a constraint, for all $w$ and $t$, with multiplier $\beta^{t} \psi_{t}^{O}$, where we omit the dependence of variables on $w$, but it is understood that both allocations and multiplier depend on firm net worth.

The planner's first-order conditions with respect to new capital, old capital, and debt 
are

$$
\begin{aligned}
1+\phi_{d, t} & =\beta\left(f_{k}\left(k_{t}\right) g_{N}\left(k_{t}^{N}, k_{t}^{O}\right)+q_{t+1}\left(1+\theta \lambda_{t}\right)\right)+\beta \eta_{t+1}+\psi_{t}^{O} \frac{\partial O_{t}}{\partial k_{t}^{N}} \\
q_{t}\left(1+\phi_{d, t}\right) & =\beta f_{k}\left(k_{t}\right) g_{O}\left(k_{t}^{N}, k_{t}^{O}\right)-\eta_{t}+\psi_{t}^{O} \frac{\partial O_{t}}{\partial k_{t}^{O}} \\
1+\phi_{d, t} & =1+\lambda_{t}-\psi_{t}^{O} \frac{\partial O_{t}}{\partial b_{t}},
\end{aligned}
$$

with

$$
\begin{aligned}
\frac{\partial O_{t}}{\partial k_{t}^{N}} & =q_{t} \phi_{d d, t}-\beta\left(f_{k k}\left(k_{t}\right) g_{N}\left(k_{t}^{N}, k_{t}^{O}\right) g_{O}\left(k_{t}^{N}, k_{t}^{O}\right)+f_{k}\left(k_{t}\right) g_{N O}\left(k_{t}^{N}, k_{t}^{O}\right)\right) \\
\frac{\partial O_{t}}{\partial k_{t}^{O}} & =q_{t}^{2} \phi_{d d, t}-\beta\left(f_{k k}\left(k_{t}\right)\left(g_{O}\left(k_{t}^{N}, k_{t}^{O}\right)\right)^{2}+f_{k}\left(k_{t}\right) g_{O O}\left(k_{t}^{N}, k_{t}^{O}\right)\right) \\
\frac{\partial O_{t}}{\partial b_{t}} & =-q_{t} \phi_{d d, t} .
\end{aligned}
$$

The first-order condition with respect to the price of old capital $q_{t}$ is

$$
\int k_{t}^{O}\left(1+\phi_{d, t}\right) d \pi=\int k_{t-1}^{N}\left(1+\theta \lambda_{t-1}\right) d \pi+\int \psi_{t}^{O}\left(1+\phi_{d, t}+q_{t} \phi_{d d, t} k_{t}^{O}\right) d \pi
$$

The left-hand side reports the distributive externality on the buyers of old capital, whereas the first term on the right-hand side reports the distributive externality on the sellers as well as the collateral externality, as in our baseline case with taxes on new and old capital. Additionally, the second term of the right-hand side is a wedge due to the constraint (A2), which is positive and implies that the planner tolerates a distributive externality that is larger than the collateral externality in the constrained-efficient allocation. Because of this wedge, the optimal reduction in the price of old capital is smaller than when the planner can distort both new and old investment. Notice that the multipliers $\psi_{t}^{O}$ are positive, because the planner would like to tax old capital.

The intuition for this result is that the planner would like to decrease the price of old capital substantially, as in the unrestricted case, but a low price of old capital reduces the left-hand side of constraint (A2) and incentivizes inefficiently large purchases of old capital, which the planner cannot offset, absent a tax on old capital.

We consider an implementation of the constrained-efficient allocation with a proportional tax on new capital. Moreover, the planner can also use a tax on debt to induce its desired value for the multiplier $\lambda$ in competitive equilibrium, consistent with equation (A4). ${ }^{32}$ These taxes are then rebated lump-sum to each firm. To obtain the optimal tax

\footnotetext{
${ }^{32}$ The tax on debt is not relevant in the baseline case in which the planner can distort both new and
} 
rate on new capital, similar to the analysis of Section 3.5, we first compute the allocation and then use the firm optimality condition

$$
\left(1+\phi_{d, t}\right)\left(1+\tau_{t}^{N}\right)=\beta\left(f_{k}\left(k_{t}\right) g_{N}\left(k_{t}^{N}, k_{t}^{O}\right)+q_{t+1}(1+\theta \lambda)\right)
$$

to solve for $\tau_{t}^{N}$. We find that the optimal tax is negative in stationary equilibrium, consistent with our main insight on the importance of the distributive externality. Increasing the supply of new capital reduces the price of old capital, improving the allocation. The incentive to subsidize capital is reflected in the last two terms on the right-hand side of equation (A3): The multiplier $\eta$ is positive as in the baseline case with unrestricted instruments. Moreover, the term $\psi_{t}^{O} \frac{\partial O_{t}}{\partial k_{t}^{N}}$ is also positive because additional new investment contributes to relax the constraint due to the missing tax on old capital. In particular, for financially constrained firms additional new investment increases the marginal value of net worth, discouraging purchases of old capital, similar to a tax on old capital. Thus, as we explain in Section 3.6, the optimal subsidy on new investment is larger for more financially constrained firms.

Figure A2 displays the optimal tax rate on new capital. Notice that there is a discontinuity around the level of net worth such that firms become unconstrained. This is because our numerical example assumes a quadratic cost of equity issuance, and thus the second derivative $\phi_{d d, t}$, which appears in the optimality conditions reported above, equals a positive constant for constrained firms, and zero for unconstrained firms.

\section{A.2.2 No Subsidies on New Capital}

We now consider the case in which the planner cannot subsidize new capital. In this case, the planner faces the Euler equation for new capital (A1) as constraint for all $w$ and $t$, with multiplier $\beta^{t} \psi_{t}^{N}$. Notice that in formulating this constraint on the planning problem, we need to substitute a differentiable expression for the Lagrange multiplier on the collateral constraint $\beta^{t+1} \lambda_{t}$. We follow, for instance, Jeanne and Korinek (2019) and use the competitive-equilibrium optimality condition for debt to substitute $\lambda_{t}=\phi_{d, t}$ in the constraint. Henceforth in the derivations of this section, we use the notation $\lambda_{t}^{P}$ to refer to the multiplier on the collateral constraint in the planning problem.

The planner's first-order conditions with respect to new capital, old capital, and debt

old investment (Section 3.5), because in that case the planner's first-order condition with respect to debt coincides with the competitive equilibrium one, (12). 


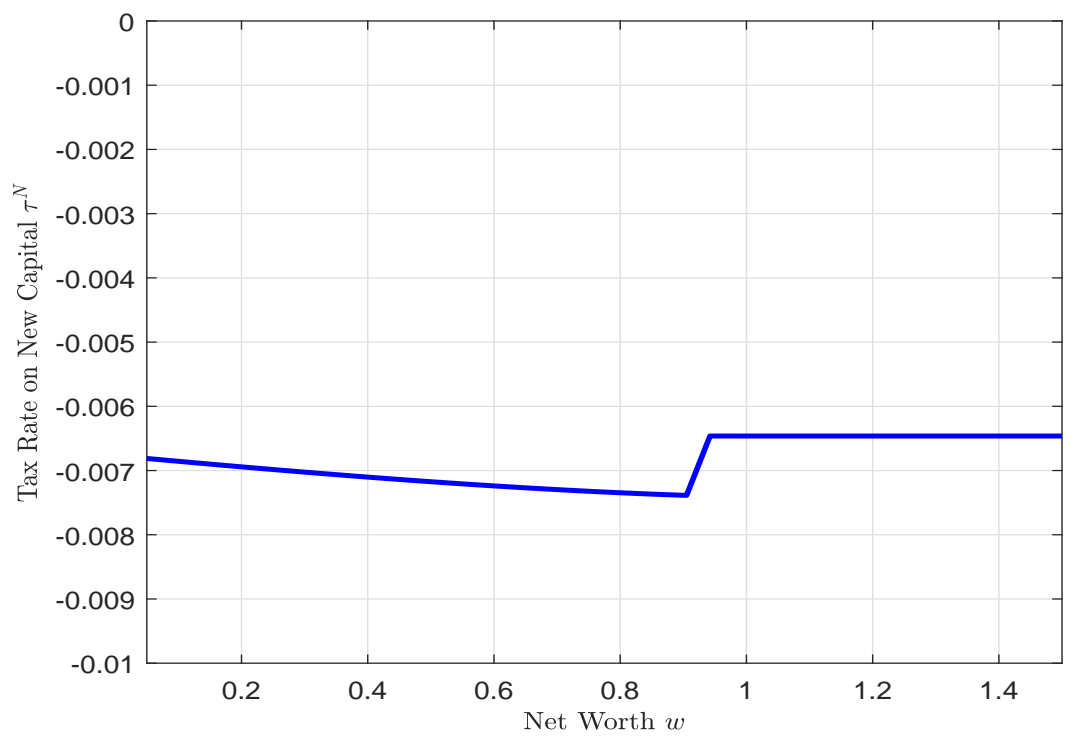

Figure A2: Tax Rate on New Capital without Tax on Old Capital. The $x$-axis reports net worth $w$. The $y$-axis reports the tax rate $\tau^{N}$.

are

$$
\begin{aligned}
1+\phi_{d, t} & =\beta\left(f_{k}\left(k_{t}\right) g_{N}\left(k_{t}^{N}, k_{t}^{O}\right)+q_{t+1}\left(1+\theta \lambda_{t}^{P}\right)\right)+\beta \eta_{t+1}+\psi_{t}^{N} \frac{\partial N_{t}}{\partial k_{t}^{N}} \\
q_{t}\left(1+\phi_{d, t}\right) & =\beta f_{k}\left(k_{t}\right) g_{O}\left(k_{t}^{N}, k_{t}^{O}\right)-\eta_{t}+\psi_{t}^{N} \frac{\partial N_{t}}{\partial k_{t}^{O}} \\
1+\phi_{d, t} & =1+\lambda_{t}^{P}-\psi_{t}^{N} \frac{\partial N_{t}}{\partial b_{t}},
\end{aligned}
$$

with

$$
\begin{aligned}
\frac{\partial N_{t}}{\partial k_{t}^{N}} & =\phi_{d d, t}\left(1-\beta \theta q_{t+1}\right)-\beta\left(f_{k k}\left(k_{t}\right)\left(g_{N}\left(k_{t}^{N}, k_{t}^{O}\right)\right)^{2}+f_{k}\left(k_{t}\right) g_{N N}\left(k_{t}^{N}, k_{t}^{O}\right)\right) \\
\frac{\partial N_{t}}{\partial k_{t}^{O}} & =q_{t} \phi_{d d, t}\left(1-\beta \theta q_{t+1}\right)-\beta\left(f_{k k}\left(k_{t}\right) g_{N}\left(k_{t}^{N}, k_{t}^{O}\right) g_{O}\left(k_{t}^{N}, k_{t}^{O}\right)+f_{k}\left(k_{t}\right) g_{N O}\left(k_{t}^{N}, k_{t}^{O}\right)\right) \\
\frac{\partial N_{t}}{\partial b_{t}} & =-\phi_{d d, t}\left(1-\beta \theta q_{t+1}\right) .
\end{aligned}
$$

The first-order condition with respect to the price of old capital $q_{t}$ is

$\int k_{t}^{O}\left(1+\phi_{d, t}\right) d \pi=\int k_{t-1}^{N}\left(1+\theta \lambda_{t-1}^{P}\right) d \pi+\int \psi_{t}^{N} \phi_{d d, t} k_{t}^{O}\left(1-\beta \theta q_{t+1}\right) d \pi-\int \psi_{t-1}^{N}\left(1+\theta \phi_{d, t-1}\right) d \pi$

The left-hand side reports the distributive externality on the buyers of old capital, whereas the first term on the right-hand side reports the distributive externality on the sellers as well 
as the collateral externality. The remaining terms of the right-hand side represent again a wedge due to the constraint (A1). This wedge is positive in our numerical example, as in the previous section, and implies that the planner tolerates a distributive externality that is larger than the collateral externality in the constrained-efficient allocation. Hence, the optimal reduction in the price of old capital is smaller than when the planner can distort both new and old investment. Notice that the multipliers $\psi_{t}^{N}$ are negative, because the planner would like to subsidize new investment.

We consider an implementation with proportional taxes on old capital and debt, rebated lump-sum to each firm. To obtain the optimal tax rate on old capital, we first compute the allocation and then use the following firm optimality condition

$$
q_{t}\left(1+\phi_{d, t}\right)\left(1+\tau_{t}^{O}\right)=\beta f_{k}\left(k_{t}\right) g_{O}\left(k_{t}^{N}, k_{t}^{O}\right)
$$

to solve for $\tau_{t}^{O}$. Figure A3 displays the stationary-equilibrium tax on old capital. We find that it is positive, consistent with our main insight on the importance of the distributive externality, which induces the planner to reduce the price of old capital. Moreover, this tax is smaller for more financially constrained firms. This is because the planner uses the tax on old capital to partially substitute for the missing subsidy on new capital and relax constraint (A1), which is more binding for unconstrained firms.

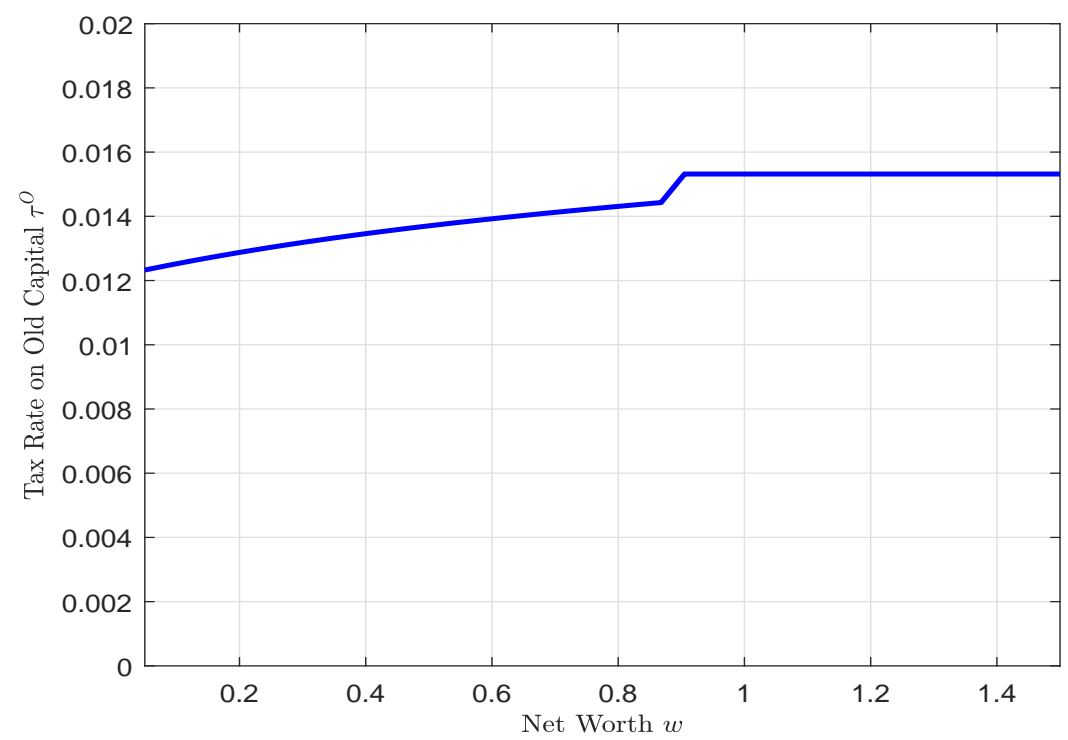

Figure A3: Tax Rate on Old Capital without Subsidy on New Capital. The $x$-axis reports net worth $w$. The $y$-axis reports the tax rate $\tau^{O}$. 


\section{A.2.3 No Lump-Sum Transfers}

We now consider the policy experiment with proportional taxes on new and old capital, but without lump-sum rebates. Figure A4 displays the overall tax liability of each firm as a function of net worth, confirming that firms with low net worth pay a positive tax and effectively subsidize firms with higher net worth under this policy.

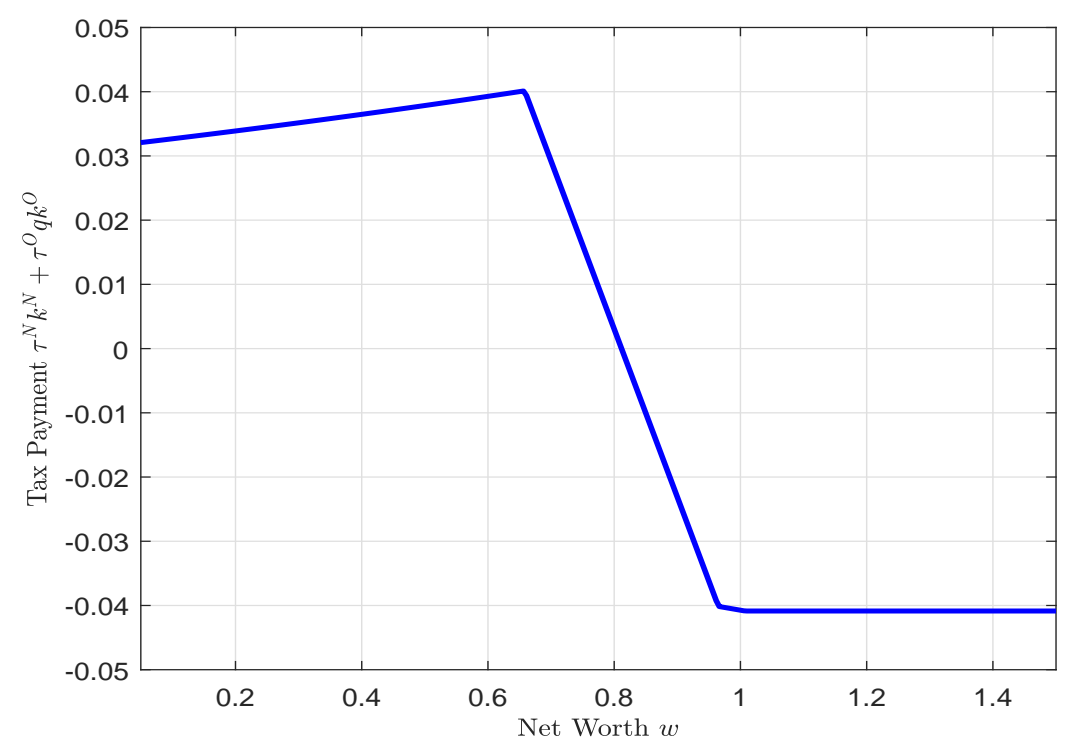

Figure A4: Tax Payment Without Lump-Sum Transfers in the Stylized Model. The $x$-axis reports net worth $w$. The $y$-axis reports the total tax payment $\tau^{N} k^{N}(w)+\tau^{O} q k^{O}(w)$ assuming that $\tau^{N}=-0.03$ and $\tau^{O}$ balances the government budget constraint.

\section{B Extensions and Limitations of Efficiency Result}

This appendix provides additional details and results on the analysis of Section 4.

\section{B.1 Risk-Averse Entrepreneurs}

In this section, we analyze the case from Section 4.1 in which each firm is owned by a risk-averse entrepreneur whose consumption at each date equals the dividend paid by the firm.

Competitive Equilibrium with Financial Frictions. Given their initial net worth $w$ and the price of old capital $q_{t}$, entrepreneurs maximize their utility by choosing consumption 
$c_{0 t}$ and $c_{1, t+1}$, new and old capital $k_{t}^{N}$ and $k_{t}^{O}$,and borrowing $b_{t}$, to solve ${ }^{33}$

$$
\max _{\left\{c_{0 t}, c_{1, t+1}, k_{t}^{N}, k_{t}^{O}, b_{t}\right\} \in \mathbb{R}_{+}^{4} \times \mathbb{R}} u\left(c_{0 t}\right)+\beta u\left(c_{1, t+1}\right)
$$

where $u$ is the utility function, with $u_{c}>0, u_{c c}<0$, and $\lim _{c \rightarrow 0} u_{c}(c)=+\infty$, subject to the budget constraints for the current and next period,

$$
\begin{aligned}
w_{0 t}+b_{t} & =c_{0 t}+k_{t}^{N}+q_{t} k_{t}^{O} \\
f\left(k_{t}^{N}+k_{t}^{O}\right)+q_{t+1} k_{t}^{N} & =c_{1, t+1}+\beta^{-1} b_{t}
\end{aligned}
$$

and the collateral constraint (9).

Denote the multipliers on the budget constraints by $\mu_{0 t}$ and $\beta \mu_{1, t+1}$, on the collateral constraint by $\beta \lambda_{t}$, and on the non-negativity constraints for new and old capital by $\underline{\nu}_{t}^{N}$ and $\underline{\nu}_{t}^{O}$, respectively. The optimal demand for new capital, old capital, and borrowing, as functions of initial net worth $w$, satisfy the following first-order conditions

$$
\begin{aligned}
u_{c}\left(c_{0 t}\right) & =\beta u_{c}\left(c_{1, t+1}\right)\left[f_{k}\left(k_{t}\right)+q_{t+1}\right]+\beta \theta \lambda_{t} q_{t+1}+\underline{\nu}_{t}^{N} \\
q_{t} u_{c}\left(c_{0 t}\right) & =\beta u_{c}\left(c_{1, t+1}\right) f_{k}\left(k_{t}\right)+\underline{\nu}_{t}^{O} \\
u_{c}\left(c_{0 t}\right) & =u_{c}\left(c_{1, t+1}\right)+\lambda_{t},
\end{aligned}
$$

where $k_{t}=k_{t}^{N}+k_{t}^{O}$. Moreover, the firm's marginal value of net worth at date $t$ is $\mu_{0, t}=$ $u_{c}\left(c_{0 t}\right)$.

A stationary competitive equilibrium is a set of policy functions mapping initial net worth to an allocation $\left\{c_{0}(w), c_{1}(w), k^{N}(w), k^{O}(w), b(w)\right\}$, that is, consumption, investment, and debt choices, and a price of old capital $q$, such that entrepreneurs maximize their utility, $\forall w \in \mathcal{W}$, and the market for old capital clears, that is, $\int k^{N}(w) d \pi(w)=$ $\int k^{O}(w) d \pi(w)$.

In a stationary equilibrium, the first-order conditions for new and old capital (B4) and (B5) can be written as investment Euler equations

$$
\begin{aligned}
& 1 \geq \beta \frac{u_{c}\left(c_{1}\right)}{u_{c}\left(c_{0}\right)} \frac{\left[f_{k}(k)+(1-\theta) q\right]}{\wp_{N}} \\
& 1 \geq \beta \frac{u_{c}\left(c_{1}\right)}{u_{c}\left(c_{0}\right)} \frac{f_{k}(k)}{q},
\end{aligned}
$$

\footnotetext{
${ }^{33}$ Because we now interpret dividends as consumption, we require that dividends are non-negative. We could alternatively allow for negative dividends, in which case this model becomes a generalization of our stylized model, which can be obtained as the special case $u(d) \equiv d-\phi(d)$.
} 
with equality if $k^{N}>0$ and $k^{O}>0$, respectively, where we use the same definition of the down payments as in Section 3. Using (B6), we can rewrite (B7) and (B8) as

$$
\begin{array}{r}
u_{N}(w) \equiv u_{N}+\frac{\lambda}{u_{c}\left(c_{1}\right)} \wp_{N}=1-\beta q+\frac{\lambda}{u_{c}\left(c_{1}\right)}(1-\beta \theta q) \geq \beta f_{k}(k) \\
u_{O}(w) \equiv u_{O}+\frac{\lambda}{u_{c}\left(c_{1}\right)} \wp_{O}=q+\frac{\lambda}{u_{c}\left(c_{1}\right)} q \geq \beta f_{k}(k)
\end{array}
$$

where we use the same definitions of the user cost as in Section 3.

Combining (B7) and (B8) we moreover have

$$
1=\beta \frac{u_{c}\left(c_{1}\right)}{u_{c}\left(c_{0}\right)} \frac{(1-\theta) q}{\wp_{N}-\wp_{O}}+\frac{\left(\underline{\nu}^{N}-\underline{\nu}^{O}\right) / u_{c}\left(c_{0}\right)}{\wp_{N}-\wp_{O}} .
$$

Arguing as before, equation (B9) implies $\wp_{N}>\wp_{O}$, and thus, in equilibrium, $u_{N} \leq u_{O}$. Consider first entrepreneurs for which $\lambda=0$. They invest $\bar{k}$ which solves $1=\beta \frac{f_{k}(\bar{k})+(1-\theta) q}{\wp_{N}}$. Moreover $k^{N}=\bar{k}$ and $k^{O}=0$ if $q>q^{F B}$ as we assume is the case in Proposition 3. Entrepreneurs with $\lambda=0$ have net worth $w \geq \bar{w}$, where $\bar{w}$ solves $\bar{w}-\wp_{N} \bar{k}=f(\bar{k})+(1-\theta) q \bar{k}$.

Entrepreneurs with sufficiently low $w$ strictly prefer old capital, because as $w \rightarrow 0$, $f_{k}(k) \rightarrow+\infty$ and therefore $\frac{u_{c}\left(c_{1}\right)}{u_{c}\left(c_{0}\right)} \rightarrow 0$, and thus equation (B9) implies $\underline{\nu}^{N}>0$. Hence, for sufficiently low $w, k^{N}=0$ and $k^{O}>0$. Moreover, $k^{O}$ is strictly increasing in $w$. To see this, consider $w_{+}>w$ and assume $k_{+}^{O} \leq k^{O}$. Then, $c_{1,+}=f\left(k_{+}^{O}\right) \leq f\left(k^{O}\right)=c_{1}$ and $f_{k}\left(k_{+}^{O}\right) \geq f_{k}\left(k^{O}\right)$, whereas $\frac{u_{c}\left(c_{1,+}\right)}{u_{c}\left(c_{0,+}\right)}>\frac{u_{c}\left(c_{1,+}\right)}{u_{c}\left(c_{0}\right)} \geq \frac{u_{c}\left(c_{1}\right)}{u_{c}\left(c_{0}\right)}$, which contradicts equation (B8).

For $w$ sufficiently close to $\bar{w}$ and $w<\bar{w}, k^{N}>0$ and $k^{O}=0$. Hence (B7) holds with equality. Moreover, $k^{N}$ is strictly increasing in $w$. To see this, consider $w_{+}>w$ and assume $k_{+}^{N} \leq k^{N}$. Then, $f_{k}\left(k_{+}^{N}\right) \geq f_{k}\left(k^{N}\right)$, whereas $c_{1,+}=f\left(k_{+}^{N}\right)+q(1-\theta) k_{+}^{N} \leq f\left(k^{N}\right)+q(1-$ $\theta) k^{N}=c_{1}$ and hence $\frac{u_{c}\left(c_{1,+}\right)}{u_{c}\left(c_{0,+}\right)}>\frac{u_{c}\left(c_{1,+}\right)}{u_{c}\left(c_{0}\right)} \geq \frac{u_{c}\left(c_{1}\right)}{u_{c}\left(c_{0}\right)}$, which contradicts equation (B7).

Consider now entrepreneurs for which $\underline{\nu}^{N}=\underline{\nu}^{O}=0$. Then, $1=\beta \frac{u_{c}\left(c_{1}\right)}{u_{c}\left(c_{0}\right)} R_{O}$, where $R_{O}=\frac{(1-\theta) q}{\wp_{N}-\wp_{O}}$. With risk-averse entrepreneurs the value function is globally strictly concave, and the envelope condition implies that $c_{0}$ is strictly increasing in $w$, and thus so is $c_{1}$. Moreover $1=R_{O}^{-1} \frac{\left[f_{k}(k)+(1-\theta) q\right]}{\wp_{N}}=R_{O}^{-1} \frac{f_{k}(k)}{q}$. Hence, $k=\underline{k} \leq \bar{k}$. Since $c_{1}=f(\underline{k})+(1-\theta) q k^{N}$, $k^{N}$ is strictly increasing and $k^{O}=\underline{k}-k^{N}$ strictly decreasing in $w$.

Entrepreneurs who are indifferent between new and old capital have net worth $\underline{w}_{N} \leq$ $w \leq \bar{w}_{O} \leq \bar{w}$ and these thresholds are implicitly characterized as follows: $c_{0}\left(\underline{w}_{N}\right)=\underline{w}_{N}-q \underline{k}$, $c_{1}\left(\underline{w}_{N}\right)=f(\underline{k}), 1=\beta R_{O} \frac{u_{c}\left(c_{1}\left(\underline{w}_{N}\right)\right)}{u_{c}\left(c_{0}\left(\underline{w}_{N}\right)\right)} ; c_{0}\left(\bar{w}_{O}\right)=\bar{w}_{O}-\wp_{N} \underline{k}, c_{1}\left(\bar{w}_{O}\right)=f(\underline{k})+(1-\theta) q \underline{k}$, $1=\beta R_{O} \frac{u_{c}\left(c_{1}\left(\bar{w}_{O}\right)\right)}{u_{c}\left(c_{0}\left(\bar{w}_{O}\right)\right)}$.

Constrained Efficiency. Given an initial distribution of new and old capital, $k_{-1}^{N}(w)$ and 
$k_{-1}^{O}(w)$, a utilitarian planner maximizes the total present discounted value of utility

$$
\int\left[u\left(c_{10}(w)\right)+\sum_{t=0}^{\infty} \beta^{t}\left(u\left(c_{0 t}(w)\right)+\beta u\left(c_{1, t+1}(w)\right)\right)\right] d \pi(w)
$$

subject to the budget constraints (B2) and (B3) with multipliers $\beta^{t} \mu_{0, t}$ and $\beta^{t+1} \mu_{1, t+1}$, the collateral constraint (9) with multiplier $\beta^{t+1} \lambda_{t}$, the non-negativity constraints on new and old capital with multipliers $\beta^{t} \underline{\nu}_{t}^{N}$ and $\beta^{t} \underline{\nu}_{t}^{O}$, and the market clearing condition for old capital (3) with multiplier $\beta^{t} \eta_{t}$.

The first-order condition with respect to the price of old capital $q_{t}$ for $t=1,2, \ldots$ is

$$
\int k_{t}^{O}(w) u_{c}\left(c_{0 t}(w)\right) d \pi(w)=\int k_{t-1}^{N}(w)\left[u_{c}\left(c_{1 t}(w)\right)+\theta \lambda_{t-1}(w)\right] d \pi(w)
$$

Thus, in the stationary constrained-efficient allocation, we have

$$
\int k^{O}(w) u_{c}\left(c_{0}(w)\right) d \pi(w)=\int k^{N}(w)\left[u_{c}\left(c_{1}(w)\right)+\theta \lambda(w)\right] d \pi(w)
$$

We now show that, in stationary competitive equilibrium, the distributive externality is larger than the collateral externality, that is,

$$
\int k^{O}(w) u_{c}\left(c_{0}(w)\right) d \pi(w)>\int k^{N}(w)\left[u_{c}\left(c_{1}(w)\right)+\theta \lambda(w)\right] d \pi(w)
$$

To do so, it is sufficient to prove that

$$
\int k^{O}(w) u_{c}\left(c_{0}(w)\right) d \pi(w)>\int k^{N}(w) u_{c}\left(c_{0}(w)\right) d \pi(w)
$$

because $u_{c}\left(c_{0}(w)\right)=u_{c}\left(c_{1}(w)\right)+\lambda(w) \geq u_{c}\left(c_{1}(w)\right)+\theta \lambda(w)$.

We can bound the two sides of (B10) as follows. If there is positive mass between $\underline{w}_{N}$ and $\bar{w}_{O}$, we apply the following result: $\mathbb{E}\left[k^{O} u_{c}\right]=\mathbb{C O V}\left(k^{O}, u_{c}\right)+\mathbb{E}\left[k^{O}\right] \mathbb{E}\left[u_{c}\right]$. Let $\bar{u}_{c} \equiv \int_{\underline{w}_{N}}^{\bar{w}_{O}} u_{c}\left(c_{0}(w)\right) d \pi(w) / \int_{\underline{w}_{N}}^{\bar{w}_{O}} d \pi(w)$. We have

$$
\int k^{O} u_{c}\left(c_{0}\right) d \pi=\int^{\bar{w}_{O}} k^{O} u_{c}\left(c_{0}\right) d \pi \geq \bar{u}_{c} \int^{\bar{w}_{O}} k^{O} d \pi
$$

because (i) $u_{c}\left(c_{0}\right)>\bar{u}_{c}$ for $w<\underline{w}_{N}$, and (ii) both $k^{O}$ and $u_{c}\left(c_{0}\right)$ are strictly decreasing in $w$ for $\underline{w}_{N} \leq w \leq \bar{w}_{O}$, thus their covariance is positive, implying $\int_{\underline{w}_{N}}^{\bar{w}_{O}} k^{O} u_{c}\left(c_{0}\right) d \pi \geq$ 
$\bar{u}_{c} \int_{\underline{w}_{N}}^{\bar{w}_{O}} k^{O} d \pi \cdot{ }^{34}$ Similarly, we have

$$
\int k^{N} u_{c}\left(c_{0}\right) d \pi=\int_{\underline{w}_{N}} k^{N} u_{c}\left(c_{0}\right) d \pi \leq \bar{u}_{c} \int_{\underline{w}_{N}} k^{N} d \pi
$$

because (i) $u_{c}\left(c_{0}\right)<\bar{u}_{c}$ for $w>\bar{w}_{O}$, and (ii) $k^{N}$ is strictly increasing in $w$ for $\underline{w}_{N} \leq w \leq \bar{w}_{O}$, implying its covariance with $u_{c}\left(c_{0}\right)$ is negative, and thus $\int_{\underline{w}_{N}}^{\bar{w}_{O}} k^{N} u_{c}\left(c_{0}\right) d \pi \leq \bar{u}_{c} \int_{\underline{w}_{N}}^{\bar{w}_{O}} k^{N} d \pi$. Furthermore, notice that at least one of the two inequalities (B11) and (B12) is strict, because the distribution of net worth $\pi(w)$ is non-degenerate. Thus, combining (B11), (B12), and the market-clearing condition $\int_{\underline{w}_{N}} k^{N} d \pi=\int^{\bar{w}_{O}} k^{O} d \pi$, we get (B10).

If there is no mass between $\underline{w}_{N}$ and $\bar{w}_{O}$, (B10) obtains more directly because all entrepreneurs investing in old capital have a marginal utility weakly greater than $u_{c}\left(c_{0}\left(\underline{w}_{N}\right)\right)$, all entrepreneurs investing in new capital have a marginal utility weakly less than $u_{c}\left(c_{0}\left(\bar{w}_{O}\right)\right)$, and $u_{c}\left(c_{0}\left(\underline{w}_{N}\right)\right)>u_{c}\left(c_{0}\left(\bar{w}_{O}\right)\right)$. This proves Proposition 3 .

We now discuss the case $q=q^{F B}$, which is not included in Proposition 3. In this case, $u_{N}=u_{O}=\wp_{O}=q=1 /(1+\beta)<1-\beta \theta q=\wp_{N}$ and $R_{O}=\beta^{-1}$. For entrepreneurs that are indifferent between new and old capital $\left(\underline{\nu}^{N}=\underline{\nu}^{O}=0\right)$, (B9) implies that $u_{c}\left(c_{1}\right)=u_{c}\left(c_{0}\right)$, so $c_{1}=c_{0}$, and (B6) implies that they are unconstrained $(\lambda=0)$. The investment Euler equations moreover imply that $\underline{k}=\bar{k}=k_{F B}$. Further, $\underline{w}_{N}<\bar{w}_{O}=\bar{w}$; specifically, $c_{0}\left(\underline{w}_{N}\right)=\underline{w}_{N}-q \underline{k}, c_{1}\left(\underline{w}_{N}\right)=f(\underline{k})$, and $\underline{w}_{N}=f(\underline{k})+q \underline{k}$, and $c_{0}\left(\bar{w}_{O}\right)=\bar{w}_{O}-\wp_{N} \underline{k}$, $c_{1}\left(\bar{w}_{O}\right)=f(\underline{k})+(1-\theta) q \underline{k}$, and $\bar{w}_{O}=f(\underline{k})+q \underline{k}+(1-\theta) \underline{k}$.

All entrepreneurs with $w \geq \underline{w}_{N}$ are indifferent between new and old capital at the margin, but entrepreneurs with $w \in\left(\underline{w}_{N}, \bar{w}_{O}\right)$ invest at least $k_{\min }^{O}(w)=\frac{\bar{w}_{O}-w}{1-\theta}$ in old capital. For entrepreneurs with $w \geq \underline{w}_{N}$ we choose the following selection of their investment policy. Let $\kappa^{O}=\left(\int_{\underline{w}_{N}} k^{O} d \pi-\int_{\underline{w}_{N}}^{\bar{w}_{O}} k_{\text {min }}^{O} d \pi\right) /\left(\int k^{N} d \pi+\int_{\underline{w}_{N}} k^{O} d \pi-\int_{\underline{w}_{N}}^{\bar{w}_{O}} k_{\text {min }}^{O} d \pi\right)$ and select $k^{O}(w)=k_{\text {min }}^{O}(w)+\kappa^{O}\left(\underline{k}-k_{\text {min }}^{O}(w)\right)$ for $w \in\left(\underline{w}_{N}, \bar{w}_{O}\right)$, and $k^{O}(w)=\kappa^{O} \bar{k}$ for $w \geq \bar{w}_{O}$.

Using this selection and defining $\bar{u}_{c} \equiv \int_{\underline{w}_{N}} u_{c}\left(c_{0}(w)\right) d \pi(w) / \int_{\underline{w}_{N}} d \pi(w)$, we have

$$
\begin{aligned}
\int k^{O} u_{c}\left(c_{0}\right) d \pi & =\int^{\underline{w}_{N}} k^{O} u_{c}\left(c_{0}\right) d \pi+\int_{\underline{w}_{N}} k^{O} u_{c}\left(c_{0}\right) d \pi \\
& \geq \int^{\underline{w}_{N}} k^{O} u_{c}\left(c_{0}\right) d \pi+\bar{u}_{c} \int_{\underline{w}_{N}} k^{O} d \pi \geq \bar{u}_{c} \int k^{O} d \pi,
\end{aligned}
$$

and $\int k^{N} u_{c}\left(c_{0}\right) d \pi \leq \bar{u}_{c} \int_{\underline{w}_{N}} k^{N} d \pi=\bar{u}_{c} \int k^{N} d \pi$. As long as some entrepreneurs are constrained, at least one of the inequalities is strict, and using $\int k^{O} d \pi=\int k^{N} d \pi$, (B10) obtains.

\footnotetext{
${ }^{34}$ See Schmidt (2003) for a proof of the sign of the covariance of monotone functions.
} 


\section{B.2 Heterogeneity in Productivity}

In this section, we analyze the model with productivity heterogeneity from Section 4.2 in more detail.

Competitive Equilibrium with Financial Frictions. A firm that draws initial net worth $w$ and productivity $s$ maximizes (6) subject to the budget constraints (7) and

$$
s f\left(k_{t}^{N}+k_{t}^{O}\right)+q_{t+1} k_{t}^{N}=d_{1, t+1}+\beta^{-1} b_{t}
$$

and the collateral constraint (9). Let $v(w, s)$ denote the value function of the firm.

Denote the multipliers on the budget constraints by $\mu_{0 t}$ and $\beta \mu_{1, t+1}$, on the collateral constraint by $\beta \lambda_{t}$, and on non-negativity constraint for new and old capital by $\underline{\nu}_{t}^{N}$ and $\underline{\nu}_{t}^{O}$, respectively. The optimality conditions are

$$
\begin{aligned}
1+\phi_{d, t} & =\beta\left[s f_{k}\left(k_{t}\right)+q_{t+1}\right]+\beta \theta \lambda_{t} q_{t+1}+\underline{\nu}_{t}^{N} \\
q_{t}\left(1+\phi_{d, t}\right) & =\beta s f_{k}\left(k_{t}\right)+\underline{\nu}_{t}^{O},
\end{aligned}
$$

and (12), where $k_{t}=k_{t}^{N}+k_{t}^{O}$.

A stationary competitive equilibrium is a set of policy functions mapping initial net worth and productivity to an allocation, that is, dividends, investment, and borrowing choices, $\left\{d_{0}(w, s), d_{1}(w, s), k^{N}(w, s), k^{O}(w, s), b(w, s)\right\}$, and a price of old capital $q$, such that firms maximize the present discounted value of dividends net of equity issuance cost, $\forall(w, s) \in \mathcal{W} \times \mathcal{S}$, and the market for old capital clears, that is, $\int k^{N}(w, s) d \pi(w, s)=$ $\int k^{O}(w, s) d \pi(w, s)$.

In a stationary equilibrium, we can rewrite equations (B14) and (B15) as

$$
\begin{aligned}
\wp_{N}\left(1+\phi_{d}\right) & =\beta\left[s f_{k}(k)+(1-\theta) q\right]+\underline{\nu}^{N} \\
q\left(1+\phi_{d}\right) & =\beta s f_{k}(k)+\underline{\nu}^{O}
\end{aligned}
$$

where $\wp_{N}=1-\beta \theta q$. Following the same arguments we develop in Section 3.3, one can show that $q \geq q^{F B}$. Moreover, for each value of $s$, there are thresholds $\underline{w}_{N}(s) \leq \bar{w}_{O}(s) \leq \bar{w}(s)$ (with strict inequalities if $q>q^{F B}$ ) such that: firms with $w \leq \underline{w}_{N}(s)$ invest only in old capital; firms with $w \in\left(\underline{w}_{N}(s), \bar{w}_{O}(s)\right)$ invest $\underline{k}(s)$ and invest in both new and old capital, and firms with $w \geq \bar{w}_{O}(s)$ invest only in new capital; firms with $w \geq \bar{w}(s)$ pay non-negative dividends and invest $\bar{k}(s) \geq k^{F B}(s) \geq \underline{k}(s)$.

We now show that the marginal equity issuance cost $\phi_{d}(w, s)$ (or equivalently the marginal value of net worth $\left.v_{w}(w, s)=1+\phi_{d}(w, s)\right)$ is weakly increasing in $s$, that is, higher productivity firms are more financially constrained, for a given level of net worth. 
First, consider firms that pay positive dividends. For these firms, $\phi_{d}(w, s)=0$.

Now consider firms with $\underline{\nu}^{N}>0$ and $\underline{\nu}^{O}=0$; for such firms rewrite equation (B16) as

$$
1+\phi_{d}\left(q k^{O}-w\right)=\beta \frac{s f_{k}\left(k^{O}\right)}{q}
$$

where we use $d_{0}=w-q k^{O}$; totally differentiating with respect to $s$, we obtain $\frac{d k^{O}}{d s}=$ $\frac{\beta f_{k}(s) q^{-1}}{q \phi_{d d}-\beta s f_{k k}(k) q^{-1}}>0$. Thus, $d_{0}$ is decreasing in $s$, which implies that $\phi_{d}(w, s)\left(\right.$ and $\left.v_{w}(w, s)\right)$ is increasing in $s$.

Next, consider firms with $\underline{\nu}^{N}=0$ and $\underline{\nu}^{O}=0$. In this case, combining equations (B16) and $(\mathrm{B} 17)$, we can write $1+\phi_{d}=\beta R_{O}$, where $R_{O}=\frac{(1-\theta) q}{\wp^{N}-q}$. Thus, all firms that are indifferent between new and old capital issue the same level of equity $\left(\underline{d}_{0}\right)$, and feature a constant marginal issuance cost $\bar{\phi}_{d}$, independent of productivity $s$. The total investment of such firms satisfies

$$
\wp^{N} R_{O}=s f_{k}(\underline{k}(s))+(1-\theta) q,
$$

which implies that $\underline{k}(s)$ is increasing in $s$. Hence, also the indifference thresholds $\underline{w}_{N}(s)=$ $\underline{d}_{0}+q \underline{k}(s)$ and $\bar{w}_{O}(s)=\underline{d}_{0}+\wp^{N} \underline{k}(s)$ are increasing in $s$.

Finally, for firms with $\underline{\nu}^{N}=0$ and $\underline{\nu}^{O}>0$, rewrite equation (B16) as

$$
1+\phi_{d}\left(\wp_{N} k^{N}-w\right)=\beta \frac{s f_{k}\left(k^{N}\right)+(1-\theta) q}{\wp_{N}} .
$$

Totally differentiating with respect to $s$, we obtain $\frac{d k^{N}}{d s}=\frac{\beta f_{k}(s) \wp_{N}^{-1}}{\wp_{N} \phi_{d d}-\beta s f_{k k}(k) \wp_{N}^{-1}}>0$. Thus, $d_{0}$ is decreasing in $s$, which implies that $\phi_{d}(w, s)$ is increasing in $s$. We conclude that $\phi_{d}(w, s)$ (and $v_{w}(w, s)$ ) is weakly increasing in productivity $s$ for all firms.

Constrained Efficiency. The planner maximizes

$$
\int\left[d_{10}(w, s)+\sum_{t=0}^{\infty} \beta^{t}\left(d_{0 t}(w, s)-\phi\left(-d_{0 t}(w, s)\right)+\beta d_{1, t+1}(w, s)\right)\right] d \pi(w, s)
$$

subject to the budget constraints (7) and (B13), the collateral constraint (9), and the market-clearing condition for old capital. The first-order condition with respect to $q_{t}$ is

$$
\int k_{t}^{O}(w, s)\left(1+\phi_{d, t}(w, s)\right) d \pi(w, s)=\int k_{t-1}^{N}(w, s)\left(1+\theta \lambda_{t-1}(w, s)\right) d \pi(w, s),
$$

which, in stationary equilibrium, can be rewritten as follows

$$
\int k^{O}(w, s) \phi_{d}(w, s) d \pi(w, s)=\theta \int k^{N}(w, s) \phi_{d}(w, s) d \pi(w, s)
$$


where we used the market-clearing condition, as well as the fact that planner optimally sets the marginal equity issuance cost equal to the multiplier on the collateral constraint.

We now show that in stationary competitive equilibrium, the left-hand side of equation (B18) is larger than the right-hand side, that is, the distributive externality dominates the collateral externality. We can bound the two sides of equation (B18) as follows. First, notice that the marginal equity issuance cost $\bar{\phi}_{d}$ is the lower bound for the marginal equity issuance cost of any firms with productivity $s$ purchasing old capital, and the upper bound for the marginal equity issuance cost of any firms with productivity $s$ purchasing new capital. Thus, for any productivity level $s$, we get

$$
\int_{w} k^{O}(w, s) \phi_{d}(w, s) d \pi(w, s) \geq \bar{\phi}_{d} \int_{w} k^{O}(w, s) d \pi(w, s)
$$

and

$$
\int_{w} k^{N}(w, s) \phi_{d}(w, s) d \pi(w, s) \leq \bar{\phi}_{d} \int_{w} k^{N}(w, s) d \pi(w, s)
$$

Next, recall that $\bar{\phi}_{d}$ is independent of $s$. Hence, by summing both sides of these two inequalities over productivity levels, we obtain

$$
\int k^{O}(w, s) \phi_{d}(w, s) d \pi(w, s) \geq \bar{\phi}_{d} \int k^{O}(w, s) d \pi(w, s)
$$

and

$$
\int k^{N}(w, s) \phi_{d}(w, s) d \pi(w, s) \leq \bar{\phi}_{d} \int k^{N}(w, s) d \pi(w, s) .
$$

The two bounds reported on the right-hand sides of these inequalities are equal to each other because of market clearing. Thus, $\theta<1$ implies

$$
\int k^{O}(w, s) \phi_{d}(w, s) d \pi(w, s)>\theta \int k^{N}(w, s) \phi_{d}(w, s) d \pi(w, s)
$$

which proves Proposition 4.

\section{B.3 Firm Life Cycle and Long-Lived Capital}

In this section, we discuss the model with a stochastic firm life cycle and long-lived capital from Section 4.3 in more detail and we prove Proposition 5.

Competitive Equilibrium with Financial Frictions. The expected present discounted 
value of dividends, net of equity issuance costs, of a firm born at time $t$ is

$$
\sum_{a=0}^{\infty} \beta^{a} \gamma_{a}\left[d_{a, t+a}-\phi\left(-d_{a, t+a}\right)\right]+\sum_{a=1}^{\infty} \beta^{a} \gamma_{a-1} \rho w_{a, t+a}
$$

where $d_{a t}$ are dividends of continuing firms of age $a$ at time $t$ and $w_{a t}$ is net worth. We leave implicit the dependence of allocations on initial firm net worth $w_{0}$ to simplify notation.

The dividend of a continuing firm satisfies the following budget constraint:

$$
d_{a t}=w_{a t}+b_{a t}-k_{a t}^{N}-q_{t} k_{a t}^{O}
$$

where $k_{a t}^{N}$ and $k_{a t}^{O}$ are investments in new and old capital, respectively, $q_{t}$ is the price of old capital, and $b_{a t}$ is debt. Firm net worth evolves as follows. For $a>0$, we have

$$
w_{a t}=f\left(k_{a-1, t-1}\right)+\left(1-\delta^{N}\left(1-q_{t}\right)\right) k_{a-1, t-1}^{N}+q_{t}\left(1-\delta^{O}\right) k_{a-1, t-1}^{O}-\beta^{-1} b_{a-1, t-1}
$$

where $k_{a-1, t-1}=k_{a-1, t-1}^{N}+k_{a-1, t-1}^{O}$ and $\beta^{-1}$ is the gross interest rate.

Firms face a collateral constraint, which states that debt cannot exceed a fraction $\theta$ of the resale value of new and old capital:

$$
\theta\left[\left(1-\delta^{N}\left(1-q_{t+1}\right)\right) k_{a t}^{N}+q_{t+1}\left(1-\delta^{O}\right) k_{a t}^{O}\right] \geq \beta^{-1} b_{a t}
$$

Denote the multiplier on the collateral constraint by $\beta^{t+1} \gamma_{a} \lambda_{a t}$ and on the non-negativity constraints for new and old capital by $\beta^{t} \gamma_{a} \nu_{a t}^{N}$ and $\beta^{t} \gamma_{a} \nu_{a t}^{O}$, and the marginal equity issuance cost by $\phi_{d, a t}$. The firm's optimality conditions for new capital, old capital, and debt, are

$$
\begin{aligned}
1+\phi_{d, a t}= & \beta\left[f_{k}\left(k_{a t}\right)+\left(1-\delta^{N}\left(1-q_{t+1}\right)\right)\right]\left(1+(1-\rho) \phi_{d, a+1, t+1}\right) \\
& +\beta \theta \lambda_{a t}\left(1-\delta^{N}\left(1-q_{t+1}\right)\right)+\underline{\nu}_{a t}^{N} \\
q_{t}\left(1+\phi_{d, a t}\right)= & \beta\left[f_{k}\left(k_{a t}\right)+\left(1-\delta^{O}\right) q_{t+1}\right]\left(1+(1-\rho) \phi_{d, a+1, t+1}\right) \\
& +\beta \theta \lambda_{a t}\left(1-\delta^{O}\right) q_{t+1}+\underline{\nu}_{a t}^{O} \\
\phi_{d, a t}= & (1-\rho) \phi_{d, a+1, t+1}+\lambda_{a t} .
\end{aligned}
$$

The market-clearing condition for old capital is

$$
\int \sum_{a=0}^{\infty} \gamma_{a}\left[\delta^{N} k_{a, t-1}^{N}+\left(1-\delta^{O}\right) k_{a, t-1}^{O}\right] d \pi_{0}\left(w_{0}\right)=\int \sum_{a=0}^{\infty} \gamma_{a} k_{a t}^{O} d \pi_{0}\left(w_{0}\right)
$$

We define a stationary competitive equilibrium writing the firm problem and the mar- 
ket clearing condition recursively. A stationary competitive equilibrium is a set of policy functions mapping net worth to an allocation, that is, dividends, investment, and borrowing choices for continuing firms, $\left\{d(w), k^{N}(w), k^{O}(w), b(w)\right\}$, a stationary distribution of net worth $\pi(w)$, and a price of old capital $q$, such that firms maximize the present discounted value of dividends net of equity issuance cost, $\forall w$, the stationary distribution is consistent with firms' policy functions, and the market for old capital clears, that is, $\int \delta^{N} k^{N}(w) d \pi(w)=\int \delta^{O} k^{O}(w) d \pi(w)$. Notice that the stationary distribution of net worth $\pi$ is an equilibrium object, whereas the distribution of net worth of new firms $\pi_{0}$ is taken as exogenous.

With long-lived capital, we define the down payment per unit of new and old capital as $\wp_{N} \equiv 1-\beta \theta\left(1-\delta^{N}(1-q)\right)$ and $\wp_{O} \equiv q\left(1-\beta \theta\left(1-\delta^{O}\right)\right)$, respectively, and the user cost of new and old capital to an unconstrained firm as $u_{N} \equiv 1-\beta\left(1-\delta^{N}(1-q)\right)$ and $u_{O} \equiv q\left(1-\beta\left(1-\delta^{O}\right)\right)$, respectively. Analogously to (15) and (16) we define the user cost of new and old capital to a firm with net worth $w$ as

$u_{N}(w) \equiv u_{N}+\frac{\lambda}{1+(1-\rho) \phi_{d}^{\prime}} \wp_{N}=1-\beta\left(1-\delta^{N}(1-q)\right)+\frac{\lambda}{1+(1-\rho) \phi_{d}^{\prime}}\left(1-\beta \theta\left(1-\delta^{N}(1-q)\right)\right)$

and

$$
u_{O}(w) \equiv u_{O}+\frac{\lambda}{1+(1-\rho) \phi_{d}^{\prime}} \wp_{O}=q\left(1-\beta\left(1-\delta^{O}\right)\right)+\frac{\lambda}{1+(1-\rho) \phi_{d}^{\prime}} q\left(1-\beta \theta\left(1-\delta^{O}\right)\right),
$$

respectively. The investment Euler equations for new and old capital are

$$
\begin{aligned}
& 1=\beta\left(\frac{1+(1-\rho) \phi_{d}^{\prime}}{1+\phi_{d}}\right) \frac{f_{k}(k)+\beta(1-\theta)\left(1-\delta^{N}(1-q)\right)}{\wp_{N}}+\frac{\underline{\nu}^{N} /\left(1+\phi_{d}\right)}{\wp_{N}} \\
& 1=\beta\left(\frac{1+(1-\rho) \phi_{d}^{\prime}}{1+\phi_{d}}\right) \frac{f_{k}(k)+\beta(1-\theta) q\left(1-\delta^{O}\right)}{\wp_{O}}+\frac{\underline{\nu}^{O} /\left(1+\phi_{d}\right)}{\wp_{O}} .
\end{aligned}
$$

Combining these two Euler equations we obtain

$$
1=\beta\left(\frac{1+(1-\rho) \phi_{d}^{\prime}}{1+\phi_{d}}\right) \frac{(1-\theta)\left(\left(1-\delta^{N}(1-q)\right)-q\left(1-\delta^{O}\right)\right)}{\wp_{N}-\wp_{O}}+\frac{\left(\underline{\nu}^{N}-\underline{\nu}^{O}\right) /\left(1+\phi_{d}\right)}{\wp_{N}-\wp_{O}} .
$$

To see that $q<1$ in a stationary equilibrium, suppose instead that $q \geq 1$; then $u_{O}>u_{N}$ and $\wp_{O}>\wp_{N}$, implying that old capital would be dominated. To see that $\wp_{N}>\wp_{O}$ in a stationary equilibrium, suppose instead that $\wp_{N} \leq \wp_{O}$; then, since $1-\delta^{N}(1-q)-q\left(1-\delta^{O}\right)=$ $\left(1-\delta^{N}\right)(1-q)+q \delta^{O}>0$, (B21) would imply that $\underline{\nu}^{O}>0$, that is, no firms would invest 
in old capital, a contradiction. Note that $\wp_{N}>\wp_{O}$ is equivalent to

$$
q<\frac{1-\beta \theta\left(1-\delta^{N}\right)}{1+\beta \theta \delta^{N}-\beta \theta\left(1-\delta^{O}\right)}<1 .
$$

To see that $u_{N} \leq u_{O}$ in a stationary equilibrium, note that otherwise $u_{N}(w)>u_{O}(w)$ for all firms, so there would not be any new investment, which cannot be an equilibrium. Further, $u_{N} \leq u_{O}$ is equivalent to

$$
q \geq q^{F B} \equiv \frac{1-\beta\left(1-\delta^{N}\right)}{1+\beta \delta^{N}-\beta\left(1-\delta^{O}\right)},
$$

that is, the price of old capital in competitive equilibrium must be weakly higher than the price of old capital in a frictionless economy.

Consider first firms for which $\lambda=0$. They invest $\bar{k}$ which solves $1=\beta \frac{f_{k}(\bar{k})+(1-\theta)\left(1-\delta^{N}(1-q)\right)}{\wp_{N}}$. Moreover $k^{N}=\bar{k}$ and $k^{O}=0$ if $q>q^{F B}$. Firms with $\lambda=0$ have net worth $w \geq \bar{w} \equiv \wp_{N} \bar{k}$.

Sufficiently constrained firms prefer old capital. Moreover, $k^{O}$ is strictly increasing in $w$ for such firms. To see this, first notice that the firm value function is concave, implying that the marginal value of net worth $1+\phi_{d}$ is weakly decreasing in net worth. Consider $w_{+}>w$ and assume $k_{+}^{O} \leq k^{O}$. Then $f\left(k_{+}^{O}\right) \leq f\left(k^{O}\right)$, and thus $w_{+}^{\prime} \leq w^{\prime}$ and $\phi_{d,+}^{\prime} \geq \phi_{d}^{\prime}$. Moreover, since $d_{+}>d$ and $d<0, \phi_{d}>\phi_{d,+}$, and thus $\frac{1+(1-\rho) \phi_{d,+}^{\prime}}{1+\phi_{d,+}}>\frac{1+(1-\rho) \phi_{d,+}^{\prime}}{1+\phi_{d}} \geq \frac{1+(1-\rho) \phi_{d}^{\prime}}{1+\phi_{d}}$; but then equation (B20) implies that $k_{+}^{O}>k^{O}$, a contradiction.

Consider now firms that are indifferent between investing in new and old capital. Let $R_{O} \equiv \frac{(1-\theta)\left(\left(1-\delta^{N}(1-q)\right)-q\left(1-\delta^{O}\right)\right)}{\wp^{N}-\wp^{O}}$. Since $q \geq q^{F B}, R^{O} \geq \beta^{-1}$ (with equality iff $q=q^{F B}$ ). For firms in the indifference region, we can write $(\mathrm{B} 21)$ as $1=\beta \frac{1+(1-\rho) \phi_{d}^{\prime}}{1+\phi_{d}} R_{O}$. For such firms, we can then write the investment Euler equation for new capital (B19) as

$$
1=R_{O}^{-1} \frac{f_{k}(k)+(1-\theta)\left(1-\delta^{N}(1-q)\right)}{\wp_{N}},
$$

implying that such firms all invest the same amount $\underline{k} \leq \bar{k}$. (If $q=q^{F B}$, then $\underline{k}=\bar{k}=k^{F B}$.) Moreover, in the indifference region, if $q>q^{F B}, k^{N}\left(k^{O}\right)$ is strictly increasing (decreasing) in net worth. To see this, assume the opposite were true. Then, $w^{\prime}$ would be (weakly) decreasing in $w$, and thus $\phi_{d}^{\prime}$ would be (weakly) increasing in $w$. Moreover, dividends $d=w-\wp^{N} k^{N}-\wp^{O}\left(\underline{k}-k^{N}\right)$ would be strictly increasing in $w$, implying that $\phi_{d}$ would be strictly decreasing in $w$, since in the indifference region $\frac{1+(1-\rho) \phi_{d}^{\prime}}{1+\phi_{d}}<1$ and hence $\phi_{d}>0$ $(d<0)$. This contradicts the fact that $\frac{1+(1-\rho) \phi_{d}^{\prime}}{1+\phi_{d}}$ is constant in the indifference region.

Firms that are indifferent between new and old capital have net worth $\underline{w}_{N} \leq w \leq$ $\bar{w}_{O} \leq \bar{w}$ and these thresholds are implicitly characterized as follows: $d\left(\underline{w}_{N}\right)=\underline{w}_{N}-\wp^{O} \underline{k}$, 
$w^{\prime}\left(\underline{w}_{N}\right)=f(\underline{k})+(1-\theta)\left(1-\delta^{O}\right) q \underline{k} ; d\left(\bar{w}_{O}\right)=\bar{w}_{O}-\wp_{N} \underline{k}, w^{\prime}\left(\bar{w}_{O}\right)=f(\underline{k})+(1-\theta)\left(1-\delta^{N}(1-\right.$ q)) $\underline{k}$; and $1=\beta \frac{1+(1-\rho) \phi_{d}^{\prime}}{1+\phi_{d}} R_{O}$.

If $q>q^{F B}$, for $w$ sufficiently close to $\bar{w}$ and $w<\bar{w}, k^{N}>0$ and $k^{O}=0$. Hence (B19) holds with $\underline{\nu}^{N}=0$. Moreover, $k^{N}$ is strictly increasing in $w$, following a similar argument by contradiction to the one developed above for firms that only purchase old capital.

Constrained Efficiency. The planner maximizes the present discounted value of aggregate dividends net of equity issuance costs

$$
\sum_{t=0}^{\infty} \beta^{t} \int\left[\sum_{a=0}^{\infty} \gamma_{a}\left[\left(d_{a t}-\phi\left(-d_{a t}\right)\right)\right]+\sum_{a=1}^{\infty} \gamma_{a-1} \rho w_{a t}\right] d \pi_{0}\left(w_{0}\right)
$$

subject to the transition for net worth, the collateral constraint and the market-clearing condition for old capital, with multiplier $\beta^{t} \eta_{t}$.

The optimality condition for the price of old capital is

$$
\begin{aligned}
& \int \sum_{a=0}^{\infty} \gamma_{a} k_{a t}^{O}\left(1+\phi_{d, a t}\right) d \pi_{0}\left(w_{0}\right)= \\
& \quad \int \sum_{a=0}^{\infty} \gamma_{a}\left[\delta^{N} k_{a, t-1}^{N}+\left(1-\delta^{O}\right) k_{a, t-1}^{O}\right]\left(1+(1-\rho) \phi_{d, a+1, t}+\theta \lambda_{a, t-1}\right) d \pi_{0}\left(w_{0}\right) .
\end{aligned}
$$

The summation on the left-hand side of equation (B22) represents the marginal cost of increasing the price $q_{t}$ for firms that purchase old capital. The summation on the righthand side represents the marginal benefit of increasing net worth for firms that own old capital, as well as the marginal effect of $q_{t}$ on the borrowing capacity of constrained firms at $t-1$.

We now prove that in the stationary competitive equilibrium the distributive externality is larger than the collateral externality, that is,

$$
\begin{aligned}
& \int \sum_{a=0}^{\infty} \gamma_{a} k_{a t}^{O}\left(1+\phi_{d, a t}\right) d \pi_{0}\left(w_{0}\right)> \\
& \int \sum_{a=0}^{\infty} \gamma_{a}\left[\delta^{N} k_{a, t-1}^{N}+\left(1-\delta^{O}\right) k_{a, t-1}^{O}\right]\left(1+(1-\rho) \phi_{d, a+1, t}+\theta \lambda_{a, t-1}\right) d \pi_{0}\left(w_{0}\right),
\end{aligned}
$$


or, written recursively,

$$
\begin{aligned}
& \int k^{O}(w)\left(1+\phi_{d}(w)\right) d \pi(w)> \\
& \qquad\left[\delta^{N} k^{N}(w)+\left(1-\delta^{O}\right) k^{O}(w)\right]\left(1+(1-\rho) \phi_{d}\left(w^{\prime}\right)+\theta \lambda(w)\right) d \pi(w)
\end{aligned}
$$

where $w^{\prime}$ denotes future net worth associated with current net worth $w$. Simplifying using the market-clearing condition, we have

$$
\int k^{O}(w) \phi_{d}(w) d \pi(w)>\int\left[\delta^{N} k^{N}(w)+\left(1-\delta^{O}\right) k^{O}(w)\right]\left((1-\rho) \phi_{d}\left(w^{\prime}\right)+\theta \lambda(w)\right) d \pi(w) .
$$

Using the first-order condition for debt to substitute out $\lambda(w)$, we obtain

$$
\begin{aligned}
& \int k^{O}(w) \phi_{d}(w) d \pi(w)> \\
& \qquad\left[\delta^{N} k^{N}(w)+\left(1-\delta^{O}\right) k^{O}(w)\right]\left(\theta \phi_{d}(w)+(1-\theta)(1-\rho) \phi_{d}\left(w^{\prime}\right)\right) d \pi(w)
\end{aligned}
$$

Notice that $\phi_{d}$ is weakly decreasing in net worth. Moreover, $\phi_{d}(w) \geq \theta \phi_{d}(w)+(1-$ $\theta)(1-\rho) \phi_{d}\left(w^{\prime}\right)$. Hence, if inequality (B23) holds (weakly) for $\theta=1$, it holds (strictly) for any $\theta<1$. Accordingly, we now prove the following inequality:

$$
\int k^{O}(w) \phi_{d}(w) d \pi(w) \geq \int\left[\delta^{N} k^{N}(w)+\left(1-\delta^{O}\right) k^{O}(w)\right] \phi_{d}(w) d \pi(w)
$$

which, rearranging, we can equivalently express as follows

$$
\delta^{O} \int k^{O}(w) \phi_{d}(w) d \pi(w) \geq \delta^{N} \int k^{N}(w) \phi_{d}(w) d \pi(w)
$$

As no firm invests in old capital above $\bar{w}_{O}$, market clearing implies:

$$
\delta^{O} \int^{\bar{w}_{O}} k^{O}(w) d \pi(w) \geq \delta^{N} \int_{\underline{w}_{N}}^{\bar{w}} k^{N}(w) d \pi(w) .
$$

Furthermore, we can bound the two sides of (B24) as follows. Since $\phi_{d}(w)$ is weakly decreasing in $w$,

$$
\int^{\underline{w}_{N}} k^{O}(w) \phi_{d}(w) d \pi(w) \geq \phi_{d}\left(\underline{w}_{N}\right) \int^{\underline{w}_{N}} k^{O}(w) d \pi(w) .
$$

In the region of indifference between new and old capital, i.e., between $\underline{w}_{N}$ and $\bar{w}_{O}$, if there 
is positive mass, we apply the following result: $\mathbb{E}\left[k^{O} \phi_{d}\right]=\mathbb{C} \mathbb{O V}\left(k^{O}, \phi_{d}\right)+\mathbb{E}\left[k^{O}\right] \mathbb{E}\left[\phi_{d}\right]$. Since $k^{O}$ and $\phi_{d}$ are both decreasing in $w$, we have $\mathbb{C O V}\left(k^{O}, \phi_{d}\right) \geq 0 .{ }^{35}$ Thus,

$$
\int_{\underline{w}_{N}}^{\bar{w}_{O}} k^{O}(w) \phi_{d}(w) d \pi(w) \geq \bar{\phi}_{d} \int_{\underline{w}_{N}}^{\bar{w}_{O}} k^{O}(w) d \pi(w)
$$

where $\bar{\phi}_{d} \equiv \int_{\underline{w}_{N}}^{\bar{w}_{O}} \phi_{d}(w) d \pi(w) / \int_{\underline{w}_{N}}^{\bar{w}_{O}} d \pi(w)$. Since $\phi_{d}\left(\underline{w}_{N}\right) \geq \bar{\phi}_{d}$, we can combine (B26) and (B27) and get

$$
\int^{\bar{w}_{O}} k^{O}(w) \phi_{d}(w) d \pi(w) \geq \bar{\phi}_{d} \int^{\bar{w}_{O}} k^{O}(w) d \pi(w) .
$$

Analogously, since $k^{N}$ is increasing in $w$, we obtain

$$
\int_{\underline{w}_{N}}^{\bar{w}} k^{N}(w) \phi_{d}(w) d \pi(w) \leq \bar{\phi}_{d} \int_{\underline{w}_{N}}^{\bar{w}} k^{N}(w) d \pi(w) .
$$

Notice that our characterization of the stationary equilibrium implies $\int_{\bar{w}_{O}} k^{O}(w) \phi_{d}(w) d \pi(w)=$ $\int_{\bar{w}} k^{N}(w) \phi_{d}(w) d \pi(w)=0$. Hence, combining (B25), (B28), and (B29), we get

$$
\delta^{O} \int k^{O}(w) \phi_{d}(w) d \pi(w) \geq \delta^{N} \int k^{N}(w) \phi_{d}(w) d \pi(w)
$$

which, given $\theta<1$, proves Proposition 5 .

If there is no mass between $\underline{w}_{N}$ and $\bar{w}_{O}$, Proposition 5 obtains more directly because financially constrained firms investing in old capital have $\phi_{d} \geq \phi_{d}\left(\underline{w}_{N}\right)$, all firms investing in new capital have $\phi_{d} \leq \phi_{d}\left(\bar{w}_{O}\right)$, and $\phi_{d}\left(\underline{w}_{N}\right)>\phi_{d}\left(\bar{w}_{O}\right)$.

\section{B.4 Current Price in the Collateral Constraint}

To microfound the presence of the current price of old capital in the collateral constraint, we assume that firms can default on their debt at the beginning of the period, before production occurs. In the case of default, they can abscond a fraction $(1-\theta)$ of their assets and there is no exclusion from asset or financial markets.

Under these assumptions, the collateral constraint is

$$
\theta\left(k_{t}^{N}+q_{t} k_{t}^{O}\right) \geq b_{t}
$$

with multiplier $\lambda_{t}$. As in Bianchi and Mendoza (2018), current asset prices determine the current borrowing capacity. However, different from their setup, it is the choice of

\footnotetext{
${ }^{35}$ See Schmidt (2003) for a proof of this result.
} 
investment at date $t$ that firms pledge as collateral, instead of the capital owned at the beginning of date $t$. We make this small departure from their assumptions to preserve the property of our model that firms' net worth is a sufficient state variable. Bianchi and Mendoza (2018) argue that their mechanism is robust to a formulation like ours, where the collateral constraint depends on the choice of asset level at date $t$.

The first-order conditions of the firm problem with respect to new capital, old capital, and debt are

$$
\begin{aligned}
1+\phi_{d, t} & =\beta\left[f_{k}\left(k_{t}\right)+q_{t+1}\right]+\theta \lambda_{t}+\underline{\nu}_{t}^{N} \\
q_{t}\left(1+\phi_{d, t}\right) & =\beta f_{k}\left(k_{t}\right)+\theta \lambda_{t} q_{t}+\underline{\nu}_{t}^{O},
\end{aligned}
$$

and (12), respectively.

In stationary equilibrium, the expressions for user costs and down payments are as follows: $u_{N}=1-\beta q, u_{O}=q, \wp_{N}=1-\theta$, and $\wp_{O}=q(1-\theta)$. We can thus rewrite the investment Euler equations as follows:

$$
\begin{aligned}
& u_{N}+\phi_{d \wp_{N}}=1-\beta q+\phi_{d}(1-\theta) \geq \beta f_{k}(k) \\
& u_{O}+\phi_{d \wp_{O}}=q+\phi_{d} q(1-\theta) \geq \beta f_{k}(k) .
\end{aligned}
$$

Moreover, combining the optimality conditions for new and old capital, we have

$$
1=\frac{(\theta+\beta) q-\theta}{\left(1+\phi_{d}\right)\left(\wp_{N}-\wp_{O}\right)}+\frac{\underline{\nu}^{N}-\underline{\nu}^{O}}{\left(1+\phi_{d}\right)\left(\wp_{N}-\wp_{O}\right)} .
$$

The price of old capital must be such that $q<1$ or, equivalently, $\wp_{N}>\wp_{O}$, otherwise all firms would invest in new capital. Hence, in order for some firms to invest in new capital, it must be that $u_{N} \leq u_{O} \Leftrightarrow q \geq \frac{1}{1+\beta}$.

Notice that the numerator of the first fraction on the right-hand side is positive, because $\frac{\theta}{\theta+\beta}<\frac{1}{1+\beta}$. Hence, equation (B30) implies that sufficiently constrained firms invest only in old capital. Firms that pay dividends weakly prefer new capital, and strictly so if $q>\frac{1}{1+\beta}$. Define $R_{O} \equiv \beta^{-1} \frac{(\theta+\beta) q-\theta}{\wp_{N}-\wp_{O}}$. Firms that are indifferent between new and old capital must have $\beta \frac{1}{1+\phi_{d}}=R_{O}^{-1}$ (from (B30)) and invest $\underline{k}$, which solves $1=R_{O}^{-1} \frac{f_{k}(\underline{k})+q-\beta^{-1} \theta}{\wp_{N}}$, where $\underline{k} \leq k^{F B}$ with equality iff $q=q^{F B}$. Firms are indifferent between new and old capital at the margin if $w \in\left(\underline{w}_{N}, \bar{w}_{O}\right)$, where $\underline{w}_{N}=\underline{d}_{0}+\wp_{O} \underline{k}$ and $\bar{w}_{O}=\underline{d}_{0}+\wp_{N} \underline{k}, \underline{d}_{0}=0$ if $q=q^{F B}$, and $\underline{d}_{0}$ solves $1+\phi_{d}=\beta R_{O}$ if $q>q^{F B}$.

Constrained Efficiency. The planner's first-order condition with respect to $q_{t}$ for $t=$ 
$1,2, \ldots$ is

$$
\int k_{t}^{O}\left(1+\phi_{d, t}\right) d \pi=\int k_{t-1}^{N} d \pi+\theta \int k_{t}^{O} \phi_{d, t} d \pi .
$$

Different from our baseline formulation with the future price in the collateral constraint, in this model a marginal change in $q_{t}$ affects both budget constraints and collateral constraints at date $t$. Using the market-clearing condition for old capital and rearranging, we get

$$
(1-\theta) \int k_{t}^{O} \phi_{d, t} d \pi=0 .
$$

In stationary competitive equilibrium, the left-hand side of equation (B31) is strictly positive as long as a positive mass of firms is financially constrained. Hence, also under these assumptions on the collateral constraint, the distributive externality dominates the collateral externality, showing that the main insight of our paper does not depend on specific timing assumptions related to limited enforcement.

\section{B.5 Relation to Models with Representative Entrepreneur and Assets in Fixed Supply}

In this section, we connect our results on constrained efficiency in capital reallocation with a related class of models, that feature a representative infinitely-lived entrepreneur subject to collateral constraints, possibly impatient relative to the equilibrium interest rate, and with an asset in fixed supply, which we will refer to as land. This class of models includes the seminal work of Kiyotaki and Moore (1997) (henceforth KM) and the small-open-economy models with collateral constraints analyzed by Bianchi and Mendoza (2018) and Jeanne and Korinek (2019). While there is some variation in the specification of collateral constraints across these papers, we maintain our formulation of collateral constraints that depend on future asset prices, as in KM and Rampini and Viswanathan (2010, 2013).

First, we show that the representative-entrepreneur assumption in this class of models implies that there is no reallocation of land in stationary equilibrium. This lack of reallocation precludes any distributive effects of asset prices: As Dávila and Korinek (2018) show, distributive externalities depend on (i) heterogeneity in the marginal valuation of resources, and (ii) non-zero equilibrium trading. ${ }^{36}$ We also connect this insight to the effects of unexpected changes in collateral values described by KM.

Second, we show that the fact that land is in fixed supply in these models, different from capital, which is endogenously produced in our model, does not affect the main insights on

\footnotetext{
${ }^{36}$ This insight is also related to arguments developed in Stiglitz (1982) and Geanakoplos and Polemarchakis (1986), showing that incomplete-markets equilibria with no trading can be constrained efficient.
} 
distributive externalities vs. collateral externalities in reallocation at the core of our paper. To illustrate this point, we recover a version of our main result on inefficiency in a model of land reallocation with overlapping generations of entrepreneurs - and hence reallocation in stationary equilibrium. Finally, we use this model to briefly discuss the role of impatience for the comparison of distributive and collateral externalities.

\section{B.5.1 Representative Entrepreneur without Reallocation}

We now describe an economy with a representative entrepreneur and a representative lender. The entrepreneur can be interpreted as the "farmer" in KM, or, alternatively, as the representative household residing in a small open economy. The lender can be interpreted as the "gatherer" in KM, or, alternatively, as a representative household in the rest of the world in small-open-economy models.

Model. A representative entrepreneur has preferences represented by the utility function

$$
\sum_{t=0}^{\infty} \beta^{t} u\left(c_{t}\right)
$$

where $\beta<1$ is the discount factor, $c_{t}$ is consumption, $u_{c}>0$, and $u_{c c}<0$. The entrepreneur has access to a technology $y_{t}=f\left(k_{t-1}\right)$ with $f_{k}>0, f_{k k}<0$, and $\lim _{k \rightarrow 0} f_{k}(k)=+\infty$, where $y_{t}$ is output and $k_{t-1}$ is land.

A representative lender has preferences represented by the following utility function

$$
\sum_{t=0}^{\infty} R^{-t} c_{t}^{l}
$$

where $R \in\left(1, \beta^{-1}\right]$ is the inverse of the discount factor and $c_{t}^{l}$ is consumption. The lender has access to a technology $y_{t}^{l}=f^{l}\left(k_{t-1}^{l}\right)$ with $f_{k}^{l} \geq 0$ and $f_{k k}^{l} \leq 0$, where $y_{t}^{l}$ is output and $k_{t-1}^{l}$ is land. The case of a small open economy corresponds to lenders having an exogenous endowment, and not operating land, that is, $f^{l}\left(k_{t-1}^{l}\right)=\bar{y}^{l}>0$.

The resource constraint of the economy is $c_{t}+c_{t}^{l}=y_{t}+y_{t}^{l}$. Land is in exogenous fixed supply, $K=k_{t}+k_{t}^{l}$. Entrepreneur and lender can trade land at price $q_{t}$ as well as a oneperiod bond $b_{t}$. Because of our assumptions on preferences, the gross interest rate is given by $R$. The budget constraints of entrepreneur and lender are as follows:

$$
\begin{aligned}
y_{t}+b_{t} & =c_{t}+q_{t}\left(k_{t}-k_{t-1}\right)+R b_{t-1} \\
y_{t}^{l}+R b_{t-1} & =c_{t}^{l}+q_{t}\left(k_{t}^{l}-k_{t-1}^{l}\right)+b_{t} .
\end{aligned}
$$

Notice that our notation implicitly imposes equilibrium in the bond market, and we inter- 
pret a positive value of $b_{t}$ as debt for the entrepreneur and assets for the lender.

The entrepreneur is also subject to the following collateral constraint

$$
\theta q_{t+1} k_{t} \geq R b_{t}
$$

which limits borrowing to a fraction $\theta<1$ of the future resale value of the entrepreneur's land.

We define the Lagrangian of the entrepreneur's problem as follows

$$
\mathcal{L} \equiv \sum_{t=0}^{\infty} \beta^{t}\left\{u\left(c_{t}\right)+\mu_{t}\left(f\left(k_{t-1}\right)+b_{t}-c_{t}-q_{t}\left(k_{t}-k_{t-1}\right)-R b_{t-1}\right)+\beta \lambda_{t}\left(\theta q_{t+1} k_{t}-R b_{t}\right)\right\}
$$

where $\beta^{t} \mu_{t}$ and $\beta^{t+1} \lambda_{t}$ denote the multipliers on the budget constraint (B33) and the collateral constraint (B35), respectively.

The entrepreneur's optimality conditions with respect to land and debt are respectively

$$
\begin{aligned}
q_{t} u_{c}\left(c_{t}\right) & =\beta u_{c}\left(c_{t+1}\right)\left(f_{k}\left(k_{t}\right)+q_{t+1}\right)+\beta \lambda_{t} \theta q_{t+1} \\
u_{c}\left(c_{t}\right) & =\beta R u_{c}\left(c_{t+1}\right)+\beta R \lambda_{t} .
\end{aligned}
$$

The lender maximizes utility (B32) subject to the budget constraint (B34) and a nonnegativity constraint on land holdings, with multiplier $R^{-t} \underline{\nu}_{t}^{l}$. The lender's optimality condition with respect to land is

$$
q_{t}=R^{-1}\left(f_{k}^{l}\left(k_{t}^{l}\right)+q_{t+1}\right)+\underline{\nu}_{t}^{l}
$$

A stationary competitive equilibrium is defined as a time-invariant allocation $\left\{c, c^{l}, k, k^{l}, b\right\}$ and a price of land $q$ that satisfy the entrepreneur's and lender's optimality conditions, as well as the market-clearing condition $K=k+k^{l}$.

Constrained Efficiency. To analyze the constrained-efficiency properties of the stationary competitive equilibrium, we now consider the marginal effect of a change in the price of land on welfare. For simplicity, we consider a planner who assigns zero weight on the lender's utility; our insights are unchanged if we allow for a positive weight on the lender. The derivative of the entrepreneur's Lagrangian with respect to $q_{t}$ is

$$
\frac{\partial \mathcal{L}}{\partial q_{t}}=-\beta^{t} \mu_{t}\left(k_{t}-k_{t-1}\right)+\beta^{t} \lambda_{t-1} \theta k_{t}
$$

In stationary equilibrium, the first term is equal to zero, because the amount of land owned by the entrepreneur is constant, whereas the second term is weakly positive, and strictly 
so if the collateral constraint is binding. In this case, the only pecuniary externality is the collateral externality, and an increase in the price of land would lead to an increase in welfare by relaxing the collateral constraint. An equivalent way to formulate this insight is to observe that even though cheaper land at date $t$, taking as given the price at $t+1$, would seemingly benefit the entrepreneur by reducing the cost of investment at $t$, it would at the same time decrease the value of the entrepreneur's net worth by the same amount. Furthermore, it would make the collateral constraint tighter at date $t-1$, resulting in an overall negative effect.

This result arises because there is no net trading of land in stationary equilibrium, so no equilibrium capital reallocation. Clearly, even if the planner assigned positive weight to the lender's utility, there would be no distributive externality, as the lender's amount of land is also constant. This model may feature misallocation in stationary equilibrium, if, as in KM, the financial friction induces an allocation such that $f_{k}(k)>f_{k}^{l}\left(k^{l}\right)$. However, the model does not feature reallocation, in the sense that land is not traded in stationary equilibrium, resulting in no effect of the price of land on budget constraints, and thus no distributive externality.

Relation to the KM mechanism. To connect our efficiency analysis to the effects of asset-price changes in the KM model, we can rearrange equation (B35) as follows, after substituting out debt $b_{t}$ from the budget constraint (B33):

$$
\left(q_{t}-R^{-1} \theta q_{t+1}\right) k_{t}-q_{t} k_{t-1}-f\left(k_{t-1}\right)+R b_{t-1}+c_{t} \leq 0
$$

or, equivalently,

$$
k_{t} \leq \frac{1}{\left(q_{t}-R^{-1} \theta q_{t+1}\right)}\left(w_{t}-c_{t}\right),
$$

where $w_{t} \equiv q_{t} k_{t-1}+f\left(k_{t-1}\right)-R b_{t-1}$ denotes the entrepreneur's net worth, which, importantly, also depends on the price of land.

Constraints (B37) and (B38) correspond to equations (4) and (7) in KM (pages 219 and 220 , respectively), which hold with equality in their model, determining the law of motion of the entrepreneur's land, whenever the collateral constraint is binding. ${ }^{37} \mathrm{KM}$ consider the following thought experiment: What would the effect of an unexpected increase in the current and future price of land on this constraint be? Notice that this marginal effect is different from the derivative (B36), which accounts for the effects of current prices on past debt, and moreover treats the price at each date as a distinct variable. Nevertheless, to consider the KM thought experiment, we assume there are two consecutive dates such that

\footnotetext{
${ }^{37}$ Under the technology assumption in $\mathrm{KM}$, consumption $c_{t}$ is a constant fraction of output, labeled as "perishable" output. Moreover, KM focus on the case in which $\theta=1$.
} 
$q_{t}=q_{t+1}=q$ and differentiate both sides of inequality (B37) with respect to $q$. We denote this derivative by $\Delta^{K M}$, and obtain

$$
\Delta^{K M}=\left(1-R^{-1} \theta\right) k_{t}-k_{t-1}
$$

As KM argue, as long as the constraint is binding and $f\left(k_{t-1}\right)-R b_{t-1}-c_{t}<0$, that is, as long as there is sufficient leverage, we have $\Delta^{K M}<0$, implying that an increase in the price of land would relax the collateral constraint, even after accounting for the effects of the price on the budget constraint. In stationary equilibrium, we have $\Delta^{K M}=-R^{-1} \theta k<0$, because, as we argued, the effects of the price of land on the budget constraint other than through the collateral constraint cancel out, as the entrepreneur is keeping a constant amount of land.

We conclude that the collateral externality is the only pecuniary externality in the stationary equilibrium of this model, and this insight about efficiency is closely related to the fact that an unexpected change in current and future collateral values, as analyzed by KM, relaxes the collateral constraint.

\section{B.5.2 Heterogeneous Entrepreneurs and Reallocation}

We now consider a modification of this model and show how to recover our main insights on the importance of distributive externalities. Specifically, instead of assuming an infinitelylived representative entrepreneur, we consider over-lapping generations of entrepreneurs, as in Section 4.1 (and as KM consider in the appendix of their paper), which introduces heterogeneity among entrepreneurs and reallocation in equilibrium.

Model. For simplicity, we assume that entrepreneurs live for two dates and that all entrepreneurs are endowed with a common initial level of net worth $w$. We maintain all other assumptions from the model in the previous subsection, namely an infinitely-lived lender with linear preferences and a productive asset in fixed supply.

The representative entrepreneur born at date $t$ has utility

$$
u\left(c_{0 t}\right)+\beta u\left(c_{1, t+1}\right)
$$

with $\beta \leq R^{-1}, u_{c}>0$, and $u_{c c}<0$. The budget constraints are

$$
\begin{aligned}
w+b_{t} & =c_{0 t}+q_{t} k_{t} \\
f\left(k_{t}\right)+q_{t+1} k_{t} & =c_{1, t+1}+R b_{t-1},
\end{aligned}
$$

and the collateral constraint is given by equation (B35) as before. 
The optimality conditions with respect to land and debt are respectively

$$
\begin{aligned}
q_{t} u_{c}\left(c_{0 t}\right) & =\beta u_{c}\left(c_{1, t+1}\right)\left(f_{k}\left(k_{t}\right)+q_{t+1}\right)+\beta \lambda_{t} \theta q_{t+1} \\
u_{c}\left(c_{0 t}\right) & =\beta R u_{c}\left(c_{1, t+1}\right)+\beta R \lambda_{t} .
\end{aligned}
$$

where, again, $\beta \lambda_{t}$ denotes the multiplier on the collateral constraint. Notice that in this model there is always net trading of land, with young entrepreneurs being buyers and old entrepreneurs being sellers.

A stationary competitive equilibrium is defined as a time-invariant allocation $\left\{c_{0}, c_{1}, c^{l}, k, k^{l}, b\right\}$ and a price of land $q$ that satisfy the entrepreneurs' and lender's optimality conditions, as well as the market-clearing condition $K=k+k^{l}$.

Constrained Efficiency. As in Section 4.1 and Online Appendix B.1, we consider a planner who maximizes the present discounted value of utilities of all generations of entrepreneurs, with discount factor $\beta$

$$
u\left(c_{10}\right)+\sum_{t=0}^{\infty} \beta^{t}\left(u\left(c_{0 t}\right)+\beta u\left(c_{1, t+1}\right)\right)
$$

subject to all budget constraints, collateral constraints, and market-clearing conditions.

The marginal effect of the price of land $q_{t}$ on aggregate welfare is given by

$$
-\beta^{t}\left(u_{c}\left(c_{0 t}\right)-u_{c}\left(c_{1 t}\right)\right) k_{t}+\beta^{t} \lambda_{t-1} \theta k_{t} .
$$

The two marginal-utility terms represent the distributive externality, due to the fact that young entrepreneurs buy land, whereas old entrepreneurs sell land in equilibrium. Thus, as long as they have different marginal utility from consumption, the aggregate distributive effect of a price change is non-zero. The last term involving the multiplier $\lambda_{t-1}$ denotes the collateral externality, because the price of land affects the collateral constraint in the previous period.

Using equation (B40) to substitute out $\lambda_{t-1}$, this expression can be rewritten as

$$
-\beta^{t}\left[\left(u_{c}\left(c_{0 t}\right)-u_{c}\left(c_{1 t}\right)\right)-\beta^{-1} R^{-1} \theta\left(u_{c}\left(c_{0, t-1}\right)-\beta R u_{c}\left(c_{1 t}\right)\right)\right] k_{t} .
$$

Case $\beta=R^{-1}$. We now show that under the baseline assumption on discounting in our paper, which is $\beta=R^{-1}$, this derivative is negative in stationary equilibrium, because buyers of land have a higher marginal utility than sellers, and moreover the distributive externality dominates the collateral externality. To see this, observe that $\beta=R^{-1}$ and 
equation (B40) imply $u_{c}\left(c_{0}\right)-u_{c}\left(c_{1}\right) \geq 0$. Furthermore, the expression in (B41) becomes

$$
-\beta^{t}\left(u_{c}\left(c_{0}\right)-u_{c}\left(c_{1}\right)\right)(1-\theta) k \leq 0
$$

with strict inequality if the collateral constraint binds. Thus, when $\beta=R^{-1}$, introducing heterogeneity and equilibrium reallocation in the model with assets in fixed supply overturns the result on the sign of inefficiency obtained in representative-entrepreneur models. The distributive externality dominates the collateral externality, consistent with the main insight in our model with endogenous investment.

Case $\beta<R^{-1}$. We now discuss the role of impatience for pecuniary externalities in the reallocation of land. In the case of relatively impatient entrepreneurs, that is, $\beta<R^{-1}$, we cannot sign the aggregate welfare effect of the price of land unambiguously in general. First, notice that under sufficient impatience, equation (B40) is consistent with young entrepreneurs having a lower marginal utility than old entrepreneurs. Second, notice that, as equation (B41) highlights, the distributive externality from the price $q_{t}$ generates an aggregate welfare effect at date $t$, whereas the collateral externality relaxes a constraint at date $t-1$. When $\beta=R^{-1}$, this timing difference is exactly offset by the discounting of the value of collateral in the collateral constraint. In contrast, when $\beta<R^{-1}$, the difference in timing between the two externalities implies that the collateral externality is relatively more important, other things equal, as reflected by the factor $\beta^{-1} R^{-1}>1$ that multiplies the corresponding terms in equation (B41).

\section{B.6 Obtaining the Opposite Sign of Inefficiency}

We have proved that the distributive externality dominates the collateral externality in stationary equilibrium in a large class of models. Both to highlight the role of several assumptions that lead to this result and to further relate to the large literature on pecuniary externalities, which in some cases obtains the opposite sign of inefficiency, we now show how one can modify our model to overturn our main efficiency result.

Specifically, we present three models. In the first model, the point of departure is the model with long-lived new and old capital, but we modify the assumptions on collateralizability of new and old capital. In the second and third model, the point of departure is the model with risk-averse entrepreneurs, but in one case we modify the assumptions on discount rates and the interest rate and in the other case we introduce saving constraints. 


\section{B.6.1 Role of Collateralizability}

We consider the model of Section 4.3 with long-lived new and old capital. However, we generalize the model, by allowing for a different collateralizability parameter for new and old capital. Specifically, let $\theta^{N}$ be the collateralizability parameter for new capital and $\theta^{O}$ for old capital. Notice that our baseline assumption in Section 4.3 is $\theta^{N}=\theta^{O}$. We further assume $\delta^{O}<1$ and, for simplicity, $\rho=1$, that is, firms are only alive at two dates.

We show that if new capital serves as sufficiently better collateral than old capital, then it is possible that the collateral externality dominates the distributive externality. In particular, to obtain a stark characterization, we focus on the case $\theta^{N}=1$ and $\theta^{O}=0$, that is, new capital can by fully pledged, whereas old capital cannot serve as collateral.

In this case, the firm's optimality conditions for new capital, old capital, and debt, are

$$
\begin{aligned}
1+\phi_{d, a t} & =\beta\left[f_{k}\left(k_{a t}\right)+\left(1-\delta^{N}\left(1-q_{t+1}\right)\right)\right]+\beta \lambda_{a t}\left(1-\delta^{N}\left(1-q_{t+1}\right)\right)+\underline{\nu}_{a t}^{N} \\
q_{t}\left(1+\phi_{d, a t}\right) & =\beta\left[f_{k}\left(k_{a t}\right)+\left(1-\delta^{O}\right) q_{t+1}\right]+\underline{\nu}_{a t}^{O} \\
1+\phi_{d, a t} & =1+\lambda_{a t} .
\end{aligned}
$$

The definitions of user cost and down payment are as follows: $u_{N}=1-\beta\left(1-\delta^{N}(1-q)\right)$, $u_{O}=q\left(1-\beta\left(1-\delta^{O}\right)\right), \wp_{N}=1-\beta\left(1-\delta^{N}(1-q)\right)$, and $\wp_{O}=q$. The investment Euler equations for new and old capital can be expressed as follows

$$
\begin{aligned}
& u_{N}+\phi_{d \wp_{N}} \geq \beta f_{k}(k) \\
& u_{O}+\phi_{d \wp_{O}} \geq \beta f_{k}(k) .
\end{aligned}
$$

Furthermore, combining the two investment Euler equations, we have

$$
1=\beta \frac{\left(1-\delta^{O}\right) q}{\left(1+\phi_{d}\right)\left(\wp_{O}-\wp_{N}\right)}+\frac{\underline{\nu}^{O}-\underline{\nu}^{N}}{\left(1+\phi_{d}\right)\left(\wp_{O}-\wp_{N}\right)} .
$$

If $\wp_{O} \leq \wp_{N}$, then $\underline{\nu}^{N}>0$, so no firm invests in new capital, which cannot be true in equilibrium. Therefore, $\wp_{O}>\wp_{N}$, or, equivalently,

$$
q>\frac{1-\beta\left(1-\delta^{N}\right)}{1+\beta \delta^{N}} .
$$

Equations (B42) and (B43) then imply $u_{N} \geq u_{O}$, as otherwise no firm would buy old capital, which cannot be true in equilibrium; equivalently, $q \leq q^{F B}=\frac{1-\beta\left(1-\delta^{N}\right)}{1+\beta \delta^{N}-\beta\left(1-\delta^{O}\right)}$.

Because new capital has a (weakly) higher user cost than old capital, but requires a lower down payment, the induced preference for new vs. old capital as a function of net 
worth is the opposite of that in our baseline model with $\theta^{N}=\theta^{O}=\theta$. In particular, more financially constrained firms invest in new capital and less financially constrained firms in old capital.

Consider first firms for which $\lambda=0$. They invest $\bar{k}$ which solves $q\left(1-\beta\left(1-\delta^{O}\right)\right)=$ $\beta f_{k}(\bar{k})$. Moreover, if $q<q^{F B}$, they set $k^{O}=\bar{k}$ and $k^{N}=0$. Firms with $\lambda=0$ have net worth $w \geq \bar{w} \equiv \wp_{O} \bar{k}$. Sufficiently constrained firms compare down payments and thus strictly prefer new capital. Consider now firms that are indifferent between investing in new and old capital. Let $R_{N} \equiv \frac{\left(1-\delta^{O}\right) q}{\left(1+\phi_{d}\right)\left(\wp_{O}-\wp_{N}\right)}$. These firms invest $\underline{k}$, which solves $q=R_{N}^{-1}\left(f_{k}(\underline{k})+\left(1-\delta^{O}\right) q\right)$. Because all indifferent firms have the same marginal value of net worth $1+\bar{\phi}_{d}$, and thus pay the same (negative) dividend, and old capital has a higher down payment than new capital, it follows that in the indifference region investment in new (old) capital is decreasing (increasing) in net worth.

Constrained Efficiency. The planner's optimality condition for the price of old capital is

$$
\int k_{t}^{O}\left(1+\phi_{d, t}\right) d \pi(w)=\int\left[\delta^{N} k_{t-1}^{N}\left(1+\lambda_{t-1}\right)+\left(1-\delta^{O}\right) k_{t-1}^{O}\right] d \pi(w) .
$$

Writing this condition with recursive notation in stationary equilibrium and using the market-clearing condition for old capital and substituting the multiplier on the collateral constraint out, we get

$$
\int k^{O}(w) \phi_{d}(w) d \pi(w)=\int \delta^{N} k^{N}(w) \phi_{d}(w) d \pi(w)
$$

We now show that for sufficiently large $\delta_{N}$, in stationary equilibrium the collateral externality is larger than the distributive externality, that is,

$$
\int k^{O}(w) \phi_{d}(w) d \pi(w) \leq \delta^{N} \int k^{N}(w) \phi_{d}(w) d \pi(w)
$$

Consider the case $\delta^{N} \leq \delta^{O}$. Then, market clearing for old capital implies $\int k^{N}(w) d \pi(w) \geq$ $\int k^{O}(w) d \pi(w)$. Using the same arguments developed in Online Appendix B.3 and the characterization of equilibrium that we derived above, we get

$$
\int k^{O}(w) \phi_{d}(w) d \pi(w)<\int k^{N}(w) \phi_{d}(w) d \pi(w)
$$

because only sufficiently constrained firms $\left(\phi_{d} \geq \bar{\phi}_{d}\right)$ purchase new capital, only sufficiently unconstrained firms $\left(\phi_{d} \leq \bar{\phi}_{d}\right)$ purchase old capital, and aggregate new capital is at least as large as aggregate old capital.

By continuity, for sufficiently large $\delta^{N}$, we obtain inequality (B44). Specifically, this 
result arises for $\delta^{N}=1-\epsilon, \delta^{O}=1-\frac{\epsilon}{\kappa}, \kappa \geq 1$, and $\epsilon>0$ sufficiently small.

Finally, we highlight that we have focused on the case $\theta^{N}=1$ and $\theta^{O}=0$, but our results can be generalized to sufficiently high $\theta^{N}$ and sufficiently low $\theta^{O}$. Overall, if new capital serves as sufficiently better collateral then old capital, it is possible that financially constrained firms prefer new capital and, as a result, the collateral externality may dominate the distributive externality.

\section{B.6.2 Role of Discounting}

We now consider the model with risk-averse entrepreneurs of Section 4.1. However, we generalize the model to allow for different discount rates for planner and entrepreneurs, as well as a generic value for the interest rate, not necessarily tied to entrepreneurs' discount factor.

Specifically, let $\beta$ be entrepreneurs' discount factor, $R \leq \beta^{-1}$ the gross interest rate entrepreneurs can borrow or lend at, and $\xi$ the planner's discount factor for the utility of each generation. Notice that our baseline assumption in Section 4.1 is $\beta=R^{-1}=\xi$.

Given their initial net worth $w$ and the price of old capital $q_{t}$, entrepreneurs maximize their utility (B1) by choosing consumption $c_{0 t}$ and $c_{1, t+1}$, new and old capital $k_{t}^{N}$ and $k_{t}^{O}$, and borrowing $b_{t}$, to with the utility function $u$ satisfying $u_{c}>0, u_{c c}<0$, and $\lim _{c \rightarrow 0} u_{c}(c)=+\infty$, subject to the budget constraints for the current and next period, (B2) and

$$
f\left(k_{t}^{N}+k_{t}^{O}\right)+q_{t+1} k_{t}^{N}=c_{1, t+1}+R b_{t},
$$

and the collateral constraint

$$
\theta q_{t+1} k_{t}^{N} \geq R b_{t}
$$

Denote the multipliers on the budget constraints by $\mu_{0 t}$ and $\beta \mu_{1, t+1}$, on the collateral constraint by $\beta \lambda_{t}$, and on non-negativity constraint for new and old capital by $\underline{\nu}_{t}^{N}$ and $\underline{\nu}_{t}^{O}$, respectively. The optimal demand for new capital, old capital, and borrowing, as functions of initial net worth $w$, satisfy the first-order conditions (B4), (B5), and

$$
u_{c}\left(c_{0 t}\right)=\beta R u_{c}\left(c_{1, t+1}\right)+\beta R \lambda_{t},
$$

where $k_{t}=k_{t}^{N}+k_{t}^{O}$.

In stationary equilibrium, the expressions for user costs and down payments are as follows: $u_{N}=1-R^{-1} q, u_{O}=q, \wp_{N}=1-R^{-1} \theta q$, and $\wp_{O}=q$. The first-order conditions for new and old capital can be rewritten as investment Euler equations (B7) and (B8), or, 
using both the definitions of user costs and down payments, as follows

$$
\begin{aligned}
& u_{N}+\frac{\lambda}{u_{c}\left(c_{1}\right)} \wp_{N} \geq R^{-1} f_{k}(k) \\
& u_{O}+\frac{\lambda}{u_{c}\left(c_{1}\right)} \wp_{O} \geq R^{-1} f_{k}(k) .
\end{aligned}
$$

Combining equations (B7) and (B8), we get (B9). Hence, using the same arguments we develop in Section 3.3, we obtain that $\frac{1}{1+R^{-1}} \leq q<\frac{1}{1+R^{-1} \theta}$. Moreover, the characterization of the choice between new and old capital is also analogous to the one we obtain when $\beta R=1$. Specifically, sufficiently constrained entrepreneurs only invest in old capital. Unconstrained entrepreneurs weakly prefer new capital, and strictly so when $q>\frac{1}{1+R^{-1}}$. In the indifference region, entrepreneurs substitute away from old capital and toward new capital as net worth increases.

Constrained Efficiency. Given an initial distribution of new capital, old capital, and debt, a utilitarian planner maximizes the total present discounted value of utility

$$
\int\left[u\left(c_{10}(w)\right)+\sum_{t=0}^{\infty} \xi^{t}\left(u\left(c_{0 t}(w)\right)+\beta u\left(c_{1, t+1}(w)\right)\right)\right] d \pi(w)
$$

subject to the budget constraints (B2) and (B45) with multipliers $\xi^{t} \mu_{0, t}$ and $\xi^{t} \beta \mu_{1, t+1}$, the collateral constraint (B46) with multiplier $\xi^{t} \beta \lambda_{t}$, the non-negativity constraints on new and old capital with multipliers $\xi^{t} \underline{\nu}_{t}^{N}$ and $\xi^{t} \underline{\nu}_{t}^{O}$, and the market clearing condition for old capital (3) with multiplier $\xi^{t} \eta_{t}$.

The first-order condition with respect to the price of old capital $q_{t}$ for $t=1,2, \ldots$ is

$$
\int k_{t}^{O}(w) u_{c}\left(c_{0 t}(w)\right) d \pi(w)=\xi^{-1} \beta \int k_{t-1}^{N}(w)\left[u_{c}\left(c_{1 t}(w)\right)+\theta \lambda_{t-1}(w)\right] d \pi(w)
$$

Thus, in the stationary constrained-efficient allocation, we have

$$
\int k^{O}(w) u_{c}\left(c_{0}(w)\right) d \pi(w)=\xi^{-1} \beta \int k^{N}(w)\left[u_{c}\left(c_{1}(w)\right)+\theta \lambda(w)\right] d \pi(w) .
$$

We can further use equation (B47) to substitute out the multiplier on the collateral constraint and obtain

$$
\int k^{O}(w) u_{c}\left(c_{0}(w)\right) d \pi(w)=\xi^{-1} \beta \int k^{N}(w)\left[\theta \beta^{-1} R^{-1} u_{c}\left(c_{0}(w)\right)+(1-\theta) u_{c}\left(c_{1}(w)\right)\right] d \pi(w) .
$$

When we evaluate the left-hand side and the right-hand side of equation (B48) in the 
stationary competitive equilibrium, we can find two reasons why the collateral externality may dominate the distributive externality. First, the planner may be sufficiently impatient relative to entrepreneurs, that is, $\xi^{-1} \beta$ is sufficiently large. Second, entrepreneurs may be sufficiently impatient relative to the interest rate, that is, $\beta^{-1} R^{-1}$ is sufficiently large. Either of these factors would magnify the collateral externality relative to the distributive externality.

To see why this is the case, notice that a marginal increase in the price of old capital $q_{t}$ affects budget constraints at date $t$ - this is the distributive externality - and relaxes collateral constraints at date $t-1$. As a result, with a sufficient degree of impatience, this relaxation of collateral constraints may dominate the redistribution of financial resources. Notice that this argument does not apply under our baseline assumption $\beta R=1$, because in this case the effect of impatience on the valuation of the collateral externality is exactly offset by the effect of a higher interest rate.

We believe this analysis of the role of discounting may be useful to connect our results to the literature on pecuniary externalities in small-open-economies, which focuses on the collateral externality and typically assumes that the interest rate is smaller than the inverse of the discount factor.

\section{B.6.3 Role of Saving Constraints}

We consider again the model with risk-averse entrepreneurs of Section 4.1. To derive a sharp characterization, we assume that all entrepreneurs are born with a common initial endowment $w_{0}$. Nevertheless, the economy features heterogeneity between young and old entrepreneurs. Moreover, we assume that entrepreneurs cannot borrow or save using bonds; in this case, we replace the collateral constraint with the equality constraint $b_{t}=0$. Because of these assumptions, the economy features distributive externalities, but no collateral externalities.

Alternatively, notice that this condition arises as an equilibrium condition if instead we assume that entrepreneurs can access a bond market, but the economy is closed and this market has to clear among entrepreneurs who are either homogeneous in all respects including their initial net worth or have heterogeneous initial net worth and we assume that $\theta=0$.

The optimality conditions for new capital and old capital in this case are

$$
\begin{aligned}
u_{c}\left(c_{0 t}\right) & =\beta u_{c}\left(c_{1, t+1}\right)\left[f_{k}\left(k_{t}\right)+q_{t+1}\right]+\underline{\nu}_{t}^{N} \\
q_{t} u_{c}\left(c_{0 t}\right) & =\beta u_{c}\left(c_{1, t+1}\right) f_{k}\left(k_{t}\right)+\underline{\nu}_{t}^{O}
\end{aligned}
$$


Because all entrepreneurs face the same problem and have the same level of net worth, they choose the same level of capital and, in equilibrium, divide this level of capital equally between new and old capital.

Constrained Efficiency. The planner's first-order condition with respect to the price of old capital $q_{t}$ for $t=1,2, \ldots$ is

$$
k_{t}^{O} u_{c}\left(c_{0 t}\right)=k_{t-1}^{N} u_{c}\left(c_{1 t}\right)
$$

Thus, in the stationary constrained-efficient allocation, we have

$$
k^{O} u_{c}\left(c_{0}\right)=k^{N} u_{c}\left(c_{1}\right)
$$

For sufficiently large initial endowment $w_{0}$, entrepreneurs would desire to save using bonds, if they were allowed to, and thus the constraint $b_{t}=0$ is a binding saving constraint. As a result, in stationary equilibrium $u_{c}\left(c_{1}\right)>u_{c}\left(c_{0}\right)$, and, using the market-clearing condition $k^{N}=k^{O}$, we obtain that the distributive externality has the opposite sign relative to our baseline model with saving. Specifically, we have

$$
k^{O} u_{c}\left(c_{0}\right)<k^{N} u_{c}\left(c_{1}\right)
$$

and a higher price of old capital would increase welfare by redistributing resources from young entrepreneurs to old entrepreneurs, who have higher marginal utility, thus alleviating the effects of the saving constraint.

This analysis is useful in relating our results to the literature that focuses on fire-sale externalities and builds on Lorenzoni (2008). In that model, there is no collateral externality. However, the distributive externality has the opposite sign relative to our baseline results. Specifically, in some states of the world, financially constrained entrepreneurs are net sellers of assets. Hence, a higher price may induce higher welfare. To obtain this result, Lorenzoni (2008) assumes lack of commitment of both households and entrepreneurs, effectively preventing entrepreneurs from saving resources into those states. Our analysis confirms the importance of this assumption, by showing that saving constraints may induce a higher marginal utility for sellers of capital also in our framework.

Finally, we highlight that under the interpretation of the condition $b_{t}=0$ as bondmarket equilibrium among homogenous entrepreneurs, we have that the equilibrium interest rate is lower than the inverse of the discount factor, connecting this model with the previous subsection on the role of discounting. 


\section{Quantitative Analysis}

This appendix provides additional details and results on the analysis of the quantitative model of Sections 5, 6, and 7 .

\section{C.1 Solution Method for Quantitative Model}

In this section, we discuss the solution method for the quantitative model. We compute the stationary constrained-efficient allocation using the following iterative procedure:

1. Guess a value for the multiplier on the market clearing condition for old capital $\eta$.

(a) Guess a value for the price of old capital $q$.

(b) Solve for the firm policy functions on a grid for net worth $w$ and productivity $s$, using the optimality conditions (49), (50), and (47) evaluated in stationary equilibrium.

(c) Obtain the stationary distribution of net worth and productivity by simulating a continuum of firms.

(d) Check the market-clearing condition (37) and update the guess for the price $q$ accordingly, until convergence.

2. Evaluate the optimality condition for the price of old capital (51) and update the guess for $\eta$ accordingly, until convergence.

The stationary competitive equilibrium is a special case of steps (a)-(d) with $\eta=0$.

\section{C.2 Additional Quantitative Results and Sensitivity}

This section provides additional results related to the quantitative analysis of Sections 6 and 7 .

Figure C1 displays the optimal tax rates on new and old capital that implement the constrained-efficient allocation in our calibrated model.

Figure C2 displays the allocation implemented with uniform tax rates for all firms, equal to the average tax rates that implement the constrained-efficient allocation. The figure compares this allocation (solid lines) with the constrained-efficient allocation (dashed lines).

Figure C3 displays the effects of single tax instruments - only on new capital or only on old capital respectively - on the stationary-equilibrium price of old capital. 

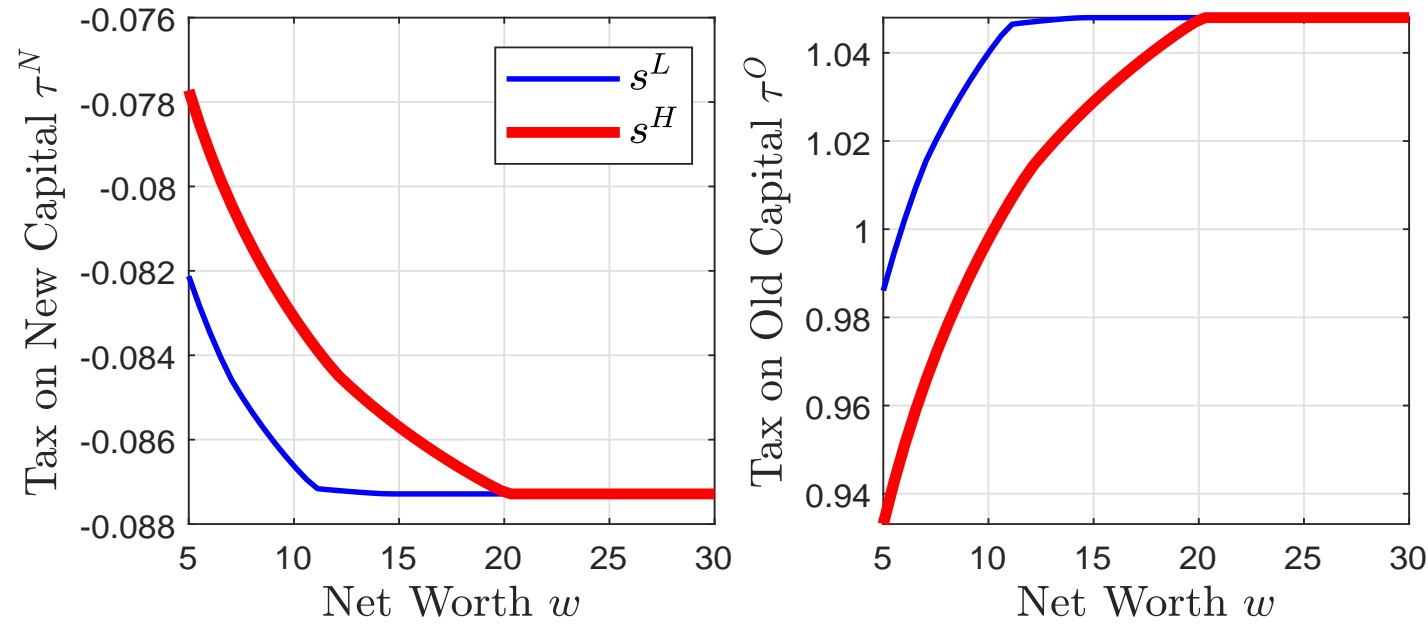

Figure C1: Optimal tax rates. Left panel: tax rate on new capital (a negative value denotes a subsidy); right panel: tax rate on old capital. The $x$-axes report net worth $w$. Thick red lines refer to the high productivity state; thin blue lines refer to the low state. See Table 1 for the parameter values.

Figures C4 and C5 refer to the analysis of the balanced-budget policy without lump-sum transfers. Specifically, the figures display the tax payment for each firm, as a function of net worth and productivity, as well as the induced allocation, compared with the stationary equilibrium without policy, respectively.

Figure C6 plots the transition dynamics associated with the implementation of a tax rate on new capital (at $t=0$ ), common for all firms and constant over time, starting from the competitive equilibrium without policy intervention (at $t=-1$ ). Net worth and productivity are sufficient firm state variables in the stationary equilibrium before the policy change and also along the perfect-foresight transition after the policy is announced. However, because the policy change is unanticipated, firms with equal net worth but different portfolios of new and old capital in the initial stationary equilibrium may be affected differently by the policy at $t=0$. To maintain computational tractability and initialize the transition at the initial distribution of net worth and productivity, we assume that at $t=0$, before the policy is announced, firms sell their initial holdings of old capital to an intermediary at the initial stationary equilibrium price.

Table C1 reports the results of the sensitivity analyses of Section 7.2. 

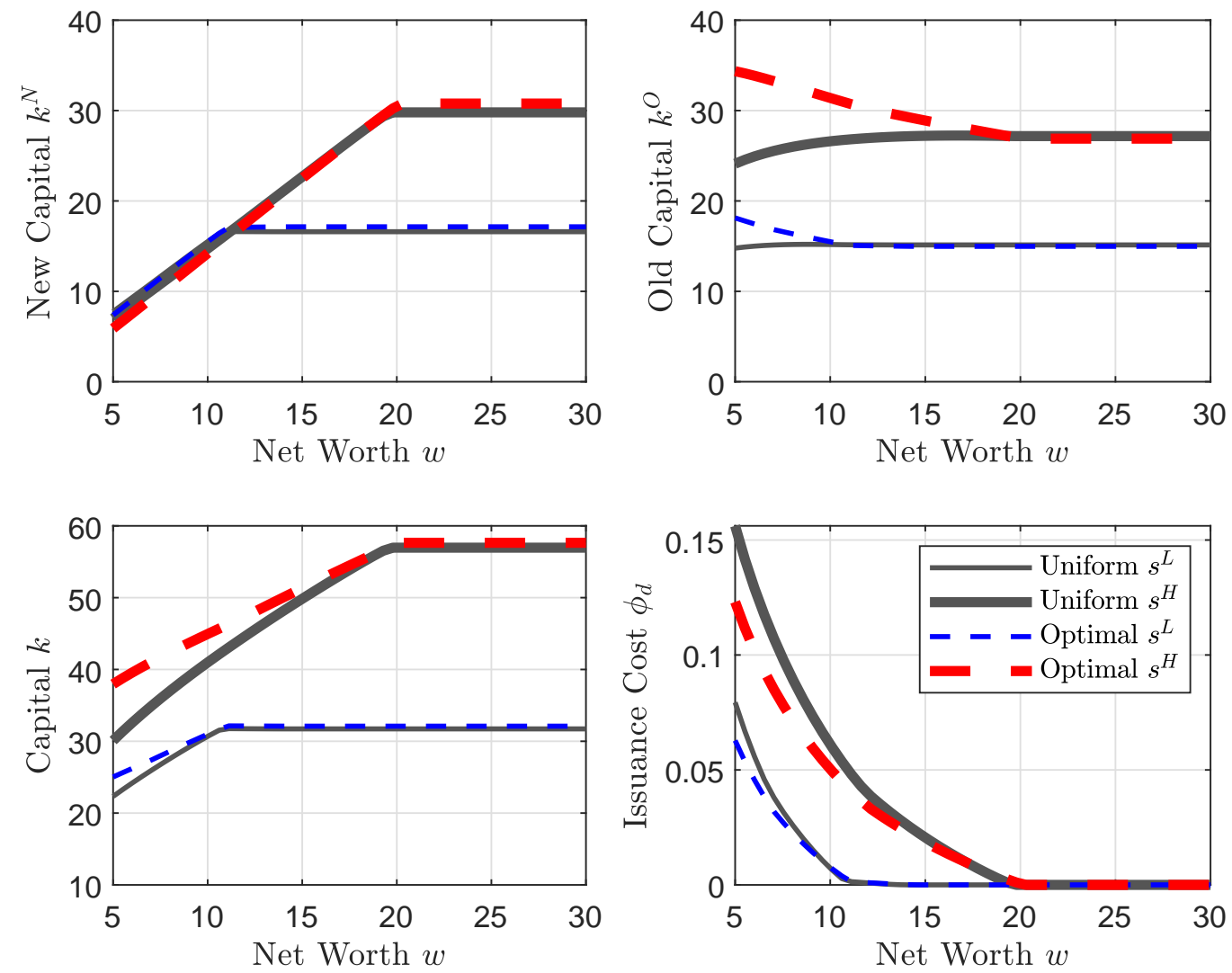

Figure C2: Firm-specific vs. Uniform Taxes. Top left: new capital $k^{N}$; top right: old capital $k^{O}$; bottom left: capital bundle $k$; bottom right: marginal cost of equity issuance $\phi_{d}$. The $x$ axes report net worth $w$. Solid lines denote the allocation implemented with uniform tax rates $\tau^{N}=-0.086$ and $\tau^{O}=1.037$; dashed lines denote the constrained-efficient allocation. Thick lines denote the high productivity state, thin lines the low state. See Table 1 for the parameter values. 

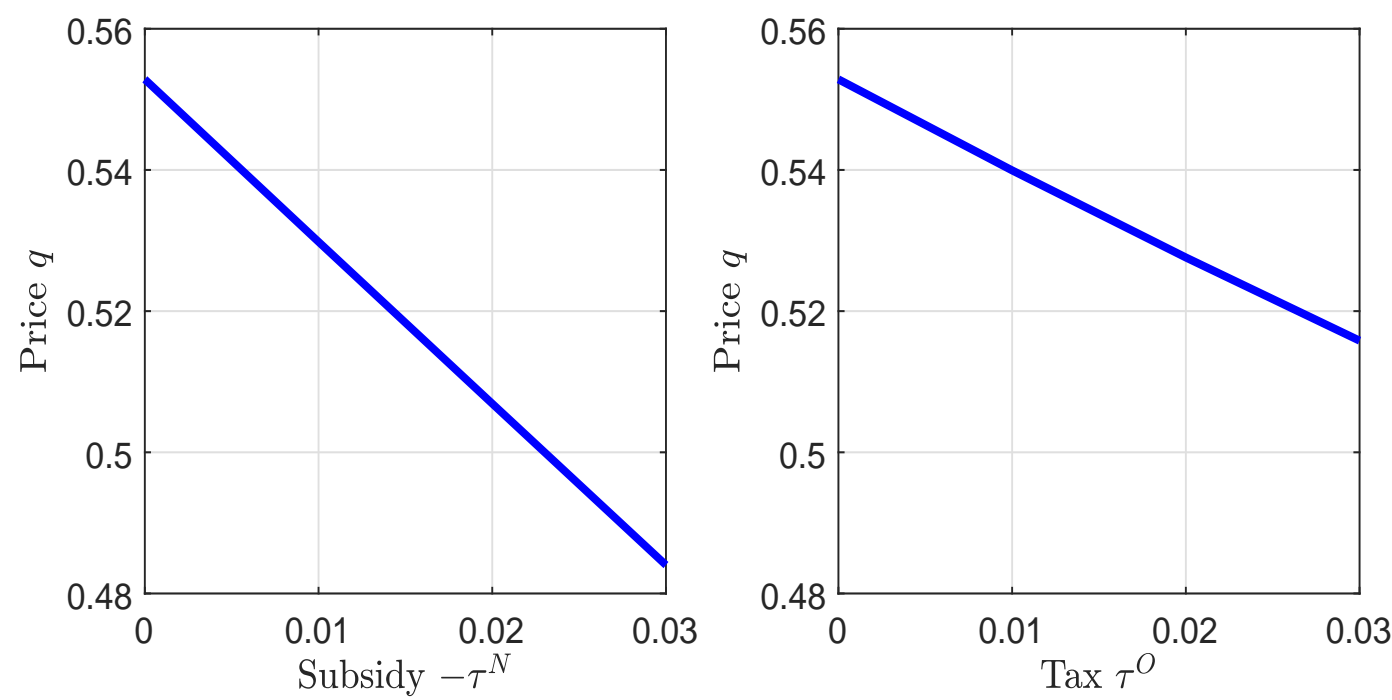

Figure C3: Effects of Single Tax Instruments on Price of Old Capital. The left panel refers to the case in which there are only subsidies on new capital, recovered from each firm in a lump-sum fashion. The $x$-axis reports the value of the subsidy rate on new capital $\left(-\tau^{N}\right)$ and the $y$-axis reports the stationary-equilibrium price of old capital $q$. The right panel refers to the case in which there are only taxes on old capital, rebated to each firm in a lump-sum fashion. The $x$-axis reports the value of the tax rate on old capital $\left(\tau^{O}\right)$ and the $y$-axis reports the stationary-equilibrium price of old capital $q$. 


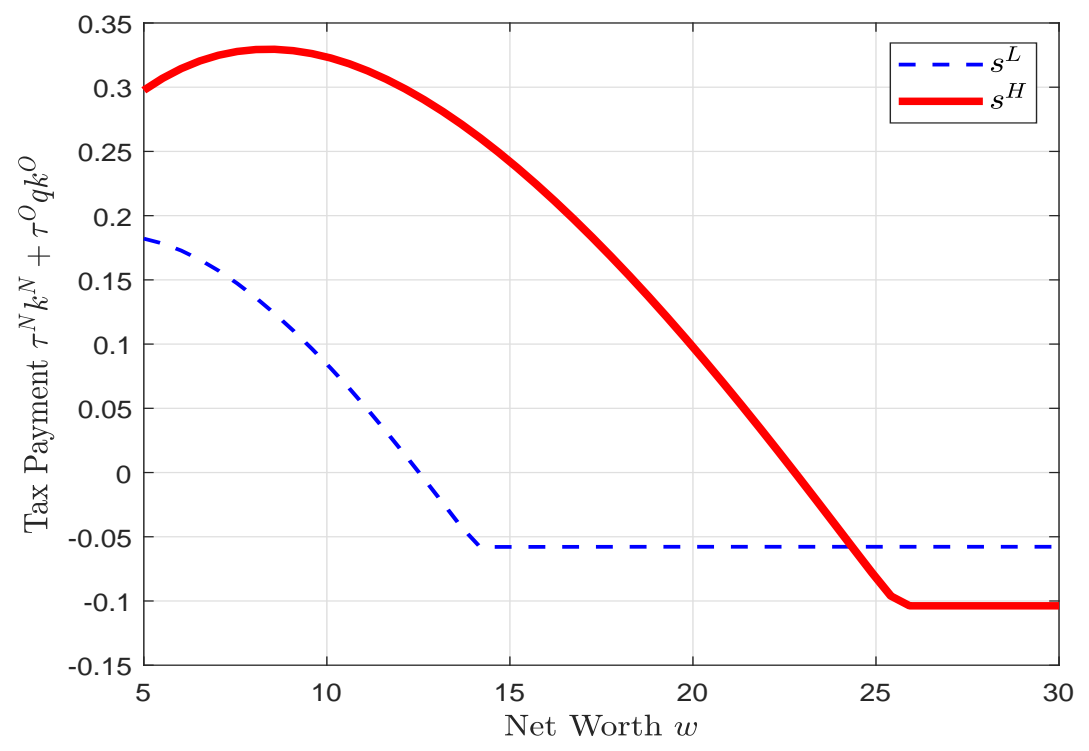

Figure C4: Tax Payment Without Lump-Sum Transfers in the Quantitative Model. The $x$-axis reports net worth $w$. The $y$-axis reports the total tax payment $\tau^{N} k^{N}(w)+\tau^{O} q k^{O}(w)$ assuming that $\tau^{N}=-0.03$ and $\tau^{O}$ balances the government budget constraint. Thick lines denote the high productivity state, thin lines the low state. See Table 1 for the parameter values. 

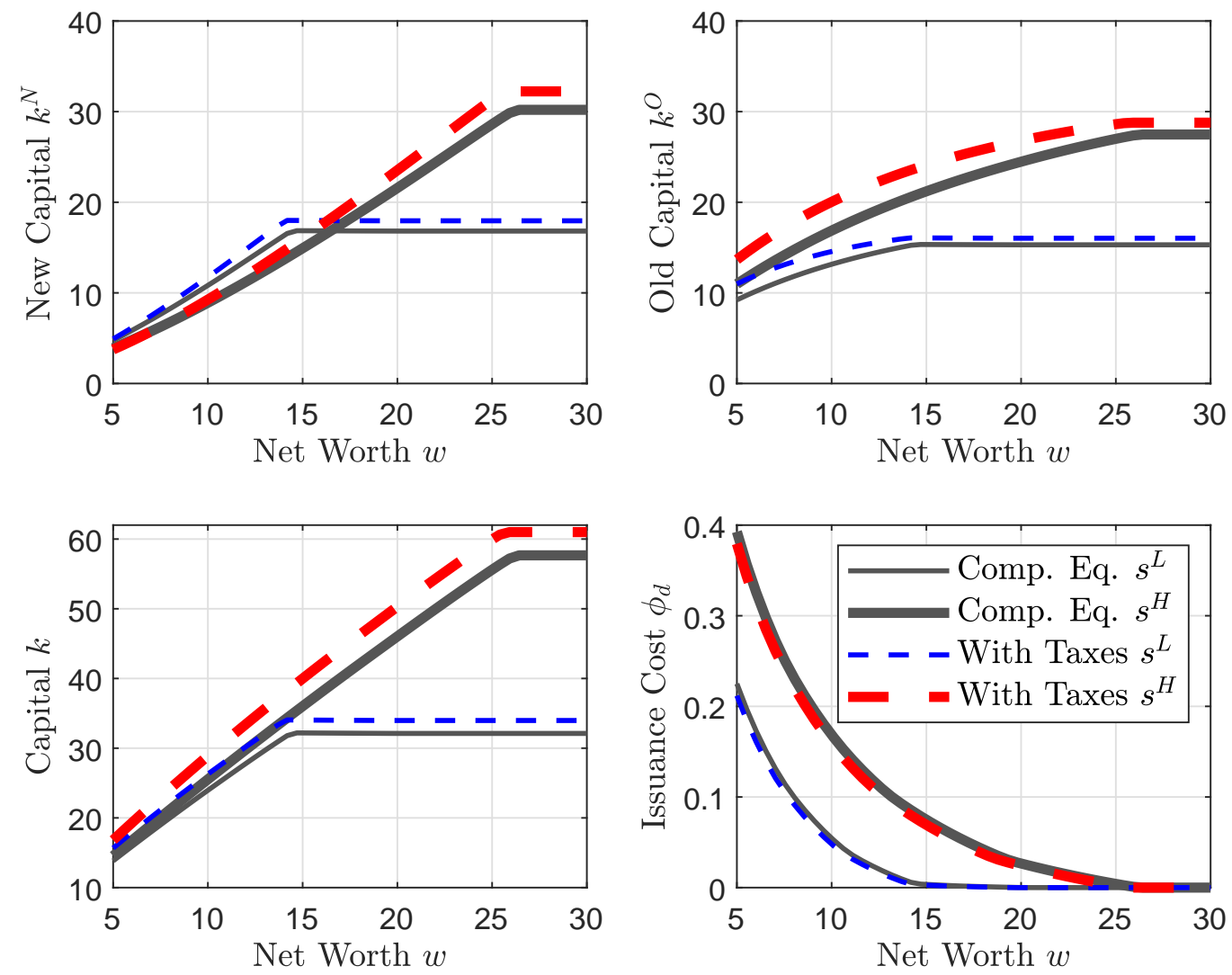

Figure C5: Uniform Taxes Without Lump-Sum Transfers. Top left: new capital $k^{N}$; top right: old capital $k^{O}$; bottom left: capital bundle $k$; bottom right: marginal cost of equity issuance $\phi_{d}$. The $x$-axes report net worth $w$. Solid lines denote the stationary competitive equilibrium without policy interventions. Dashed lines denote the allocation with the following policy: $\tau^{N}=-0.03$ and $\tau^{O}$ balances to government budget constraint. Thick lines denote the high productivity state, thin lines the low state. See Table 1 for the parameter values. 

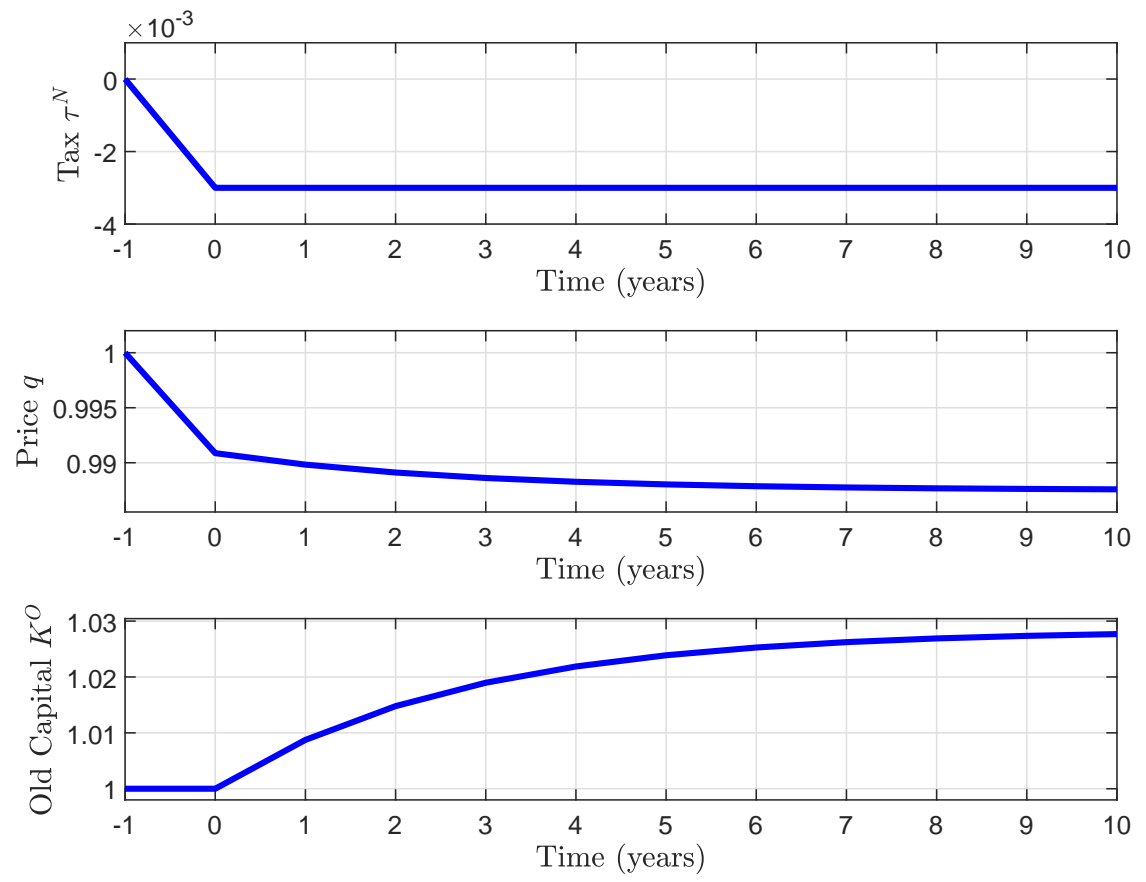

Figure C6: Equilibrium transition dynamics associated with the optimal constant tax $\operatorname{rate} \tau^{N}$, common for all firms. Top panel: tax rate $\tau^{N}$; middle panel: price of old capital $q_{t}$; bottom panel: aggregate stock of old capital $K_{t}^{O}$. See Table 1 for the parameter values. 


\section{Table C1: Quantitative Results - Sensitivity Analysis}

This table provides the sensitivity analysis of the quantitative results with respect the collateralizability $\theta$ (Panel A), elasticity of substitution $\epsilon$ (Panel B), and scrap value $\underline{q}$ (Panel $\mathrm{C}$ ). Output, investment, consumption, and the price of used capital for the competitive equilibrium and constrained-efficient allocation are expressed as fractions of the corresponding first-best value, reported in parenthesis the first column of Panel A. See Table 1 for the baseline parameter values.

Panel A: Collateralizability $\theta$

\begin{tabular}{lccccccc}
\hline \hline & & & \multicolumn{2}{c}{$\theta=0$} & & \multicolumn{2}{c}{$\theta=0.75$} \\
Variable & First Best & & Comp. Eq. & Constr. Eff. & & Comp. Eq. & Constr. Eff. \\
\cline { 1 - 2 } Output & $(9.910)$ & & 0.808 & 0.949 & & 0.949 & 0.985 \\
Investment & $(4.497)$ & & 0.736 & 0.929 & & 0.925 & 0.978 \\
Consumption & $(5.413)$ & & 0.865 & 0.966 & & 0.968 & 0.991 \\
Price $q$ & $(0.547)$ & & 1.023 & 0.183 & & 1.004 & 0.183 \\
Average $\operatorname{tax} \tau^{N}$ & 0 & & 0 & $-8.8 \%$ & & 0 & $-8.6 \%$ \\
Average $\operatorname{tax} \tau^{O}$ & 0 & & 0 & $106.9 \%$ & & 0 & $102.9 \%$ \\
\hline
\end{tabular}

Panel B: Elasticity of Substitution $\epsilon$

\begin{tabular}{|c|c|c|c|c|}
\hline \multirow[b]{2}{*}{ Variable } & \multicolumn{2}{|c|}{$\epsilon=1$} & \multicolumn{2}{|c|}{$\epsilon=10$} \\
\hline & Comp. Eq. & Constr. Eff. & Comp. Eq. & Constr. Eff. \\
\hline Output & 0.894 & 0.944 & 0.905 & 0.985 \\
\hline Investment & 0.850 & 0.919 & 0.864 & 0.978 \\
\hline Consumption & 0.929 & 0.964 & 0.937 & 0.990 \\
\hline Price $q$ & 1.011 & 0.183 & 1.010 & 0.183 \\
\hline Average tax $\tau^{N}$ & 0 & $-8.6 \%$ & 0 & $-8.6 \%$ \\
\hline Average tax $\tau^{O}$ & 0 & $103.7 \%$ & 0 & $103.3 \%$ \\
\hline \multicolumn{5}{|c|}{ Panel C: Scrap Value $\underline{q}$} \\
\hline & \multicolumn{2}{|c|}{$\underline{q}=0.05$} & \multicolumn{2}{|c|}{$\underline{q}=0.2$} \\
\hline Variable & Comp. Eq. & Constr. Eff. & Comp. Eq. & Constr. Eff. \\
\hline Output & 0.899 & 0.979 & 0.899 & 0.959 \\
\hline Investment & 0.857 & 0.969 & 0.857 & 0.942 \\
\hline Consumption & 0.933 & 0.986 & 0.933 & 0.974 \\
\hline Price $q$ & 1.010 & 0.091 & 1.010 & 0.366 \\
\hline Average tax $\tau^{N}$ & 0 & $-9.6 \%$ & 0 & $-6.7 \%$ \\
\hline Average tax $\tau^{O}$ & 0 & $229.8 \%$ & 0 & $40.5 \%$ \\
\hline
\end{tabular}

